\title{
Interface AMIGO-MPI: Uma Abordagem Flexível e Dinâmica para Escalonamento de Processos
}

Tatiana Carvalho de Figueiredo

Orientador: Prof. Dr. Marcos José Santana

Dissertação apresentada ao Instituto de Ciências Matemáticas e de Computação - ICMC-USP, como parte dos requisitos para obtenção do título de Mestre em Ciências - Área: Ciências de Computação e Matemática Computacional.

USP - São Carlos

Outubro de 2000 


\section{Dedicatória}

Aos meus pais, Napoleão e Cleusa, pelo amor e carinho em todos os momentos. 


\section{Agradecimentos}

Primeiramente, gostaria de agradecer ao meu guia incansável pelo apoio em todos os momentos. Contigo compartilhei as minhas dúvidas, angústias e desesperos. Agora compartilho a alegria de mais uma conquista. Meu Deus, obrigada por iluminar meus caminhos.

"Se podemos sonhar, também podemos tornar nossos sonhos realidade." Agradeço ao Prof. Dr. Marcos José Santana e Profa. Dra. Regina H. Carlucci Santana por tornarem possível essa conquista.

"A inteligência é o farol que nos guia, mas é a vontade que nos faz caminhar." Por isso, agradeço aos meus pais, Napoleão e Cleusa, pela força, estímulo, carinho, amor ... Enfim, por termos caminhado juntos todo esse tempo! Aos meus irmãos (Ro, Bia e Poli), pelo apoio encontrado nos momentos de maior dificuldade. $\mathrm{E}$ a todos os meus familiares, em especial à Vovó Lulu que me incentivou todo o tempo com suas palavras de carinho.

O carinho, a paciência, o companheirismo, a amizade, o amor ... todas essas virtudes tornaram essa pessoa ainda mais especial em minha vida. Marco Antonio, obrigada pelos grandes momentos e pela compreensão nos momentos mais dificeis.

Os verdadeiros amigos a gente nunca esquece. Assim são os meus grandes amigos Xande e Mari, inesquecíveis por todos os momentos que compartilhamos juntos desde a época da graduação. Agradeço a vocês pelo carinho, apoio e conselhos nos momentos certos.

As pessoas se tornam especiais não pelo fazem mas pelo que realmente são. Mauro, o laço de amizade que construímos aqui certamente se prolongará por toda a vida. Obrigada por todos os momentos de apoio, carinho e estímulo.

Às vezes conhecemos uma pessoa há tempos e não nos damos conta do quão maravilhosas elas são. Aqui tive a oportunidade de conviver com uma pessoa que se mostrou 
acima de tudo um grande amigo. Edmilson, obrigada pelo apoio e pelas palavras de carinho nos momentos em que mais precisei.

Às vezes o desespero nos impede de enxergarmos as coisas claramente. Fred, você foi uma pessoa essencial para que eu encontrasse o equilibrio em uma das fases mais dificeis que passei aqui. Obrigada por tudo!

É bom saber que existem pessoas sempre dispostas a ajudar e a apoiar nos momentos em que mais precisamos. Aqui vai um agradecimento todo especial ao amigo Paulo Sérgio por todas as dicas e pela grande paciência com me ajudou durante o desenvolvimento do trabalho.

"Não existe esquecimento total, as pegadas impressas na alma são indestrutíveis". Os amigos que encontrei aqui no LsSDPC certamente serão inesquecíveis: Álvaro, Andrezza, Arion, Daniel, Fernanda, João Carlos, Jorge, Luciano, Mara, Márcio (obrigada pelo auxílio com o Linux e com o LAM), Mário, Omar (obrigada pela força com as aplicações), Renata, Renato (obrigada pelo carinho de sempre), Ricardo, Roberta, Tomás (valeu a ajuda com as execuções dos testes) e Vera. Em especial gostaria de agradecer às minhas amiguinhas do coração, Sarita, Kalinka e Célia, pelo carinho, a amizade, o companheirismo, 0 apoio, os momentos de alegria, as grandes risadas que trocamos... tudo que vocês três me proporcionaram durante este tempo.

Um agradecimento especial a duas pessoas que, provavelmente, não terão conhecimento deste, mas foram de extrema importância para o entendimento do código-fonte do LAM. Jeff Squyres e Arun Rodrigues, da Universidade de Notre Dame, meu obrigada pela atenção dispensada sempre que precisei.

Finalmente, agradeço à CNPq pelo auxílio financeiro, sem o qual este trabalho não seria possível. 


\section{Sumário}

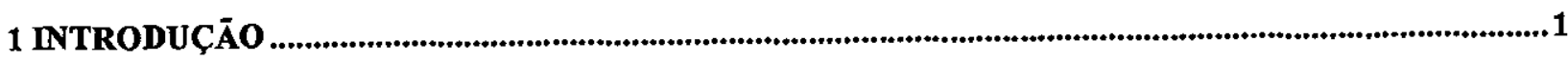

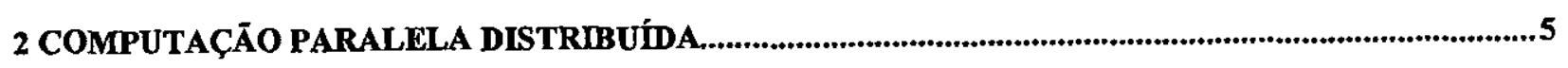

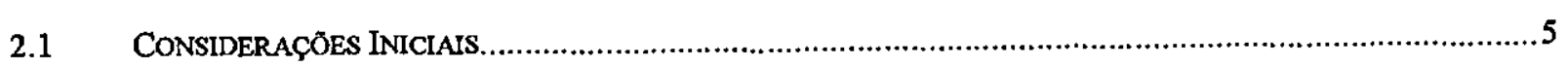

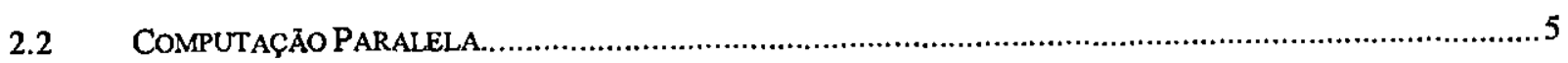

2.2.1 Conceitos Básicos de Computação Paralela ....................................................................... 6

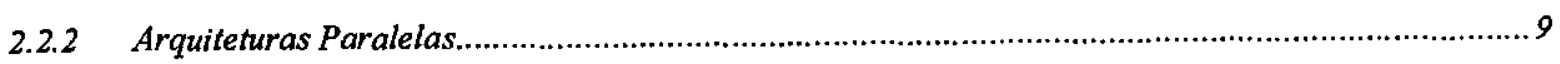

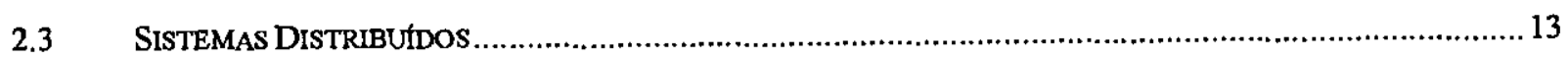

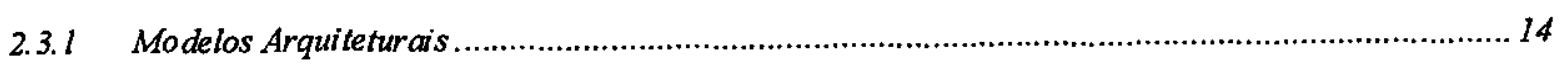

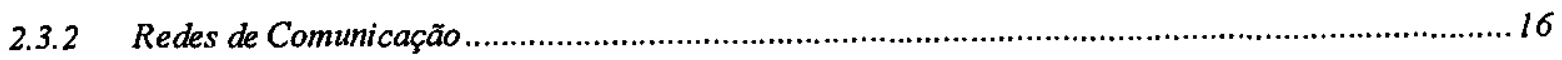

2.3.3 Comunicação entre Processos...........................................................................................16

2.4 COMPUTAÇÃo PARALELA SOBRE SISTEMAS DiSTRIBUIDOS........................................................ 17

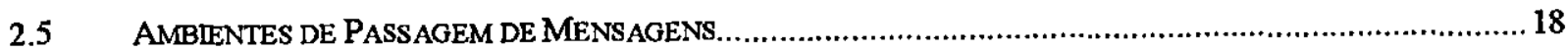

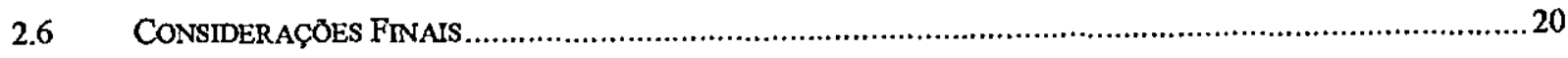

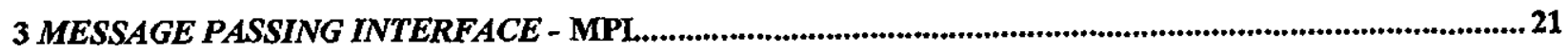

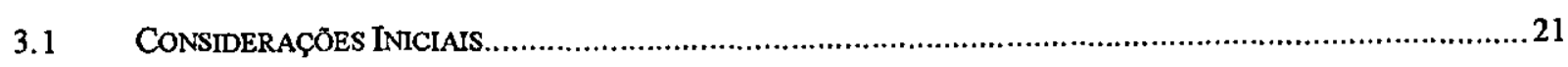

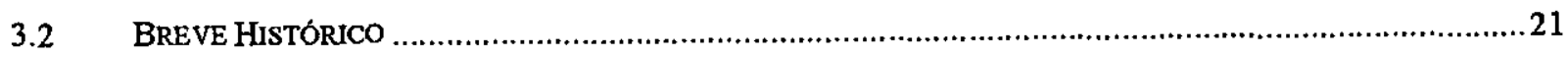

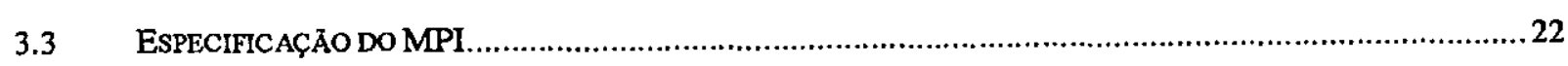

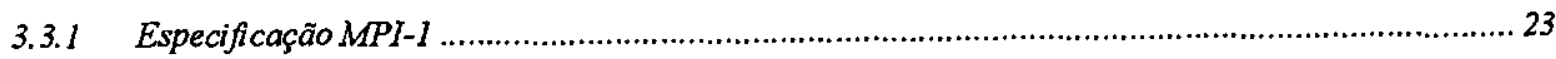

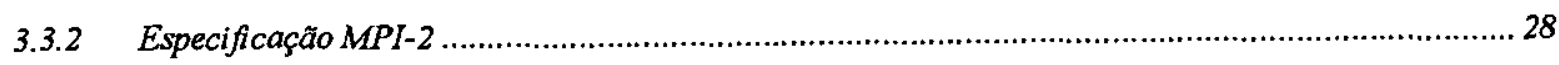

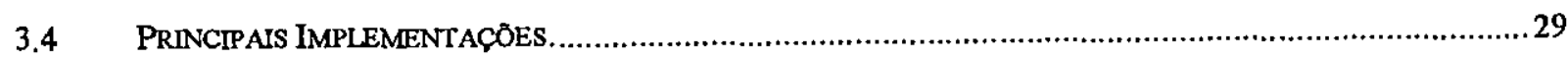

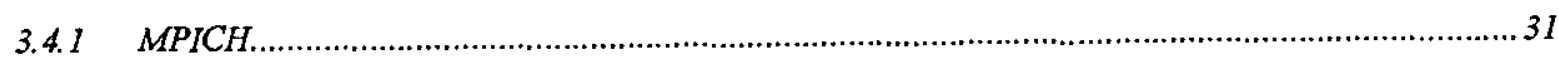

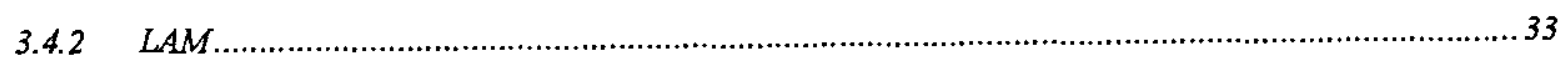

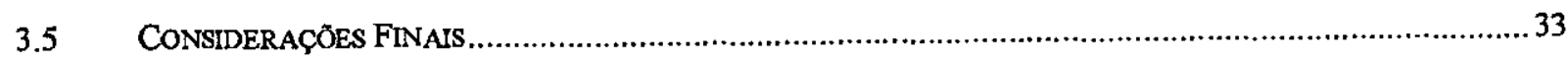

4 ESCALONAMENTO E BALANCEAMENTO DE CARGA …...................................................................35

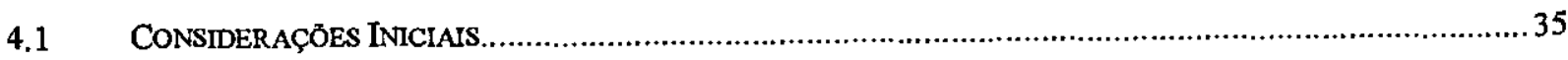

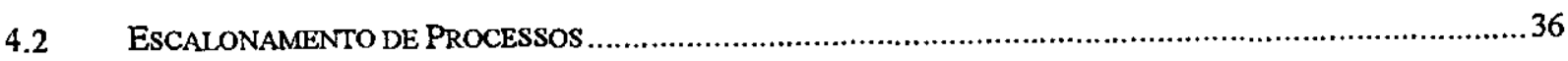

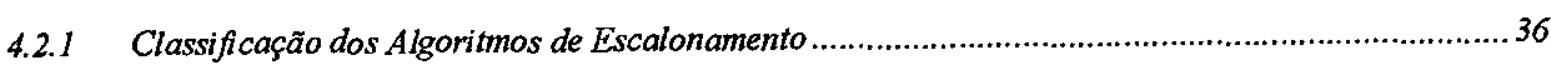

4.2.2 Componentes de um Algoritmo de Escalonamento ......................................................................40

4.2.3 O Ambiente de Escalonamento Flexível e Dinâmico - AMIGO ................................................... 42

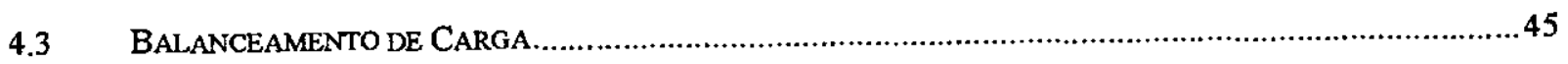




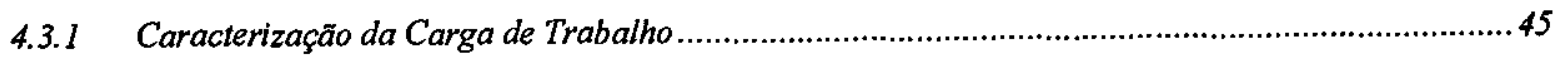

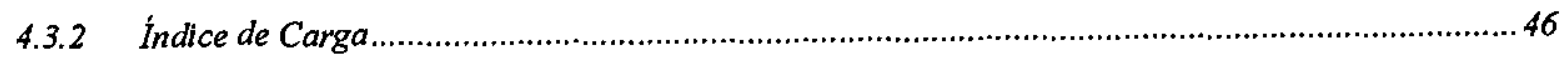

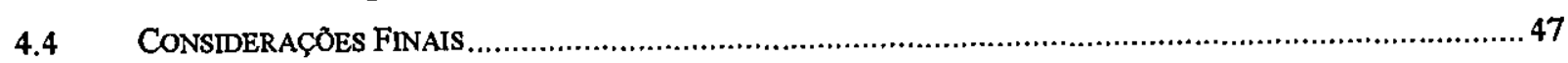

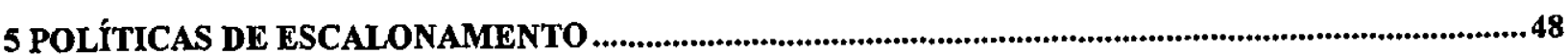

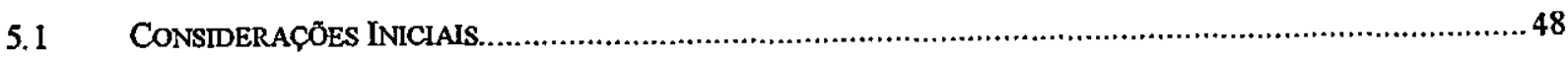

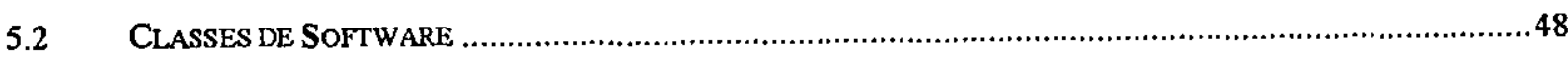

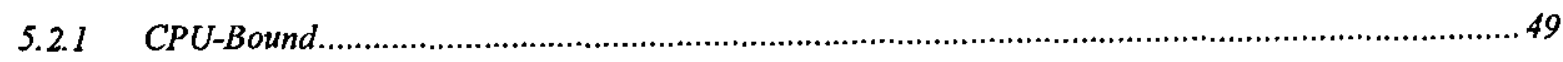

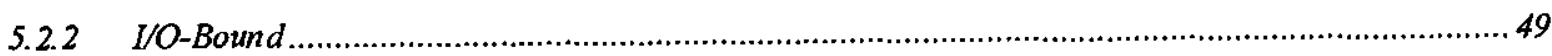

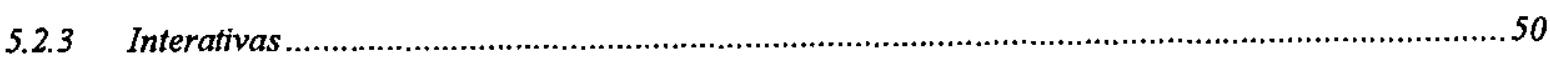

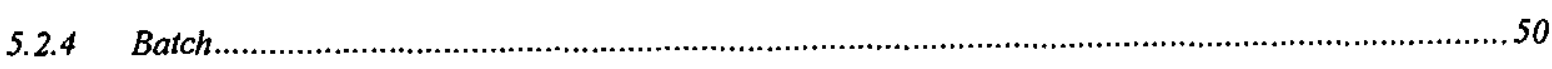

5.3 UMA NOVA ABORDAGEM ÀS POLITTCAS DE ESCALONAMENTO ......................................................50

5.3.1 A DPWP - Dynamical Policy Without Preemption .................................................................5I

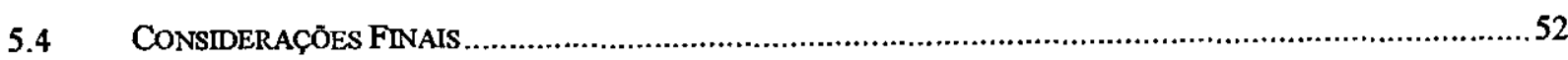

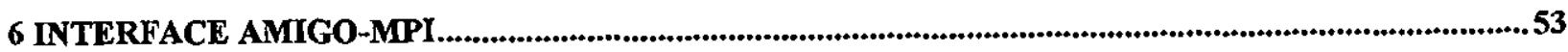

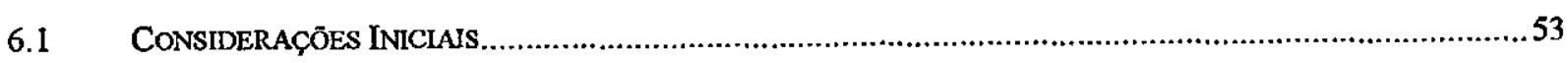

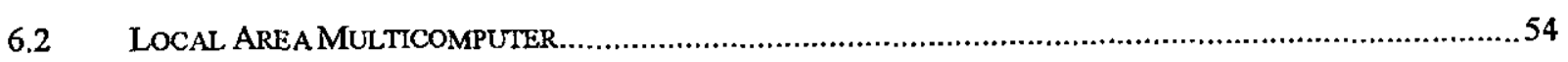

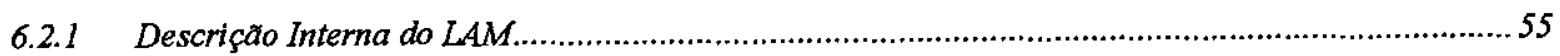

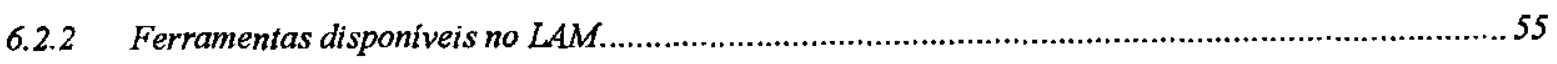

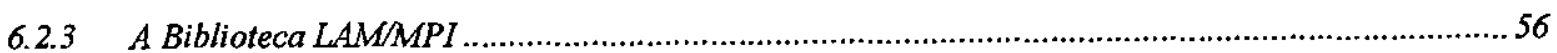

6.2.4 O Software LAM - Descrição e utilização tipica .............................................................................59

6.2.5 Comandos para o Gerenciamento do Multicomputador .............................................................60

6.2.6 Detalhamento das Ferramentas Principais do LAM .................................................................61

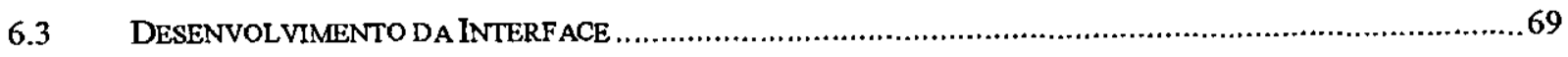

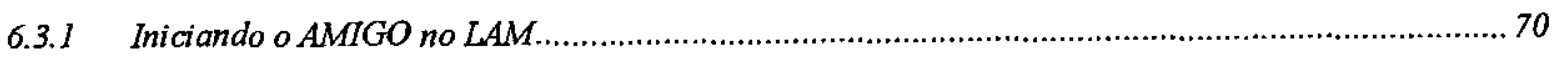

6.3.2 Escalonamento de processos no LAM utilizando o AMIGO ….................................................. 71

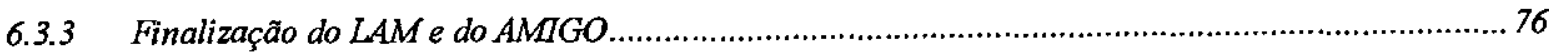

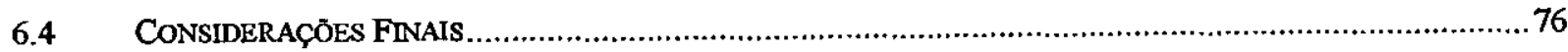

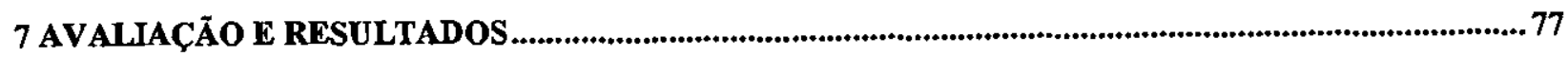

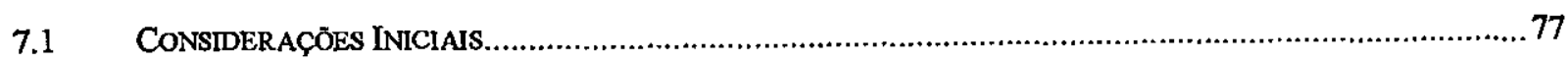

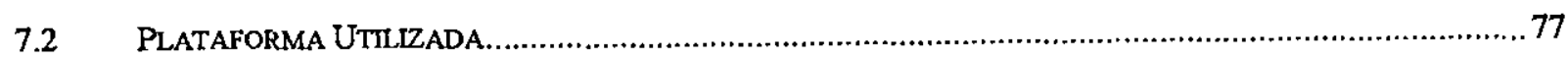

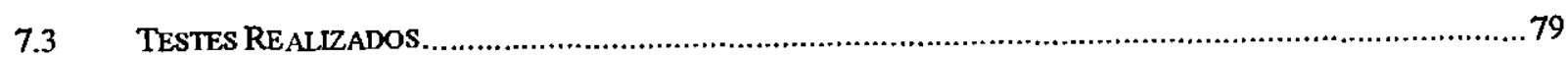

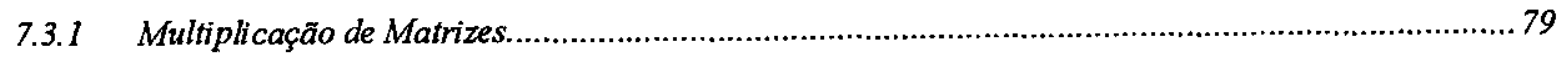

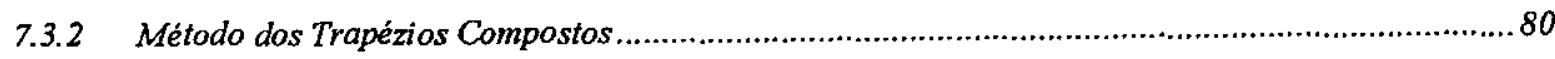

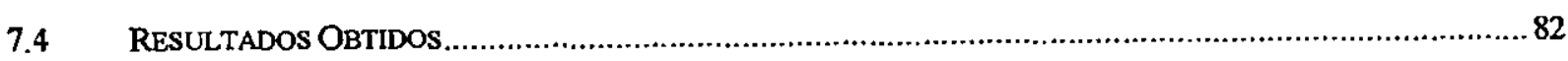

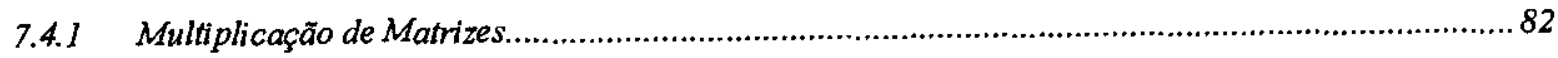

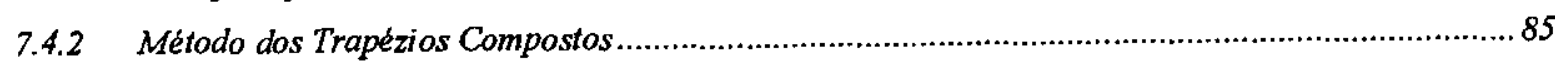




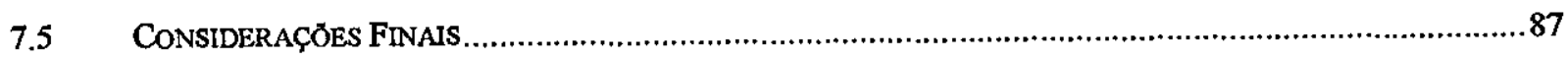

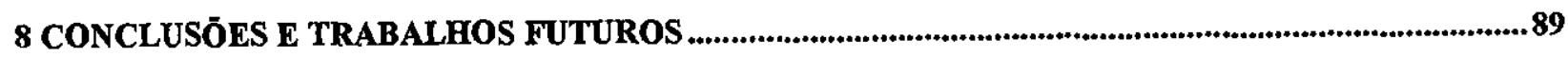

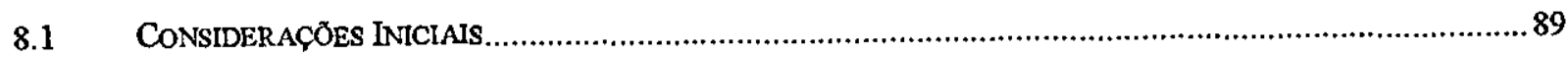

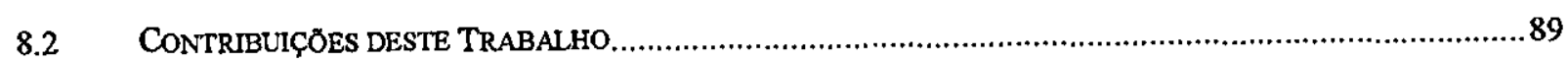

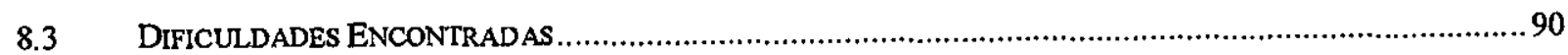

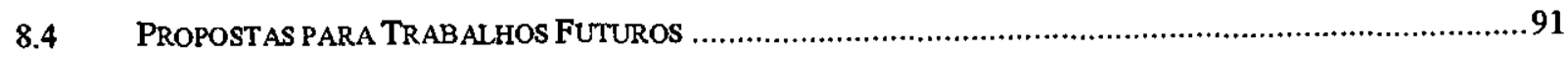

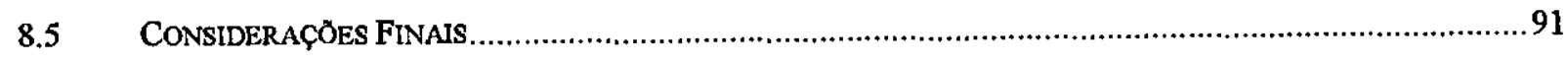

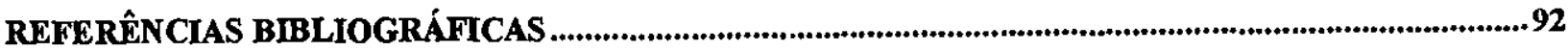




\section{Lista de Figuras}

Figura 2.1 - FunCIONAMENTO DE UM PIPFIINE .

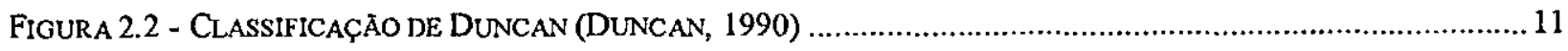

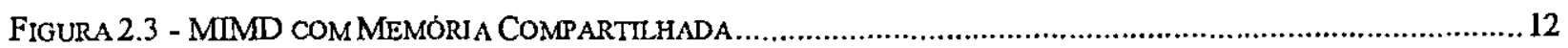

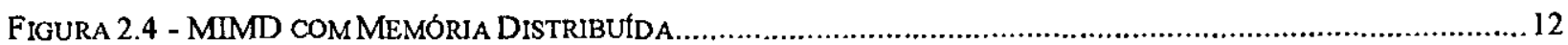

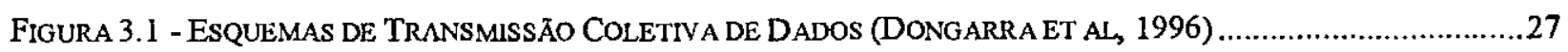

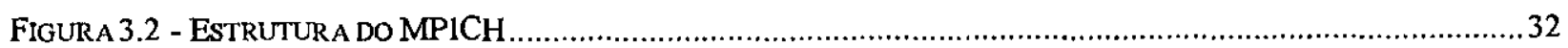

Figura 4.1 - ClassificaçÃo Hierárquica Proposta por Casavant (Casavant \& KuHL, 1988) .....................37

FIGURA 4.2 - EsQUEMA ESTRUTURAL DO AMIGO (SOUZAET AL, 1998) ......................................................44

FIGURA 6.1 - COMPONENTES DA BIBLIOTECA LAM/MPI (SQUYRES ET AL, 2000) ..............................................56

FIGURA 6.2 - ESQUEMA DA RPI LAMD (SQUYRES ET AL, 2000) ..................................................................57

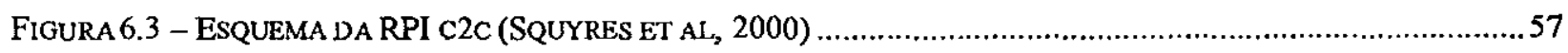

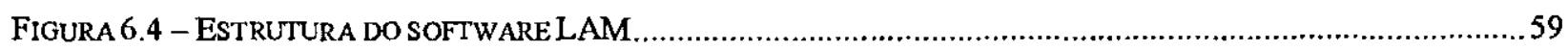

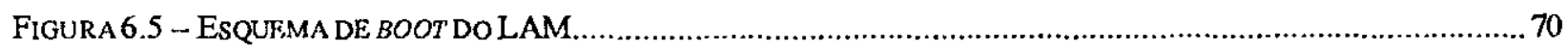

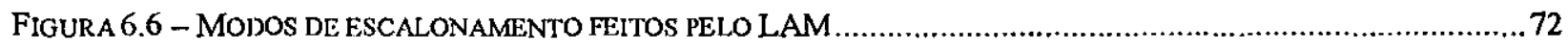

FIGURA 6.7 - CRIAÇÃO DOS PROCESSOS (SQUYRES ET AL, 2000) …..........................................................72

FIGURA 6.8 - PROCESSO DE COMUNICAÇÃO ENVOLVIDO ENTRE OS AMBIENTES LAM E AMIGO .............................73

FIGURA 6.9 - MECANISMO DE COMUNICAÇĀO ENVOLVIDO NO ESCALONAMENTO …............................................74

FIGURA 6.10 - MANIPULAÇÃO DE VALORES IPS E IDENTIFICADORES DOS NÓs ...................................................75

FIGURA 7.1 - PLATAFORMA UTILIZADA PARA AVALIAÇǍO ...........................................................................

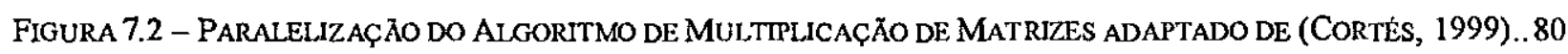

FIGURA 7.3 - PARALELIZAÇÃo DO AlgortTMO dos TRAPÉZIOS COMPOSTOS (CORTÉS, 1999) ...............................81 


\section{Lista de Tabelas}

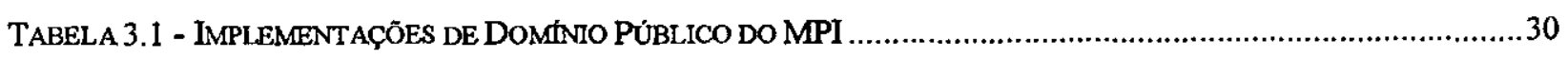

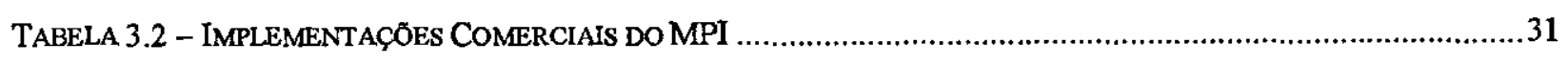

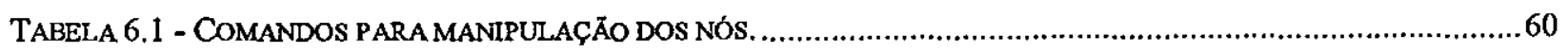

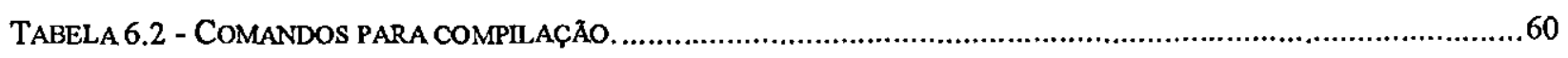

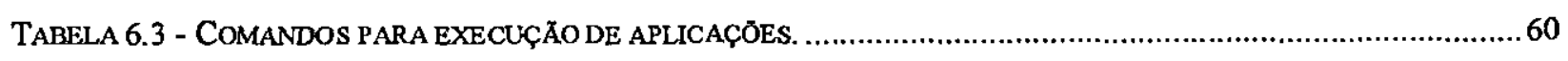

TABELA 6.4 - COMANDOS PARA MONTORAMENTO DE PROCESSOS. ...............................................................61

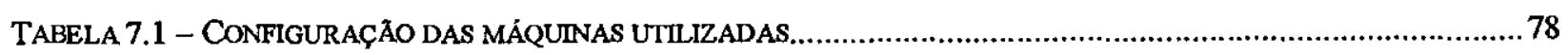

TABELA 7.2 - RESULTADOS OBTIDOS COM A MULTIPLICAÇÃO DE MATRIZES (SISTEMA OCIOSO) ............................82

TABELA 7.3 - RESUlTADOS OBTIDOS COM A MULTIPLICAÇÃo DE MATRIZES (SISTEMA CARREGADO) ......................84

TABELA 7.4 - RESULTADOS OBTIDOS COM O MÉTODO DOS TRAPÉZIOS...............................................................86

\section{Lista de Gráficos}

GRÁFICO 7.1 - TEMPOS DE EXECUÇð̃ (MULTIPLICAÇÃo DE MATRIZES) ............................................................83

GRÁFICO 7.2 - GANHO DE DESEMPENHO (MULTIPLICAÇÃo DE MATRIZES) ......................................................8

GrÁFICO 7.3 - TEMPOS DE EXECUÇÃo (MULTIPLICAÇÃo DE MATRIZZES - SiSTEMA CARREGADO) ...........................85

GrÁFICO 7.4 - GANHO DE DESEMPENHO (MULTIPLICAÇÃo DE MATRIZES - SISTEMA CARREGADO) ........................85

GRÁFICO 7.5 - TEMPOS DE EXECUÇÃO (MÉTODO DOS TRAPÉZIOS) ….............................................................8

GRÁFICO 7.6 - GANHO DE DESEMPENHO (MÉTODO DOS TRAPÉZIOS) .............................................................87 


\section{Resumo}

Este trabalho propõe uma interface para a integração do ambiente de escalonamento de processos AMIGO (dyn $\underline{A M}$ ical flex $\underline{I} b l e$ schedulin $\underline{G}$ envirOnment) ao MPI (Message Passing Interface), permitindo que aplicações construídas nesse ambiente de passagem de mensagens sejam escalonadas de acordo com as políticas adotadas pelo AMIGO. Essas políticas são independentes do ambiente de passagem de mensagens, o que caracteriza a flexibilidade do ambiente AMIGO.

Assim, foi proposta e construída uma interface de comunicação entre o ambiente paralelo virtual adotado (MPI) e o ambiente AMIGO, responsável por interagir com a(s) política(s) de escalonamento implementada(s). Para essa interface, a implementação do padrão MPI escolhida foi o LAM (Local Area Multicomputer) por preencher os requisitos desejados a priori (implementação de domínio público, destinada à plataforma Unix e por utilizar processos daemons).

As análises e os resultados obtidos demonstram as vantagens em se integrar o LAM a um ambiente de escalonamento com os objetivos aos quais o AMIGO se propõe. A interface proposta foi implementada com sucesso e aplicações tradicionais MPI podem ser escalonadas com ganhos de desempenho quando seus processos são escalonados através das políticas do AMIGO. 


\section{Abstract}

This work proposes an interface for the integration of the process scheduling environment AMIGO (dynAMical flexIble schedulinG envirOnment) to the MPI (Message Passing Interface), allowing to the applications developed in this message passing environment the possibility of being scheduled according to the policies used by the AMIGO. These policies are independent from the message passing environment, fact that stamps the flexibility of the AMIGO.

Thus, it was developed and implemented a communication interface between the adopted virtual parallel environment (MPI) and the AMIGO environment, responsable for interacting with the implemented scheduling policy(ies). For this interface, it was chosen the LAM (Local Area Multicomputer) as the implementation of the MPI pattern because it fulfills the desired conditions beforehand (implementation of public domain addressed to Unix platform and because it makes use of daemon processes).

The obtained analyses and results demonstrate the advantages in integrating a scheduling environment to the LAM with the objectives required by the AMIGO. The proposed interface was implemented successfully and traditional MPI applications can be scheduled with a lot of performance gain when their processes are scheduled through the AMIGO policies. 


\title{
1
}

\section{Introdução}

\author{
"A tecnologia só é importante quando nos força a fazer coisas novas e não \\ apenas quando nos permite melhorar as coisas velhas." \\ Peter Drucker)
}

A sociedade atual está totalmente integrada ao universo da Computação. Diversos são os fatores que contribuíram para tal acontecimento, dentre os quais se destaca o advento da Internet que possibilitou a conexão direta com qualquer parte do mundo, para a disseminação da informação.

A grande diversidade das áreas nas quais a Computação se aplica tem elevado consideraveimente o volume de pesquisas, o que faz com que novas tecnologias sejam desenvolvidas a fim de suprir as necessidades encontradas.

A computação paralela surgiu com o intuito de prover alto desempenho para aplicações específicas. A idéia é manter em uma só máquina diversos processadores que cooperam e comunicam-se entre si, para solucionarem alguns desses problemas de maneira mais rápida e eficiente. No entanto, o alto custo de aquisição de equipamentos com arquitetura paralela e a implantação desses sistemas dificultaram de diversas formas a sua disseminação. 
No anseio de se diminuir os custos de hardware, surgiram os sistemas computacionais distribuídos cujo objetivo maior concentra-se no compartilhamento de recursos fisicamente separados. Através de uma rede de comunicação pode-se manter um conjunto de computadores autônomos, controlados por um sistema operacional distribuído responsável por gerenciar os recursos e disponibilizá-los aos usuários.

Os sistemas distribuídos mostraram-se extremamente vantajosos e, em pouco tempo, conquistaram um lugar de destaque no cenário computacional. Ao longo dos tempos esses sistemas foram aprimorados oferecendo aos usuários sistemas amigáveis, com alto desempenho e a um custo relativamente baixo.

Embora a computação paralela e os sistemas distribuidos tenham surgido com objetivos diferentes, observou-se que um era complemento do outro, sob diferentes pontos de vista. Assim, poderia se unir o baixo custo oferecido pelos sistemas distribuídos e o alto desempenho fornecido pelo processamento paralelo, originando o que atualmente se conhece por computação paralela distribuida.

Aliados a essa nova tecnologia foram desenvolvidos ambientes que viabilizassem a idéia. Esses ambientes, conhecidos por ambientes paralelos virtuais, são ambientes de passagem de mensagens que permitem aos sistemas distribuídos desempenharem a função de uma máquina paralela (virtual).

As vantagens são evidentes, porém, junto a elas encontram-se diversos problemas oriundos dessa nova tecnologia. Dentre eles estão os problemas com o escalonamento de processos e suas implicações no desempenho final do sistema.

Diversos são os objetivos que podem ser atingidos com a técnica de escalonamento de processos. Dentre os principais está o balanceamento de cargas que fornece o equilibrio necessário ao sistema, mantendo a sua estabilidade e, conseqüentemente, elevando o seu desempenho. Dessa forma, mecanismos e políticas de escalonamento vêm sendo largamente pesquisados nos últimos anos.

Este trabalho consiste em integrar o ambiente de escalonamento proposto por um trabalho anterior (AMIGO - dyn $\underline{A M}$ ical flexIble schedulin $\underline{G}$ envir $\underline{O}$ nment (Souza et al, 1998)) ao 
MPI (Message Passing Interface), permitindo que aplicações construídas nesse ambiente de passagem de mensagens sejam escalonadas, transparentemente, de acordo com as políticas adotadas pelo ambiente de escalonamento.

Para tanto, foi necessário desenvolver uma Interface de comunicação entre os ambientes envolvidos (AMIGO-MPI) e, dessa forma, a implementação do padrão MPI conhecida por Local Área Multicomputer (LAM) foi escolhida para o desenvolvido deste trabalho. A Interface foi construída, basicamente, através de alterações em alguns códigos-fontes específicos do LAM que permitissem a troca de informações com o ambiente AMIGO.

O AMIGO já estava integrado ao PVM (Parallel Virtual Machine), tendo-se implementada uma politica de escalonamento voltada para aplicações do tipo CPU-Bound e cujo objetivo é obter o balanceamento de cargas. Essa politica, conhecida por DPWP (Dynamical Policy Without Preemption) é também utilizada neste trabalho para a execução de aplicações MPI.

O segundo capítulo desta dissertação aborda os conceitos gerais e mais relevantes da computação paralela e dos sistemas distribuidos, assim como as vantagens encontradas na utilização da computação paralela distribuída e o funcionamento dos ambientes de passagem de mensagens, os quais tornam possivel essa tecnologia.

O terceiro capitulo descreve uma especificação proposta para ser um padrão para os ambientes de passagem de mensagens - o MPI (Message Passing Interface) - que é utilizado no desenvolvimento deste trabalho.

No quarto capitulo, encontram-se as definições e técnicas para se efetuar o escalonamento de processos e formas para se obter $o$ balanceamento de cargas.

O quinto capítulo aborda algumas considerações a respeito das políticas de escalonamento, visando adequá-las às diversas classes de software existentes. Dessa forma, descreve-se, de modo sucinto, a DPWP (Dynamic Policy Without Preemption) que é uma política de escalonamento voltada para aplicações CPU-bound. 
O sexto capítulo descreve detalhadamente a implementação LAM (Local Area Multicomputer) do padrão MPI e inclui também todos os passos necessários para a elaboração da Interface AMIGO-MPI, foco principal do trabalho.

No sétimo capítulo encontram-se os testes efetuados para a validação da Interface construída e os resultados obtidos com a sua utilização.

Finalmente, o oitavo capitulo conclui esta dissertação e propõe novos caminhos para trabalhos futuros na mesma linha desta pesquisa. 


\section{2 \\ Computação Paralela Distribuída}

\subsection{Considerações Iniciais}

Este capitulo apresenta conceitos importantes sobre computação paralela e sistemas distribuídos, mostrando como realidade atual a convergência dessas duas áreas, originando a computação paralela distribuída.

Não se pode falar em computaçāo paralela distribuída sem mencionar os ambientes de passagem de mensagens, os quais fornecem o mecanismo necessário para a construção de aplicações paralelas sobre plataformas distribuídas. Portanto, este capítulo também descreve, de modo geral, o funcionamento dos ambientes de passagem de mensagens existentes.

\subsection{Computação Paralela}

As diversas áreas nas quais a computação se aplica requerem cada vez mais potência computacional, em virtude dos algoritmos complexos que são utilizados e do tamanho do conjunto de dados envolvido no processamento. Dessa forma, a busca por um melhor tempo de resposta e, conseqüentemente, um melhor desempenho na execução das aplicações, constitui o fator principal que impulsiona o desenvolvimento da computação paralela. 
Segundo Almasi (Almasi \& Gottlieb, 1994), computação paralela consiste basicamente em um conjunto de elementos de processamento, que cooperam e comunicam-se entre si para solucionarem problemas mais complexos, de maneira mais rápida do que se estivessem sendo solucionados seqüencialmente.

De acordo com a definição acima, as vantagens em se utilizar a computação paralela são evidentes, porém há inúmeras características que não são encontradas na computação seqüencial que a tornam mais complexa. Por exemplo, organização e gerenciamento dos processadores e manutenção da coerência da informação que trafega na máquina.

\subsubsection{Conceitos Básicos de Computação Paralela}

Os conceitos que são apresentados devem ser discutidos pelo fato de influenciar diretamente o desenvolvimento e o desempenho de aplicaçőes paralelas.

\section{Paralelismo e Concorrência}

Segundo Almasi (Almasi \& Gottlieb, 1994), a concorrência existe quando, em um determinado instante, dois ou mais processos começaram a sua execução, mas não terminaram. Portanto, pode existir concorrência em sistemas com um único processador ou com vários processadores.

Por outro lado, o paralelismo (ou paralelismo fisico) só existe quando se tem mais de um processador e, portanto, mais de um processo é executado no mesmo intervalo de tempo. Dentre as várias formas de se classificar o paralelismo, tem-se (CENAPADNe, 1999):

- Paralelismo de Dados, onde o processador executa as mesmas instruções sobre dados diferentes;

- Paralelismo Funcional, onde o processador executa diferentes instruçбes que podem ou não operar sobre o mesmo conjunto de dados; 
- Paralelismo de Objetos, que utiliza o conceito de objetos distribuídos por uma rede, capazes de serem acessados por métodos (funções) em diferentes processadores para uma determinada finalidade.

\section{Niveis de Paralelismo}

O tamanho da tarefa executada pelo processador define o seu nível de paralelismo ou a sua granulosidade, que pode ser classificada em fina, média e grossa.

A granulosidade fina indica um paralelismo em nível de operações, sendo geralmente implementada em hardware. Quando o paralelismo é atingido entre os blocos ou subrotinas do programa, tem-se uma granulosidade média. Finalmente, quando se paralelizam processos, obtém-se uma granulosidade grossa.

\section{Speedup e Efíciência}

O Speedup e a Eficiência são duas medidas utilizadas para se calcular o ganho de velocidade obtido pelo uso da computação paralela.

O Speedup (Sp) fornece o ganho de velocidade quando se executa um determinado processo em $p$ processadores em relação à execução desse processo em um processador, sendo calculado por:

$$
\mathrm{Sp}=\mathrm{T} 1 / \mathrm{Tp}
$$

onde: Tl é o tempo de execução em um processador $\mathrm{e}$

Tp é o tempo de execugão em $p$ processadores.

A Eficiência determina a taxa de utilização dos processadores, onde os valores variam de 0 a 1 sendo, portanto:

$$
\mathrm{Ep}=\mathrm{Sp} / \mathrm{p}
$$

onde: $p$ é o número de processadores. 
$\mathrm{O}$ ideal é obter $\mathrm{Ep}=1$, isto é, $100 \%$ de ưilização dos processadores. No entanto, fatores como sobrecarga de comunicação entre os processadores, parte estritamente seqüencial do código e granulosidade inadequada, podem interferir no resultado final, levando a uma eficiência não ideal.

\section{Pipeline}

O pipeline é obtido dividindo-se o processo em uma sequência de sub-processos, onde cada um será executado por um estágio de hardware especifico, que trabalhará concorrentemente com os outros estágios do pipeline (Navaux, 1989).

A Figura 2.1 exemplifica o funcionamento de um pipeline. O primeiro estágio (E1) executa uma parte do processa P1. Ao terminar, entrega os seus resultados para o segundo estágio (E2) do pipeline, que dará continuidade ao processamento. Portanto, o estágio (E2) não pode executar nada referente àquele processo enquanto não receber o sub-processo do estágio (E1). Percebe-se que a execução do pipeline é feita seqũencialmente pelos estágios, no entanto, o paralelismo ocorre porque, quando o processo está em um estágio (por exemplo E2), outro processo (P2) já pode ser executado no estágio anterior (E1).

Dessa forma, pode-se subdividir o paralelismo fisico em dois tipos: paralelismo espacial (paralelismo real) e paralelismo temporal (pipeline) (Kirner, 1991).

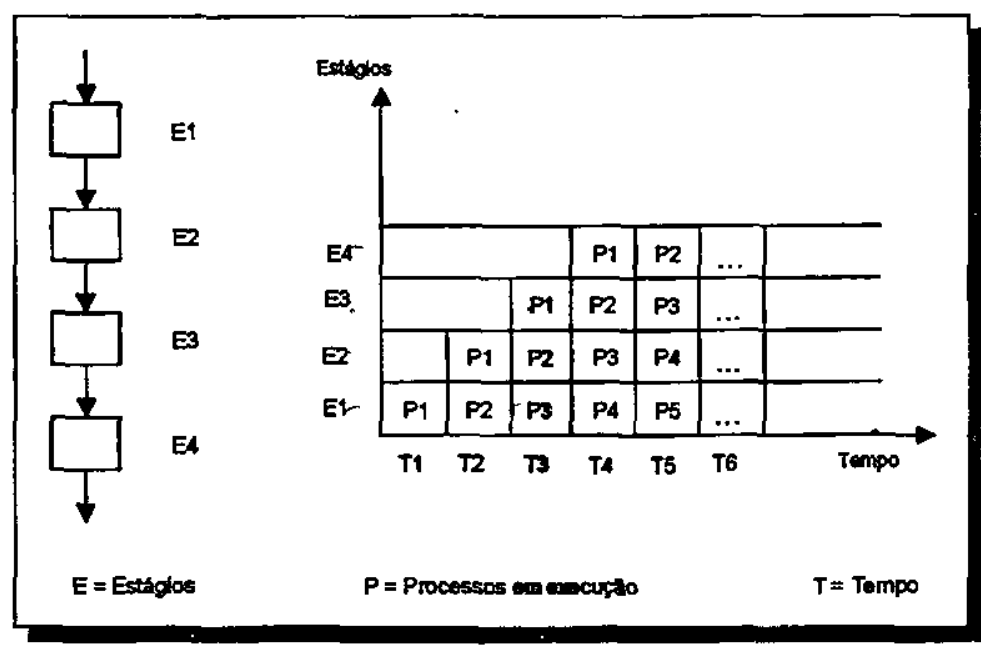

Figura 2.1 - Funcionamento de um Pipeline 


\subsubsection{Arquiteturas Paralelas}

Por arquitetura paralela entende-se uma máquina capaz de executar mais de uma tarefa ao mesmo tempo, excluindo-se paralelismo de baixo nivel. Devido à existência de inúmeras arquiteturas que apresentam características diferentes, foram propostas algumas classificações que agrupassem características comuns.

Por serem amplamente utilizadas e conhecidas, duas classificações se destacam: a classificação de Flynn (Flynn, 1972) e a classificação de Duncan (Duncan, 1990).

\section{Classificação de Flynn}

A classificação de Flynn baseia-se no fluxo de instruções e no fluxo de dados. Um fluxo de instruções eqüivale a uma seqüência de instruções executadas (em uma unidade de processamento) sobre um fluxo de dados aos quais essas instruções estão relacionadas (Almasi \& Gottlieb, 1994) (Duncan, 1990) (Flynn, 1972) (Hwang \& Briggs, 1984) (Navaux, 1989).

As arquiteturas, segundo a classificação de Flynn, estão divididas em quatro categorias:

\section{(1) SISD (Single Instruction Single Data Stream)}

A categoria SISD apresenta um único fluxo de instruções e de dados. Compreendem as máquinas de von Neumann, amplamente utilizadas, cuja execução é seqüencial.

\section{(2) SIMD (Single Instruction Multiple Data Stream)}

A categoria SIMD apresenta um único fluxo de instruções atuando sobre múltiplos fluxos de dados. Dessa forma, essa arquitetura possui várias unidades de processamento supervisionadas por uma única unidade de controle. Nesse tipo de arquitetura encontram-se os processadores matriciais. 


\section{(3) MISD (Multiple Instruction Single Data Stream)}

A categoria MISD apresenta múltiplos fluxos de instruções atuando em um único fluxo de dados. Dessa forma, o fluxo de dados passaria por todas as unidades de processamento, sendo que o resultado de uma seria a entrada para a próxima unidade. Não existem exemplos de máquinas MISD na literatura, entretanto, alguns autores (Almasi \& Gottlieb, 1994) (Navaux, 1989) consideram o pipeline como representante dessa categoria.

\section{(4) MIMD (Multiple Instruction Multiple Data Stream)}

A categoria MIMD apresenta múltiplos fluxos de instruções atuando em múltiplos fluxos de dados. Portanto, essa arquitetura envolve várias unidades de processamento executando diferentes instruções, em diferentes conjuntos de dados, de maneira independente. Englobam a maioria das arquiteturas paralelas.

A classificação de Flynn não é abrangente o suficiente para incluir alguns computadores modernos (como processadores vetoriais e máquinas de fluxo de dados) e não é facilmente extensivel devido à falta de hierarquia da classificação (não apresenta subníveis). No entanto, apesar de antiga (proposta em 1972) é bastante concisa, sendo a mais utilizada.

\section{Classificação de Duncan}

A classificação de Duncan tem por objetivo acabar com a dificuldade de acomodar as novas arquiteturas dentro da classificação de Flynn (Souza, 1996a), excluindo arquiteturas que apresentem apenas mecanismos de paralelismo de baixo nível, que já se tornaram lugar comum nos computadores modernos.

Duncan (Duncan, 1990) propõe dois grandes grupos: Arquiteturas Sincronas, que coordenam suas operaçóes concorrentes sincronamente em todas as unidades de processamento, através de relógios globais, e Arquiteturas Assíncronas, que caracterizam-se pelo controle descentralizado de hardware. As subdivisões desta classificação podem ser vistas na Figura 2.2. 


\begin{tabular}{|c|l|l|}
\hline \multirow{2}{*}{ Arquiteturas Sincronas } & $\begin{array}{l}\text { Processadores Vetoriais } \\
\text { Arquiteturas SIMD (Processadores Matriciais) } \\
\text { Arquiteturas Sistólicas }\end{array}$ \\
\hline \multirow{4}{*}{ Arquiteturas Assíncronas } & Arquiteturas MIMD & $\begin{array}{l}\text { Memória Compartilhada } \\
\text { Memória Distribuida }\end{array}$ \\
\cline { 2 - 3 } & Arquiteturas não \\
convencionais & $\begin{array}{l}\text { Arquiteturas Hibridas } \\
\text { Arquiteturas a Fiuxo de Dados } \\
\text { Arquiteturas de Reduçäo } \\
\text { Arquiteturas de Frente de Onda }\end{array}$ \\
\hline
\end{tabular}

Figura 2.2 - Classificação de Duncan (Duncan, 1990)

\section{(1) Arquiteturas Síncronas:}

- Processadores Vetoriais - possuem um hardware específico capaz de executar seqüências de instruções idênticas sobre vetores, de forma mais rápida do que uma seqüência de operações escalares.

- Arquiteturas SIMD - seguem o mesmo princípio já descrito na classificação de Flynn, onde tem-se um único fluxo de instruções atuando sobre diferentes dados.

- Arquiteturas Sistólicas - possuem vários processadores enfileirados (pipeline), onde a informação trafega por todos eles antes de retornar à memória. $\mathrm{O}$ nome sistólica foi escolhido porque os dados são movimentados de processador a processador de forma síncrona. São

- empregadas em problemas específicos (como processamento de sinais) por apresentarem alto grau de paralelismo e, por conseguinte, alto desempenho.

\section{(2)Arquiteturas Assíncronas:}

- Arquiteturas MIMD - são formadas por várias unidades de processamento executando diferentes instruçőes sobre diferentes dados, conforme visto na classificação de Flynn. Porém, são subdividas segundo a organização da memória, que determina o sincronismo e a forma de comunicação entre as unidades de processamento, podendo ser compartilhada (entre todos os processadores) ou distribuída (cada processador possui sua própria memória). 
Em Arquiteturas MIMD com memória compartilhada (também chamadas multiprocessadores), a comunicação é baseada no compartilhamento de posições de memória, sendo necessário um método de controle de acesso a essas variáveis compartilhadas para que os dados se mantenham consistentes. Um esquema hipotético desse tipo de arquitetura pode ser observado na Figura 2.3.

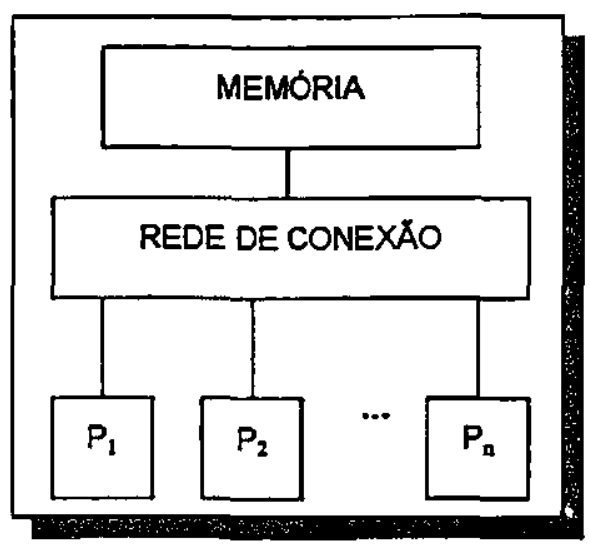

Figura 2.3 - MIMD com Memória Compartilhada

No caso de Arquiteturas MIMD com memória distribuída (ou multicomputadores), a comunicação é feita através de troca de mensagens por meio da rede de conexão. Dessa forma, não há mais o problema de inconsistência (visto que um processador não tem acesso à memória de outro), porém é preciso levar em consideração o tempo de latência na troca de mensagens que pode interferir no desempenho. A Figura 2.4 representa um modelo hipotético desse tipo de arquitetura.

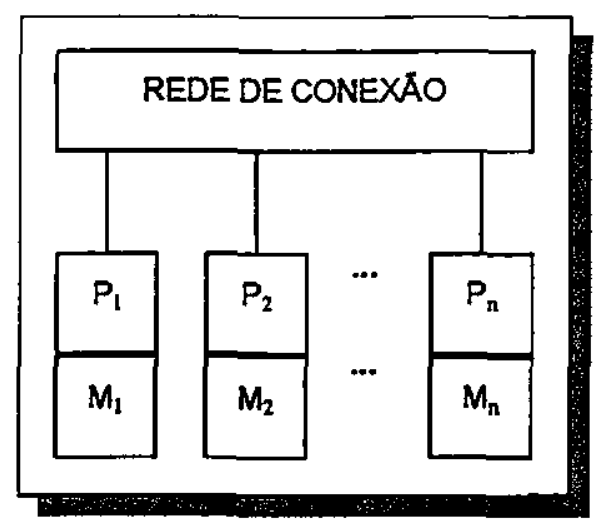

Figura 2.4 - MIMD com Memória Distribuída 
- Arquiteturas Não Convencionais - englobam arquiteturas que apresentam aspectos MIMD, porém com caracteristicas próprias impedindo que sejam classificadas apenas como MIMD.

As Arquiteturas Híbridas (MIMD/SMMD) são compostas basicamente por uma arquitetura MIMD que possui algumas partes controladas por arquiteturas SIMD.

As Arquiteturas a Fluxo de Dados (datoflow) se caracterizam por habilitarem a execução das instruções apenas quando seus operandos estiverem disponíveis e, portanto, estão baseadas na dependência de dados.

Arquiteturas de Reducão (ou dirigidas por demanda) são assim chamadas por substituírem porções do código fonte original de um programa pelo seu significado e, portanto, os processadores só executam os comandos quando as expressões necessitam do seu cálculo.

As Arquiteturas de Frente de Onda caracterizam-se por apresentarem uma estrutura sistólica de processadores combinada ao paradigma assíncrono de execução, baseado no fluxo de dados.

A classificação de Duncan é, claramente, mais completa, permitindo uma visão geral dos estilos de organização para computadores paralelos modernos, o que a toina adequada aos estudos atuais.

\subsection{Sistemas Distribuídos}

Um sistema distribuído consiste em um conjunto de computadores autônomos interligados por uma rede de comunicação e equipados com um sistema operacional distribuído. Esse sistema operacional distribuído é o responsável por coordenar as atividades desenvolvidas e compartilhar os recursos do sistema (como hardware, software e dados) (Coulouris et al, 1994).

Não há uma definição única para os sistemas distribuídos. Dessa forma, diversos autores descrevem um conjunto de características que um sistema deve possuir para que possa ser considerado um sistema distribuído. Dentre as principais, destacam-se: 
- Compartilhamento de recursos - constitui uma das características fundamentais dos sistemas distribuidos, cuja finalidade é disponibilizar aos usuários os componentes de hardware e de software do sistema. O principal objetivo concentra-se na melhor utilização dos componentes e redução de custos;

- Transparência - um sistema é transparente se não deixa transparecer para o usuário e para sua aplicação a existência de múltiplos recursos;

- Tolerância a falhas - consiste em evitar que possíveis falhas no sistema produzam resultados incorretos ou dados inconsistentes. Isso pode ser feito considerando-se aspectos como redundância de hardware (replicação de componentes) e recuperação de software (programas para recuperação de falhas);

- Escalabilidade - essa característica descreve a possibilidade de um sistema em aumentar sua capacidade computacional sem grandes alterações;

- Concorrência - ocorre quando os processos disputam pela utilização dos recursos (necessariamente o número de processos deve ser maior que o número de recursos disponíveis);

- Abertura - um sistema é considerado aberto se novos recursos (hardware ou software) podem ser adicionados a ele sem causar prejuízo aos módulos já existentes.

A disponibilidade de microprocessadores de baixo custo e os avanços na tecnologia de comunicação têm estimulado consideravelmente o interesse na utilização de sistemas distribuídos. As principais vantagens desses sistemas são o alto desempenho, a disponibilidade de recursos e a extensibilidade a um baixo custo (Shivaratri et al, 1992).

\subsubsection{Modelos Arquiteturais}

Há diversos modelos arquiteturais para a implementação de sistemas distribuídos, variando suas características de software e hardware, destacando-se: 
(1) Estação de Trabalho/Servidor - Consiste em estações de trabalho interligadas por uma rede de comunicação, onde máquinas com melhores configurações operam, geralmente, como servidores do sistema e máquinas mais simples são utilizadas para executar aplicações de usuários. Esse modelo apresenta como inconveniente variações na potência computacional do sistema (que ora pode estar ociosa, ora insuficiente para a aplicação), porém possui baixo custo de implementação.

(2) Banco de Processadores - Consiste em um conjunto de terminais e um banco de processadores, onde um ou mais processadores podem ser alocados conforme a necessidade da aplicação e, posteriormente, liberados para utilização por outros usuários. É necessário um servidor de processamento que controle a alocação e liberação dos processadores. Esse modelo otimiza a potência computacional do sistema, porém mostra-se inadequado para aplicações muito interativas, devido ao tráfego gerado na rede.

(3) Modelo Híbrido - Representa a combinação do modelo Estação de Trabalho/Servidor com o modelo Banco de Processadores, explorando as vantagens de ambos e minimizando suas desvantagens.

(4) Modelo Integrado - Dessenvolvido para interligar minicomputadores com estações de trabalho e terminais através de uma rede de comunicação, onde cada computador possui software adequado para desempenhar as funções de servidor e de execução das aplicações.

- O modelo preferencial é, sem dúvida, o modelo Estação de Trabalho/Servidor por atender

- a maioria das necessidades dos usuários e por apresentar baixo custo. No entanto, a tendência moderna é expandir o modelo Estação de Trabalho/Servidor com o uso de estações inativas, cujo objetivo é fazer com que máquinas ociosas ou com baixas cargas de processamento funcionem como um banco de processadores temporário.

Como tendência futura, é possível que seja sedimentado o Modelo Orientado a Objetos que utiliza o paradigma da programação orientada a objetos, generalizando os conceitos envolvidos no modelo Estação de Trabalho/Servidor (e suas extensões). 


\subsubsection{Redes de Comunicação}

Os sistemas distribuídos podem ser considerados uma arquitetura MIMD com memória distribuida sendo necessária, portanto, uma rede de comunicação que permita a conexão entre as unidades de processamento independentes.

Essa rede de comunicação pode ser dedicada (geralmente utilizada em computadores paralelos para comunicação entre os processadores, por apresentar alto desempenho $\mathbf{e}$ confiabilidade) ou de propósito geral (correspondendo às redes de computadores).

Com a evolução da velocidade de transferência das redes e a redução dos custos, as redes de computadores tomaram-se o meio de comunicação mais utilizado em sistemas distribuídos (Coulouris et al, 1994). É importante salientar que o desempenho e a confiabilidade estão diretamente relacionados à tecnologia adotada para a rede de comunicação do sistema.

Um ponto de fundamental importância, que também é um fator crítico para o desempenho de um sistema distribuído, săo os métodos de comunicação entre processos.

\subsubsection{Comunicação entre Processos}

A comunicąão entre processos envolve operações como transferência de dados e sincronização. Em sistemas distribuídos, a cọmunicação é feita via troca de mensagens, através das primitivas send (para transmissão) e receive (para recepção). Cada ação de passagem de mensagens envolve a transmissão de um conjunto de dados (de um processo) através de um mecanismo de comunicação (canal ou porta) e o recebimento da mensagem por outro processo envolvido.

O mecanismo de comunicação pode ser síncrono ou assíncrono. No mecanismo síncrono, os processos encontram-se sincronizados em todas as mensagens envolvidas, sendo que 0 processo emissor deve ser bloqueado até que o correspondente receptor esteja apto a receber a mensagem. Por outro lado, no mecanismo assíncrono, os processos não são bloqueados e, portanto, faz-se uso de um buffer para armazenamento temporário das mensagens. 
Os padrões de comunicação mais utilizados na construção de sistemas distribuídos são a comunicação cliente/servidor e a comunicação em grupo.

A comunicação cliente/servidor consiste, basicamente, em um processo cliente solicitando um serviço a um processo servidor, cuja função é executar o pedido e enviar uma mensagem ao cliente como resposta. Um mecanismo bastante utilizado nesse tipo de comunicação é o RPC (Remote Procedure Call), ou Chamada de Procedimento Remoto, cujo objetivo é esconder do usuário as técnicas utilizadas para realizar as trocas de mensagens entre processos que estão espalhados pela rede (Stevens, 1990).

A comunicação em grupo é utilizada quando há necessidade de um processo comunicar-se com um grupo de processos, com o intuito de se obter maior tolerância a falhas e maior disponibilidade de recursos.

\subsection{Computação Paralela sobre Sistemas Distribuídos}

A Computação paralela possui a vantagem do alto desempenho, porém fatores como alto custo de aquisição e manutenção e, principalmente, dependência ao fabricante têm dificultado a sua disseminação.

A utilização dos sistemas distribuídos como plataforma de execução paralela, fornecendo menor custo de implantação e maior flexibilidade no processo computacional paralelo tornou-se viável nos últimos anos, favorecendo fortemente o desenvolvimento da computação paralela em vários domínios de aplicações.

A idéia básica é possuir um grupo de computadores interligados, funcionando como unidades de processamento de uma máquina paralela. Isso é possível através da utilização de ambientes de passagem de mensagens (conhecidos por ambientes paralelos virtuais), que são constituídos basicamente de uma biblioteca de comunicação, que permite a construção de aplicações paralelas (tais ambientes serão abordados com maiores detalhes a seguir).

Uma das grandes dificuldades encontradas quando se utiliza a computação paralela sobre sistemas distribuídos está relacionada aos vários tipos de heterogeneidade encontrados, como por 
exemplo: tipos arquiteturais de cada máquina (CISC ou RISC), formato de dados, potência computacional e carga de trabalho. Esses fatores são, geralmente, considerados e tratados nos ambientes de passagem de mensagens disponiveis.

Da mesma forma, fatores como mecanismos de escalonamento de processos e balanceamento de carga são freqüentemente estudados, por estarem diretamente relacionados ao desempenho de sistemas que adotam esse tipo de arquitetura.

\subsection{Ambientes de Passagem de Mensagens}

Como já mencionado, um ambiente de passagem de mensagens consiste basicamente em uma biblioteca de comunicação que, atuando como uma extensão das linguagens seqüenciais (como $\mathrm{C}$ e Fortran, por exemplo), permite a construção de aplicações paralelas.

Há um conjunto de rotinas básicas necessárias para a formação de uma biblioteca de comunicação:

- Rotinas de comunicação ponto-a-ponto, responsáveis pela transferência de mensagens entre exatamente dois processos, um transmissor e um receptor. As primitivas utilizadas são: send e receive, para transmissão e recep̧̧ão de mensagens, respectivamente.

- Rotinas coletivas, que se caracterizam pela presença de dois ou mais processos em cada operação de comunicação. As primitivas utilizadas são: broadcast, reduce, barrier, para distribuir uma mensagem a partir de um processo para todos os outros participantes, para rotinas aritméticas globais e para sincronização global de todos os processos, respectivamente.

- Rotinas Probe, responsáveis por verificar se uma determinada mensagem já foi recebida.

- Rotinas informativas, responsáveis pelo retorno de informações a respeito da última mensagem recebida. Tem-se as primitivas: info_pid, info_tam, info_id, para retornar o identificador do processo transmissor, o tamanho da mensagem e o identificador da mensagem, respectivamente. 
Inicialmente, os ambientes de passagem de mensagens foram desenvolvidos para máquinas com processamento maciçamente paralelo (Massively Parallel Processing - MPP), para efetuar a comunicação entre os diversos processadores. Segundo essa abordagem, tais ambientes estavam diretamente ligados à arquitetura de hardware de seu fabricante e, portanto, não levavam em consideração a portabilidade do software gerado.

Dessa forma, os ambientes de passagem de mensagens foram remodelados objetivando a utilização do potencial dos sistemas distribuídos, a uniāo de plataformas heterogêneas e a portabilidade das aplicações paralelas desenvolvidas.

Fundamentados nesses objetivos surgiram os ambientes de passagem de mensagens com plataforma portátil e, portanto, independentes da máquina a ser utilizada. Como exemplos destas plataformas, tem-se: Express (Flower \& Kolawa, 1994), Linda (Carriero et al, 1994), P4 (Butler \& Lusk, 1994), PARMACS (Calkin et al, 1994), ZipCode (Skjellum et al, 1994) e PVM (Beguelin et al, 1994) (Sunderam et al, 1994). Dentre eles, destaca-se o PVM (Parallel Virtual Machine), devido a sua grande aceitação e utilização, podendo ser descrito como um padrão "de fato".

O grande número de plataformas de portabilidade existentes gera um problema semelhante ao de ambientes específicos a arquiteturas em relação à real portabilidade de programas. Além disso, grande parte dessas plataformas dá suporte a apenas um subconjunto das características de determinadas arquiteturas, ocasionando o não uso de características importantes de algumas delas (McBryan, 1994).

Diante desses aspectos, iniciou-se um processo de padronização para plataformas de portabilidade. Esse padrāo, que não é apoiado por nenhuma organização oficial, foi nomeado Message Passing Interface - MPI (Interface para Passagem de Mensagens), e será discutido no próximo capitulo. 


\subsection{Considerações Finais}

Há tempos a computação paralela se faz necessária para solucionar problemas complexos, os quais utilizam grande quantidade de dados. No entanto, 0 alto custo do hardware e a dificuldade em se encontrar software de desenvolvimento para aplicações paralelas constituíam um grande obstáculo.

Assim, procurou-se uma maneira de conciliar o alto desempenho, pelo processamento paralelo, e o baixo custo da plataforma (hardware) a ser utilizada, com o uso de sistemas distribuídos.

A idéia mostrou ser extremamente vantajosa, de modo que a chamada computação paralela distribuída expandiu-se nos mais diversos meios computacionais. Isso levou à necessidade de se desenvolver ambientes, os quais possibilitassem fazer com que os vários elementos de processamento da plataforma distribuída fossem utilizados para desempenhar a função de uma máquina paralela.

Tais ambientes conhecidos por ambientes paralelos virtuais, vêm sendo aperfeiçoados para satisfazer às mais diversas necessidades da comunidade computacional.

Um padrão para esses ambientes (conhecido por MPI) que vem sendo desenvolvido por várias entidades computacionais do mundo todo é detalhadamente apresentado no próximo capitulo, devido a sua grande importância no contexto deste trabalho. 


\section{3 \\ Message Passing Interface - MPI}

\subsection{Considerações Iniciais}

A grande quantidade de ambientes de passagem de mensagens existentes, embora forneça um certo grau de portabilidade, não consegue apresentar-se eficientemente em qualquer tipo de plataforma. Diante disso, observou-se a necessidade da criação de um padrão para tais ambientes, que executasse de forma eficiente, independente da plataforma utilizada.

Este capitulo aborda detalhes a respeito do padrão MPI, apresentando sua história, especificações, rotinas de comunicação e as principais implementações existentes.

\subsection{Breve Histórico}

Em abril de 1992 iniciou-se o processo de desenvolvimento do MPI, o qual envolveu cerca de 80 pesquisadores provenientes de 40 organizações, principalmente americanas e européias. Grande parte dos principais fabricantes de computadores paralelos participou do desenvolvimento do MPI, além de universidades e laboratórios ligados ao governo americano (Doss, 1996) (Walker, 1994). 
Os principais objetivos que guiaram o processo de padronização foram: lançar uma versão inicial em um tempo predefinido, de modo que não se perdesse o controle sobre o padrão; formecer portabilidade real; implementação eficiente em plataformas paralelas distintas; e possuir uma interface compativel com a atualidade, visto que uma interface totalmente nova dificultaria a sua aceitação.

Baseando-se nesses objetivos, em novembro de 1992 surgiu uma versão inicial do MPI, cuja implementação apresentava-se bastante incompleta. Desde então, foram criados comitês para cada componente do MPI, os quais se comunicavam através de mailing-lists e, a cada seis semanas, o grupo de desenvolvimento se encontrava (Souza, 1996b). Esse conjunto de reunióes e mailing-lists passou a ser conhecido por Fónum MPI.

Em novembro de 1993 foi apresentada a especificação da versão 1.0 (MPI-1) para o padrão MPI, sendo publicada em maio de 1994. Essa versão foi reavaliada e corrigida dando origem à versîo 1.1, publicada em julho de 1995.

Desde então, o Fónum MPI iniciou o estudo para uma nova versão do MPI com características significativamente novas. Em agosto de 1997 foi apresentada uma segunda versão (MPI-2), concluindo os trabalhos do Fórum MPI (Skjellum et al, 1994) (MPI, 1997a) (MPI, 1997b).

\subsection{Especificação do MPI}

O padrão MPI procura aproveitar as melhores características de cada uma das plataformas de portabilidade existentes, tendo como base principal o PVM (Beguelin et al, 1994) (Sunderam et al, 1994), o Express (Flower \& Kolawa, 1994), o P4 (Butler \& Lusk, 1994), o ZipCode (Skjellum et al, 1994) e o PARMACS (Calkin et al, 1994), além das plataformas vendidas pela IBM, Intel, Meiko Scientific, Cray Research e nCUBE (Dongarra et al, 1996).

Sob esse aspecto, o padrão MPI apresenta as seguintes características: 
* Eficiência - foi cuidadosamente projetado para executar eficientemente em máquinas diferentes;

- Facilidade - define uma interface não muito diferente dos padrões existentes;

* Portabilidade - possibilidade de migração de programas paralelos entre diferentes plataformas.

* Transparência - permite que um programa seja executado em sistemas heterogêneos sem mudanças significativas;

- Segurança - fornece uma interface de comunicação confiável, onde o usuário não precisa se preocupar com falhas de comunicação.

É importante ressaltar que a especificação do MPI fornece tais características e, portanto, as implementą̧os existentes devem assegurá-las.

\subsubsection{Especificação MPI-1}

O padrão MPI-1 define a semântica e a sintaxe de um conjunto de 129 rotinas que oferecem os seguintes serviços (Macdonald et al, 1997) (Dongarra et al, 1996) (Snir et al, 1996) (Souza, 1996b) (McBryan, 1994) (Walker, 1994):

* Comunicações ponto-a-ponto;

- Comunicações coletivas;

- Grupos de processos;

- Domínios de comunicação;

- Topologias virtuais de processos;

- Gerenciamento do ambiente e funções de pesquisa (inquiry);

- Interface para monitoramento (profiling interface); 
- Interface para as linguagens C e Fortran 77.

As especificações mais importantes do MPI são a comunicação entre processos, tipos de dados definidos pelo usuário, grupos de processos e contextos de mensagens.

O núcleo básico do MPI é constitúdo pelas rotinas de comunicação, que podem ser divididas em comunicação ponto-a-ponto e comunicação coletiva.

\section{(1) Comunicação Ponto-a-Ponto}

As rotinas de comunicação ponto-a-ponto envolvem apenas um par de processos e podem ser feitas através das primitivas send e receive, que necessitam da especificação dos tipos de dados enviados e tags.

Especificar os tipos de dados enviados é necessário para que se possa efetuar a correta interpretação em plataformas heterogêneas. Além de permitir seqüências de tipos primitivos idênticos (como char, int e outros), o MPI também permite tipos de dados especificados pelo usuário, os quais possibilitam enviar porções não contínuas da memória e tipos de dados heterogêneos (como structs).

Os tags são necessários para que o processo receptor selecione as mensagens, permitindo que apenas mensagens de um determinado tipo sejam recebidas. Entretanto, há a possibilidade de recebimento de mensagens com qualquer tag através de sua generalização (wild-cards).

O MPI permite a utilização de rotinas bloqueantes e não bloqueantes. Segundo o Fórum MPI (Snir et al, 1996), a definição de bloqueio é caracterizada pela sobreposição ou não de comunicação em relação à execução do programa. Portanto, uma rotina é dita bloqueante quando o processo transmissor/receptor fica bloqueado até que a transmissão/recepção da mensagem se complete. Caso contrário, tem-se uma rotina não bloqueante (Souza, 1996b).

As operações de comunicação podem ser analisadas não somente pelo uso de rotinas bloqueantes ou não, mas também, pela utilização ou não de buffers e a garantia ou não de sincronismo. Esses fatores estão relacionados com a semântica das primitivas e afetam diretamente o desempenho das operações (Souza, 1997). 
O MPI especifica quatro semânticas (ou modos) diferentes para a primitiva send (que podem ser bloqueantes ou não bloqueantes): padrão, com buffers (buffered), síncrono e pronto (ready). A primitiva receive possui apenas um modo que se adapta a qualquer um dos modos send (Snir et al, 1996).

No modo padrão, o MPI se responsabiliza pela utilização ou não de buffers para a transmissão da menșagem, geralmente, baseado na arquitetura para a qual a implementação foi projetada. Quando forem utilizados buffers, a primitiva send poderá retornar antes da primitiva receive ser executada pelo outro processo. Caso o buffer seja insuficiente para a mensagem, o MPI pode decidir pela não utilização deste e, portanto, a primitiva send não será finalizada enquanto a primitiva receive não for executada no processo destino.

No modo com buffers (buffered), a operação send pode ser efetuada independentemente da execução ou não da operação receive, sendo necessário que o usuário reserve uma quantidade de memória para o buffer.

O modo síncrono também possibilita que a operacão send possa ser iniciada independentemente da execução da operação receive, porém, somente quando o processo destino executar a operação receive e obtiver a mensagem, a operação send é concluída. (

No modo pronto (ready), a operação send somente pode ser executada se o seu receive correspondente já foi iniciado pelo processo destino. Como não há uso de buffers, o modo pronto permite melhores desempenhos.

\section{(2) Comunicação Coletiva}

A comunicação coletiva envolve todos os processos inseridos em um determinado contexto, especificado por um objeto chamado comunicador (comunicator).

Embora as comunicações coletivas tenham sido projetadas para serem consistentes com as comunicações ponto-a-ponto, existem algumas simplificą̧ões/restrições, tais como: a quantidade de dados enviados pela primitiva send deve ser a mesma determinada pela primitiva receive; apresentam apenas comunicações bloqueantes; ausência do parâmetro tag e especificação de apenas um modo para comunicação, análogo ao modo padrão. 
As funções coletivas especificadas pelo padrão MPI são:

- Barrier, responsável pela sincronização de todos os processos de um grupo;

- Funções para transmissão global de dados (Figura 3.1):

- Broadcast (difusão), responsável por transmitir a mesma informação a todos os processos de um grupo;

- Gather (coleta), responsável por reunir em um processo, dados diferentes provenientes de todos os processos de um grupo;

- Scatter (espalhamento), responsável por distribuir para todos os processos de um grupo, dados diferentes provenientes de um processo;

- Allgather, semelhante à função gather, porém, todos os processos recebem os dados (reunindo as características das funções gather e broadcast);

- AlltoAll, os dados diferentes de todos os processos são enviados para todos os processos (reunindo as características das funções gather e scatter); 

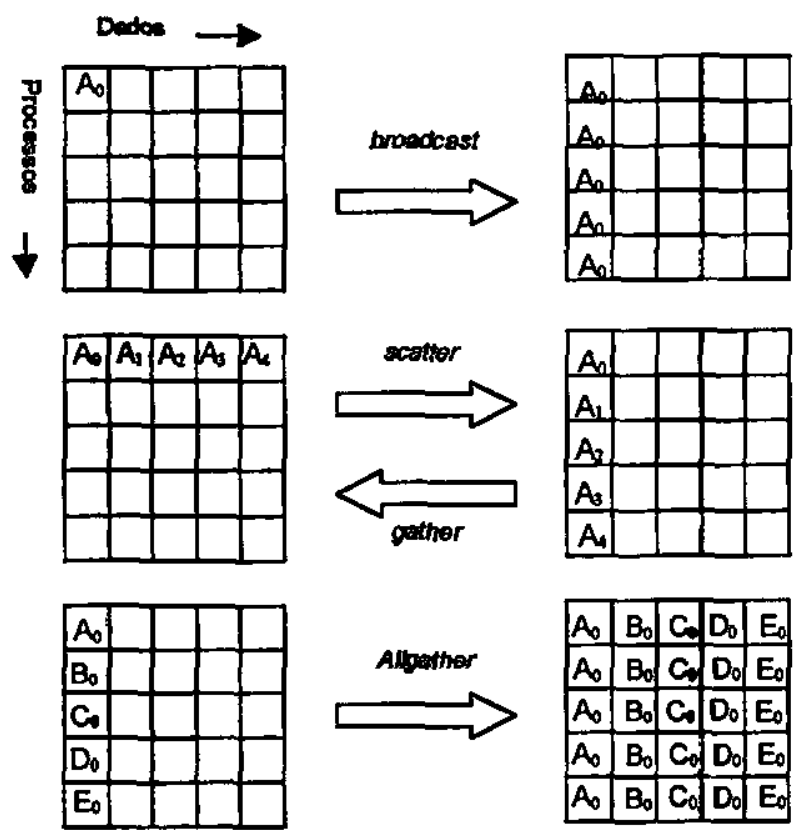

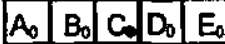

\begin{tabular}{lllllll}
$A_{0}$ & $B_{0}$ & $C_{0}$ & $D_{0}$ & $E_{0}$ \\
\hline$A_{0}$ & $B_{0}$ & $C$ & & \\
\hline
\end{tabular}

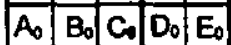

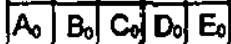

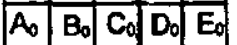

\begin{tabular}{|l|l|l|l|l|}
\hline$A_{0}$ & $A_{1}$ & $A_{2}$ & $A_{0}$ & $A_{1}$ \\
\hline$B_{0}$ & $B_{1}$ & $B_{2}$ & $B_{3}$ & $B_{4}$ \\
\hline$C_{2}$ & $C_{3}$ & $C_{2}$ & $C_{3}$ & $C_{4}$ \\
\hline$D_{0}$ & $D_{1}$ & $D_{2}$ & $D_{3}$ & $D_{4}$ \\
\hline$E_{0}$ & $E_{1}$ & $E_{2}$ & $E_{3}$ & $E_{1}$ \\
\hline
\end{tabular}

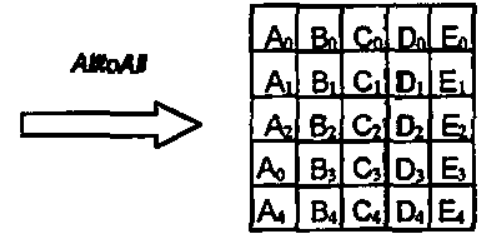

Figura 3.1 - Esquemas de Transmissão Coletiva de Dados (Dongarra et al, 1996)

- Funções globais de redução, como sum, max, min e funções definidas pelo usuário. Essas funçōes possibilitam efetuar operações de redução onde o resultado é enviado para todos os processos do grupo ou para apenas um processo; combinar operaçōes de redução e scatter e efetuar operações scan (parallel prefix), onde os valores obtidos pela operação de redução nos processos com ranks (números inteiros consecutivos para identificação de cada processo) de 0 a i, são repassados aos processos com rank $i$.

Todas as funções envolvendo a transferência coletiva de dados, com exceção da função broadcast, possuem duas variações: na primeira, chamada variação simples, todos os itens comunicados são mensagens do mesmo tamanho; na segunda, chamada variação vetorial, cada item pode possuir um tamanho diferente (Snir et al, 1996). 


\section{Comunicadores, Contextos e Grupos de Processos}

Para permitir maior segurança e menos conflitos entre as mensagens, o MPI define explicitamente grupos de processos e contextos (ou domínios) de comunicação especificados por comunicadores.

Um grupo é um objeto opaco ${ }^{1}$ que representa um conjunto ordenado de identificadores de processos. Como a cada processo iniciado é atribuido um rank sucessivo e iniciado em zero, no MPI um processo é identificado por um grupo seguido por um rank.

Um comunicador é um objeto opaco com um número fixo de atributos, juntamente com regras para gerenciar sua criação, uso e destruição.

O comunicador representa um domínio (ou contexto) de comunicação, o qual é utilizado para definir os processos que podem participar da comunicação. Quando o MPI é iniciado, um comunicador padrão é criado (MPI_COMM_WORLD), cuja finalidade é definir um contexto inicial para todos os processos e servir de base à criação de outros comunicadores.

Existem dois tipos de comunicadores: intracomunicadores, usados para comunicação dentro de um único grupo de processos, e intercomunicadores, os quais permitem a comunicação ponto-a-ponto entre processos de dois grupos.

A importância em se utilizar o conceito de comunicadores pode também ser justificada por simplificar as operaçōes do MPI, reduzindo o número de argumentos utilizados nas funções.

\subsubsection{Especificação MPI-2}

A segunda versão especificada para o padrão, concluída em agosto de 1997, acrescenta novas funcionalidades, como:

${ }^{1}$ Objetos opacos são representaçōes de vários objetos MPI que estão inseridos em posições de memória não acessiveis diretamente pelos usuários, sendo utilizados através de handles. 
- Controle e gerenciamento de processos: rotinas de início, término e controle de processos. Pode-se fazer a comunicação entre processos iniciados em diferentes aplicações, através de rotinas que especificam portas de comunicação globais;

- Entrada e saida paralelas: rotinas que permitem que vários processos tentem acesso a um arquivo concorrentemente;

- Rotinas coletivas estendidas: definição de rotinas coletivas que envolvam diferentes grupos de processos;

- Comunicacão unilateral (one-sided): define rotinas de acesso remoto à memória (RMA Remote Memory Access), onde o transmissor é responsável por controlar a transmissão e a recepção de uma mensagem, de forma a possibilitar rotinas assíncronas.

\section{- Interface para linguagem $\mathrm{C}++$ e Fortran 90.}

Ainda não há uma implementação que englobe todas as funcionalidades especificadas pelo padrão. Os módulos são implementados e aos poucos acrescentados às implementações existentes.

Estudos estão sendo desenvolvidos para acrescentar outras funcionalidades ao padrão, como criação de processos independentes, suporte para threads, identificador para comunicadores, interface completa para Fortran 90 , comunicação coletiva não bloqueante e suporte para processamento em tempo real (MPI/RT).

\subsection{Principais Implementações}

Existem diversas implementações do pađrão MPL de dominio público e comerciais (Tabela 3.1 e Tabela 3.2, respectivamente). Esta seção descreve, com maiores detalhes, duas implementações de domínio público, que se destacam pela grande aceitação e por possuírem suporte ao Sistema Operacional Linux, o qual será utilizado neste trabalho. 
Tabela 3.1 - Implementações de Domínio Público do MPI

\begin{tabular}{|c|c|c|}
\hline 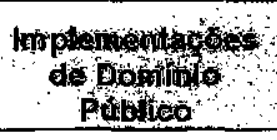 & 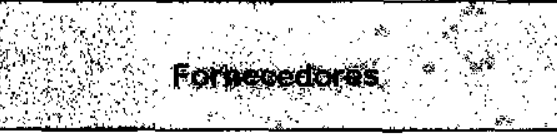 & Shothos \\
\hline Appleseed & U.C. Los Angeles & $\begin{array}{l}\text { Power Macitosh G3 e G4 executando Macos } 8.1 \text { ou } \\
\text { superior }\end{array}$ \\
\hline CHIMPIMPI & $\begin{array}{c}\text { Edinburgh Parallel Computing Centre } \\
\text { (EPCC) }\end{array}$ & $\begin{array}{l}\text { SunOS 4, Solaris 5, IRIX4, IRIX 5, Digital Unix, HP- } \\
\text { UX, AIX, DYNIX, Meiko CS-2 }\end{array}$ \\
\hline $\begin{array}{l}\text { CRI/EPCC MPI for } \\
\text { Cray T3D }\end{array}$ & $\begin{array}{l}\text { Cray Research Incorporated via } \\
\text { Edinburgh Paralfel Computing Centre }\end{array}$ & Cray T3D \\
\hline DISI & Universita'di Genova, Italy & $\begin{array}{c}\text { Clusters de PC's Intel X86 com linux, interconctados } \\
\text { por Fast Ethernet ou Gigabit Ethernet }\end{array}$ \\
\hline LAM & $\begin{array}{l}\text { Laboratory for Scientific Computing, } \\
\text { University of Notre Dame }\end{array}$ & $\begin{array}{l}\text { Solaris 2.6.1-2.6, IRIX6.2-6.5, AIX 4.1.x-4.2.x, OSF/1 } \\
\text { V4.0, HP-UX B.10.20-B.11.00, Linux V2.0.36-v.2.2.x }\end{array}$ \\
\hline MP-MPICH & RWTH: Scalable Computing, Aachen & Plataformas Unix e Windows NT \\
\hline MPI-FM & $\begin{array}{l}\text { University of Illinois, Concurrent } \\
\text { Systems Architecture Group }\end{array}$ & $\begin{array}{c}\text { Clusters WinNT/x86 e Linux/X86 baseados em } \\
\text { Myninet }\end{array}$ \\
\hline MPIAP & $\begin{array}{c}\text { Australian Nationel University - CAP } \\
\text { Research }\end{array}$ & $\begin{array}{c}\text { Fujtsu AP1000 (CellOS), AP1000+ (CellOS, } \\
\text { APLINUX) }\end{array}$ \\
\hline MPICH & $\begin{array}{l}\text { Argonne National Laboratory \& } \\
\text { Mississipi State University }\end{array}$ & $\begin{array}{l}\text { MPP's, IBM SP, Intel Paragon, SGI Onyx, Challenga } \\
\text { e Power Challenga, Convex (HP) Exemplar, nCUBE, } \\
\text { Maiko CS-2, TMC CM-5, Cray T3D, SunOS e Solaris, } \\
\text { SGl, HP, TS/6000, DEC Alpha, Cray C-90 }\end{array}$ \\
\hline MPICH/NT & Mississipi State Univarsity & Intel X86 WindowsNT $3.51,4.0 \mathrm{~b} 1$ \\
\hline MacMP! & University of California & Macintosh \\
\hline RACE-MPI & Hughes Aircraft Co. & $\begin{array}{l}\text { PC's rodando MCOS } 3.2 .0 \text { ou MCOS 4.0.0i860 } \\
\text { rodando MCOS 3.2.0 ou MCOS 4.0.0 Sparc rodando } \\
\text { SunOS ou SolarisMVME } 1604 \text { rodando VxWorks } 5.3\end{array}$ \\
\hline WMPI & Universidade de Coimbra - Portugal & Windows 95 e NT \\
\hline
\end{tabular}


Tabela 3.2 - Implementações Comerciais do MPI

\begin{tabular}{|c|c|c|}
\hline 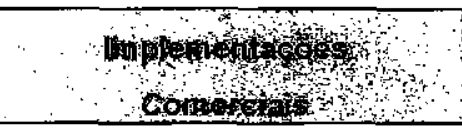 & 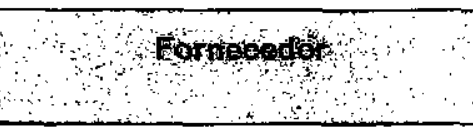 & 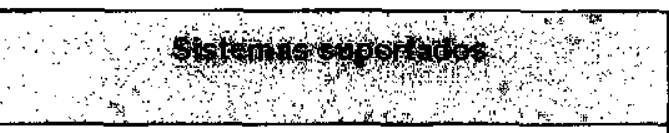 \\
\hline Apha Data MPI & Apha Data parallel systems Ltd. & $\begin{array}{c}\text { Apha Data Systems baseados em AD164, } \\
\text { AD64 e AD66 }\end{array}$ \\
\hline $\mathrm{HP} \mathrm{MPI}$ & $\begin{array}{l}\text { Hewlett-Packard, Co.; High } \\
\text { Performance Systems Division }\end{array}$ & $\begin{array}{c}\text { Todos os sistemas rodando HP-UX } 10.20, \\
11.0 \text { ou SPP-U }\end{array}$ \\
\hline $\begin{array}{l}\text { IBM Parallel Environment for } \\
\text { AIX-MPI Library }\end{array}$ & IBM Corporation & Risc System/6000, RS/6000 SP \\
\hline MPI & Hitachi, Ltd. & Hitachi SR2201 \\
\hline MPI para sistemas IRIX & SG! & Sistemas SGI rodando IRIX 6.2 e superior \\
\hline $\begin{array}{l}\text { MPI para sistemas UNICOS } \\
\text { (Cray Parallel-Vector) }\end{array}$ & SGI & $\begin{array}{c}\begin{array}{c}\text { Todos os sistemas rodando UNICOS } 9.3 \mathrm{e} \\
\text { superior }\end{array} \\
\end{array}$ \\
\hline MPI para sistemas UNICOS/mk & SG! & $\begin{array}{c}\text { Todos os sistemas rodando UNICOS/mk } 1.5 \mathrm{e} \\
\text { superior }\end{array}$ \\
\hline MPI/DE & NEC Corporation & NEC Cenju-3 (Cenju-3/DE) \\
\hline MPI/PRO & MPI Software Technology & $\begin{array}{l}\text { Redhat Linux para arquiteturas Intel e Alpha, } \\
\text { Yellow Dog PPC para Macintosh G3 boxes, } \\
\text { Windows NT, Mercury RACE }\end{array}$ \\
\hline $\begin{array}{c}\text { OS/390 Unix System Services } \\
\text { Parallel Environment }\end{array}$ & IBM Corporation & OS/390 Unix System Services \\
\hline Paragon OS R1.4 & Intel Corp. & Paragon \\
\hline ScaMPl & Scali AS & $\begin{array}{l}\text { Redhat linux e Solanis } 2.6 \text { para arquiteturas } \\
\text { Intel e Sparc usando interconexão Dolphin SCI }\end{array}$ \\
\hline Sun MPI & Sun Microsystems, inc. & $\begin{array}{c}\text { Todos os sistemas Solaris/ultraSPARC e } \\
\text { clusters dos mesmos }\end{array}$ \\
\hline T.MPI & Telmat Multinode & $\begin{array}{c}\text { Telmat séries TN110 e TN300 (T9000 } \\
\text { transputer) }\end{array}$ \\
\hline TransMPI & PERIASTRON & Todos os transputers de 32 bits ou superior \\
\hline
\end{tabular}

\subsubsection{MPICH}

A implementação do MPICH iniciou-se junto aos trabalhos de definição do padrão MPI, sendo resultado de um trabalho conjunto entre as organizações americanas Argonne National Laboratory e Mississipi State University (Gropp \& Lusk, 1999).

Fornecer uma implementação portátil e eficiente para uma grande variedade de sistemas computacionais paralelos que dessem suporte ao modelo de computação via troca de mensagens, constituiu o principal objetivo para o desenvolvimento do MPICH. 
Devido à sua alta portabilidade, foi batizado de MPI Chameleon ou MPICH. Implementa todas as rotinas do padrão MPI-1, utilizando a combinação de plataformas de portabilidade já existentes (como P4, Chameleon e ZipCode).

A arquitetura do MPICH está dividida em dois níveis. No primeiro nível está todo o código fonte independente de hardware, que pode ser transportado diretamente, e onde estão implementadas todas as funções do MPI. Todo o código dependente de plataforma (chamado dispositivo) encontra-se no segundo nível, o qual especifica uma camada denominada ADI (Abstract Device Interface - Interface de Dispositivo Abstrata), responsável pela comunicação entre os dois níveis (Gropp \& Lusk, 1996) (Meyer, 1994) (Souza, 1996b). A Figura 3.2 apresenta o modelo resumido da estrutura do MPICH.

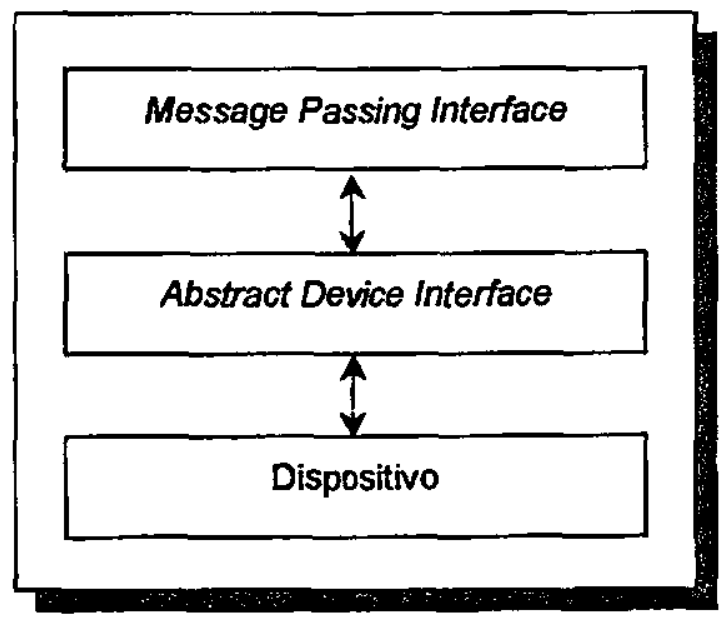

Figura 3.2 - Estrutura do MPICH

O MPICH apresenta ferramentas adicionais como, por exemplo, uma biblioteca chamada MPE (Multi-Processing Environment) cujo objetivo é auxiliar o desenvolvimento e a depuração de programas paralelos. 
computadores. Assim como o PVM, o LAM cria uma máquina paralela virtual, onde cada um dos computadores que formam parte dessa máquina executa um daemon (processo executado intermitentemente, em background, num sistema Unix (Stevens, 1990)). A função desse daemon é controlar todo o funcionamento da máquina virtual e a depuração de programas executados sobre ela.

Segundo os criadores do LAM, sua principal característica se concentra no total controle da máquina paralela virtual (Burns \& Daoud, 1995), no qual possibilita executar e encerrar programas de qualquer componente da máquina virtual, visualizar mensagens a medida em que são transmitidas e fornecer uma ferramenta para depuração de problemas de sincronização entre processos e mensagens.

Essa implementação está detalhadamente descrita mais adiante por ter sido escolhida para o desenvolvimento deste trabalho.

\subsection{Considerações Finais}

A principal vantagem em se estabelecer um padrão para passagem de mensagens está na portabilidade e facilidade de uso. O padrão MPI, além de fornecer essas características essenciais, ainda provê eficiência, transparência e segurança.

No entanto, alguns pesquisadores dizem que o padrão MPI é muito extenso dificultando o seu entendimento e utilização. Ao todo são mais de 120 rotinas especificadas, as quais tendem a aumentar a cada nova versão. Há duas razões fundamentais que explicam esse fato. A primeira é que o MPI foi desenvolvido para ser rico em funcionalidade. Isso é refletido no suporte a tipos de dados derivados do padrão, comunicação modular via abstração de comunicadores, caching, topologias de aplicação e rotinas de comunicação coletiva. A segunda razão reflete a diversidade e a complexidade dos computadores de alto desempenho de hoje.

O múmero de funções poderia ser diminuído se aumentasse o número de parâmetros utilizados em cada função. Entretanto, isto aumentaria o overhead gerado e tornaria as funções mais complexas. Portanto, a disponibilidade de um grande número de funçōes permite fornecer uma interface mais simples para as funções mais freqüentemente utilizadas. 
É importante ressaltar novamente que o padrão MPI consiste em uma especificação, na qual provê as funcionalidades e vantagens descritas. No entanto, as diversas implementações existentes devem assegurar que tais funcionalidades sejam alcançadas.

No próximo capítulo são abordados os conceitos de escalonamento de processos e balanceamento de carga, os quais fornecem um importante conhecimento para o desenvolvimento deste trabalho. 


\section{4 \\ Escalonamento e Balanceamento de Carga}

\subsection{Considerações Iniciais}

A utilização da computação paralela distribuida proporcionou diversas vantagens à comunidade computacional, mas alguns novos problemas surgiram juntamente com essa nova tecnologia, entre eles, como desenvolver mecanismos para o escalonamento dos processos e a distribuição de cargas entre as diversas unidades de processamento disponíveis.

Não basta ter sistemas com grande número de unidades de processamento. É preciso garantir que essas unidades sejam bem aproveitadas, que haja trabalho suficiente e compatível com a capacidade global do sistema e que todas as unidades tenham uma carga uniforme (Shivaratri et al, 1992).

Através de uma boa técnica de escalonamento de processos pode-se atingir um de seus grandes objetivos, o balanceamento de carga, que possibilita manter a estabilidade do sistema, atingindo grande eficiência $e$, conseqüentemente, alto desempenho.

Este capítulo apresenta definições, mecanismos, políticas e algoritmos utilizados no escalonamento de processos em plataformas distribuidas, bem como as consideraçōes relevantes para se conseguir o balanceamento de carga. 


\subsection{Escalonamento de Processos}

O escalonamento de processos é a atividade responsável por atribuir processos às unidades de processamento e determinar a ordem em que esses processos serão executados.

Quando o escalonamento envolve apenas uma unidade de processamento, somente fatores locais são considerados (como por exemplo, entrada/saída e porções de tempo disponíveis no processador). Por outro lado, o escalonamento em sistemas computacionais distribuidos, envolvendo várias unidades de processamento, tem por finalidade distribuir os processos entre essas unidades, seguindo alguns objetivos previamente estabelecidos, que podem ser: diminuir o tempo médio de resposta, diminuir atrasos na comunicação e maximizar a utilização dos recursos disponíveis (Shirazi et al, 1995) (Souza et al, 1998). Entretanto, as atividades mais importantes do escalonamento de processos são a satisfação dos seus usuários e o aumento de produtividade com a utilização de seus recursos (Feitelson et al, 1997).

\subsubsection{Classificação dos Algoritmos de Escalonamento}

Casavant (Casavant \& Kuhl, 1988) propõe uma classificação para os algoritmos de escalonamento, cujo objetivo é reunir os mais diversos conceitos empregados na área em uma classificação hierárquica e em uma classificação plana.

\section{Classificação Hierárquica}

$\mathrm{Na}$ classificação hierárquica, os métodos de escalonamento são tipicamente classificados em diversas subcategorias, conforme a hierarquia estabelecida na Figura 4.1 (Casavant \& Kuhl, 1988). Nessa hierarquia pode-se distinguir entre escalonamento local e global. 


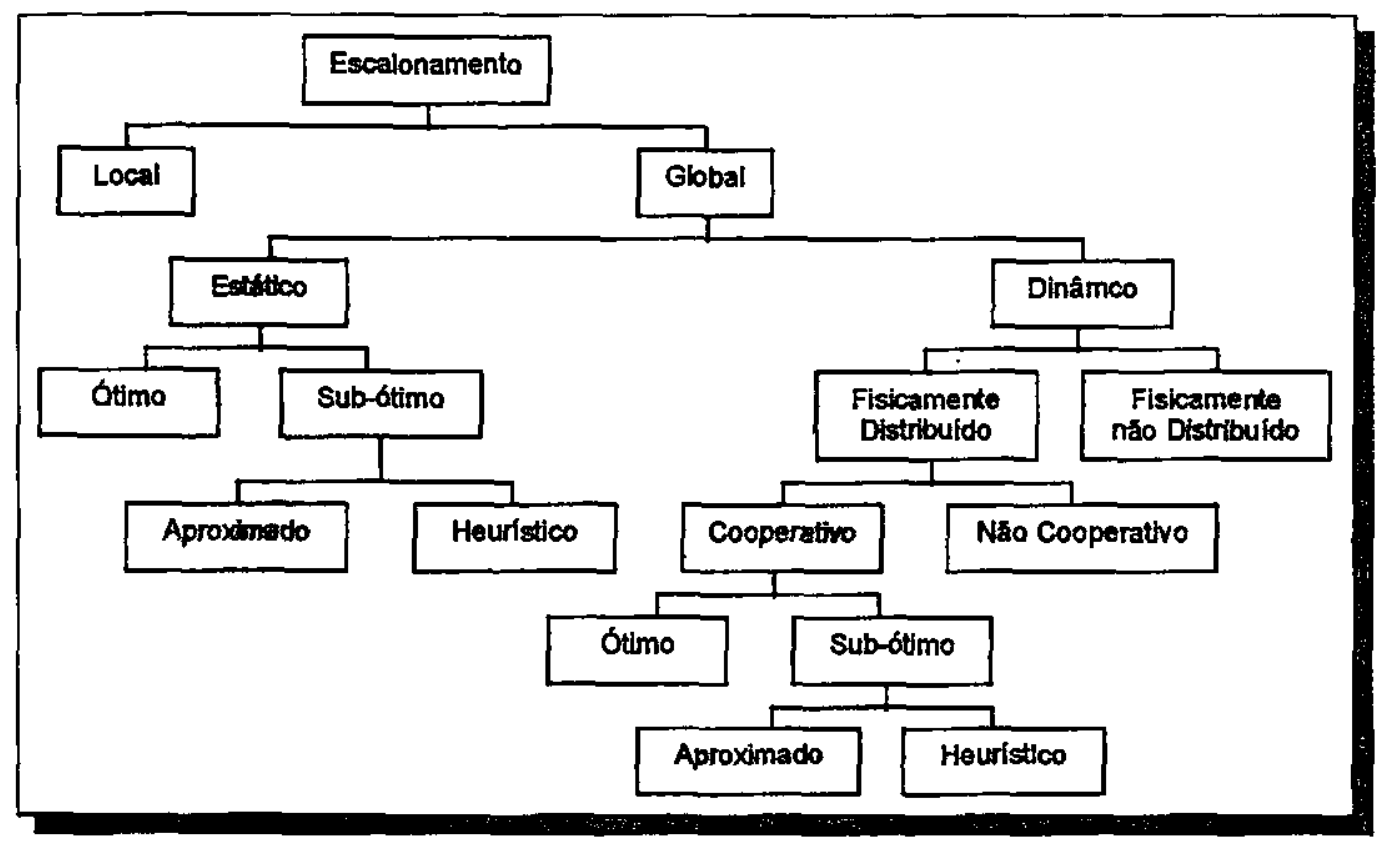

Figura 4.1 - Classificação Hierárquica proposta por Casavant (Casavant \& Kuhl, 1988)

\section{(1) Escalonamento Local}

O escalonamento local, realizado pelo sistema operacional de um computador, consiste en distribuir os periodos de tempo de um único processador entre os diversos processos et execução (time-slice).

\section{(2) Escalonamento Global}

O escalonamento global é executado em um sistema computacional distribuído corresponde à tomada de decisão de qual unidade de processamento executará um determina processo. Esse tipo de escalonamento pode ser subdividido em dois grupos: escalonamer estático e escalonamento dinâmico.

- Escalonamento Estático (ou determinístico) - a tomada de decisão de escalonament realizada em tempo de compilação. Isso é possível quando há conhecimento prévio sobr tempos de execução dos processos e recursos de processamento. Os método escalonamento estático podem ser classificados em ótimos e sub-ótimos. 
A geração de escalonamentos ótimos é um problema do tipo NP-completo, o qual requer um período de tempo exponencial para ser solucionado. Dessa forma, só é possível gerar soluções ótimas em casos específicos que envolvam poucas combinações.

Os métodos de escalonamento sub-ótimos tentam encontrar uma solução "aceitável" para o problema, sendo que o termo "aceitável" varia de acordo com cada situação (Souza et al, 1998). As soluçôs sub-ótimas podem ser encontradas através de duas abordagens: aproximada, que utiliza algum método de busca conhecido, e heuristica, onde são utilizadas regras especiais (como Inteligência Artificial) para conduzir o processo de escalonamento na direção aproximada de uma solução ótima.

- Escalonamento Dinâmico (ou balanceamento de carga dinâmico) - a decisão de distribuição de processos é feita em tempo de execução. Portanto, não é necessário ter conhecimento a respeito do comportamento da aplicação antes que ela seja executada, tornando o sistema mais flexível e capaz de se adaptar às mudanças ambientais durante a execução dos programas (Shirazi et al, 1995). Os métodos de escalonamento podem ser divididos em fisicamente distribuídos e não distribuídos, dependendo de como a responsabilidade por esses métodos está organizada.

No método dinâmico fisicamente distribuído, o processo de decisão do escalonamento é distribuído entre as diversas unidades de processamento do sistema, podendo ser de forma cooperativa, que leva em consideração um objetivo comum para o sistema como um todo, ou de forma não cooperativa, onde cada unidade de processamento toma as decisões independentemente das demais.

O escalonamento dinâmico fisicamente não distribuido possui uma unidade de processamento central, que é responsável pelas decisões para todo o sistema. As outras unidades de processamento coletam informacões locais, enviando-as para a unidade central (Shirazi et al, 1995) (Casavant \& Kuhl, 1988). 


\section{Classificação Plana}

A classificação plana não segue nenhuma hierarquia e classifica os métodos de escalonamento de acordo com outras características que não são exclusivas de qualquer dos tipos descritos anteriormente. Essa classificação considera se um sistema é adaptativo ou não, se possui preempção ou não e se é estável e apresenta eficiência.

\section{(1) Sistemas Adaptativos e Não Adaptativos}

Nos sistemas adaptativos, os algoritmos que implementam a politica de escalonamento são capazes de se adaptarem dinamicamente às mudanças sofridas no ambiente, em função dos estados anteriores e atuais do sistema, isto $\mathrm{e}$, em fungão do histórico do sistema.

Por outro lado, um sistema não adaptativo é aquele que não leva em consideração o histórico do sistema em suas decisóes e, dessa forma, apresenta sempre o mesmo comportamento na presença de situações semelhantes.

\section{(2) Sistemas Preemptivos e Não Preemptivos}

Em um sistema preemptivo, também conhecido por sistema com migração de processos, um processo é realocado para outra unidade de processamento mesmo após já ter sido iniciada sua execução. Essa operação geralmente é dispendiosa e dificil de ser realizada, uma vez que é necessário reunir todas as informações sobre o estado do processo e transferi-las para a unidade de processamento destino na qual o processo continuará sua execução.

Ao contrário, em um sistema não-preemptivo, também conhecido por atribuição dinâmica de processos, os processos são escolhidos para a distribuição antes de começarem a executar e, desse modo, não há transferência de dados entre as unidades de processamento.

\section{(3) Estabilidade e Eficiência}

A estabilidade de um sistema está relacionada à sua capacidade de responder à sua carga de trabalho (workload). $\mathrm{Na}$ área de transferência de tarefas, a estabilidade se divide em duas formas (Shivaratri et al, 1992): a perspectiva da teoria de filas e a perspectiva dos algoritmos de distribuição. 
De acordo com a teoria de filas, um sistema é considerado instável se apresenta uma taxa de chegada de tarefas maior que sua taxa de conclusão, fazendo com que suas filas cresçam indefinidamente.

Um algoritmo de distribuição de carga é eficiente sob um determinado conjunto de condições se ele consegue aumentar o desempenho relativo de um sistema. Assim, um algoritmo eficiente é estável, mas o contrário nem sempre é verdadeiro.

Analisando sob a perspectiva dos algoritmos de distribuição, se um algoritmo consegue realizar operações improdutivas indefinidamente, com uma probabilidade diferente de zero, então esse algoritmo é instável.

\subsubsection{Componentes de um Algoritmo de Escalonamento}

Um algoritmo de escalonamento é composto por um mecanismo e por uma política, os quais manipulam os seus objetivos. O mecanismo é responsável em definir como o escalonamento será efetuado e a política define o que deve ser feito para que haja o escalonamento de processos.

Shivaratri (Shivaratri et al, 1992) dividiu a responsabilidade da política em quatro categorias: política de informação, política de seleção, política de localização e política de informação.

\section{(1) Política de Transferência}

Essa política é responsável por determinar se um host está em um estado adequado para participar de uma transferência, isto é, se pode ser receptor ou transmissor de cargas.

Em geral, essa politica baseia-se em valores limites (threshold) para determinar o estado de um host. Caso a carga do host esteja abaixo do limite estipulado, considera-se que é receptor, caso contrário, transmissor de cargas. 


\section{(2) Política de Seleção}

A política de seleção é responsável por selecionar quais os processos que devem participar da distribuição de cargas. Alguns fatores devem ser considerados no momento da escolha, tais como:

- A sobrecarga causada pela transferência deve ser mínima;

- O processo a ser transferido deve requerer um tempo de processamento que compense a sobrecarga causada pela transferência;

- O número de chamadas do sistema dependentes da localização deve ser mínimo.

\section{(3) Política de Localização}

Essa politica tem por finalidade identificar para qual host o processo deve ser transferido. Há duas maneiras de se implementar a politica de localização: descentralizada e centralizada.

No caso de uma política de localização descentralizada, o host destino pode ser escolhido basicamente de três maneiras: aleatoriamente (o host é escolhido de maneira aleatória), através de coleta de informações (o estado de todos os hosts é analisado e escolhe-se o melhor) ou através da análise dos vizinhos (apenas os hosts mais próximos são analisados).

Por outro lado, em uma política de localização centralizada há um coordenador (host específico), responsável por localizar o host destino adequado ao compartilhamento da carga.

\section{(4) Política de Informação}

A política de informação decide quando as informações sobre o estado de outros hosts no sistema devem ser coletadas, de onde serão coletadas e quais informações coletar. Existem três tipos de políticas de informação:

- Política dirigida por demanda: nessa política um host coleta o estado de outro host somente quando este se torna também um transmissor ou receptor disponível para iniciar e compartilhar a carga. 
- Política periódica: essa política pode ser implementada de maneira centralizada ou descentralizada e realiza a coleta de informações periodicamente. $\mathrm{Na}$ política periódica centralizada, de tempos em tempos, os hosts enviam informações do seu estado para um host centralizado. No segundo caso, a informação de cada host é distribuída entre as demais máquinas pertencentes ao sistema.

* Política dirigida pela mudança de estado: nessa política os hosts difundem as informações sobre os seus estados, todas as vezes que o seu estado muda por um certo grau. Na política centralizada os hosts enviam as informaçőes para um único host coordenador e, no caso descentralizado, as informações são enviadas para todos os hosts do sistema.

\subsubsection{O Ambiente de Escalonamento Flexível e Dinâmico - AMIGO}

O Ambiente de Escalonamento Flexível e Dinâmico (dyn $\underline{A M i c a l}$ flex $\underline{I} b l e$ schedulin $\underline{G}$ envirOnment - AMIGO) (Souza et al, 1998), consiste em uma ferramenta de software capaz de agrupar diferentes algoritmos de escalonamento, permitindo que o usuário escolha o algoritmo mais apropriado para a sua aplicação paralela (Araújo, 1999).

Inicialmente, o ambiente AMIGO foi projetado para abranger aplicações paralelas desenvolvidas para redes de estações de trabalho com o sistema operacional UNIX (MIMD com memória distribuida), gerenciadas por um ambiente de passagem de mensagens como o PVM (Beguelin et al, 1994) (Souza, 1996a) ou o MPI (Geist et al, 1996) (Souza, 1996b). Entretanto, a sua utilização não está restrita a essas plataformas, podendo ser usado sobre um sistema distribuido, executando aplicações seqũenciais, ou então para máquinas paralelas de fato (Souza et al, 1998) (Araújo, 1999).

No ambiente AMIGO têm-se que:

- o termo Flexivel refere-se à capacidade de inserir e escolher a política e o mecanismo mais adequados às necessidades reais do usuário. Para viabilizar a flexibilidade, o AMIGO deve ser totalmente "aberto", definindo interfaces claras e objetivas para permitir futuras inclusões; 
* o termo Dinâmico refere-se à capacidade de mudar completamente a política e o mecanismo de escalonamento adotados, em tempo de execução da aplicação. Nota-se que o termo Dinâmico aqui não se refere a um "algoritmo de escalonamento dinâmico" e sim à capacidade do AMIGO de ser dinâmico.

O AMIGO está estruturado em duas camadas, conforme mostra a Figura 4.2. Na camada superior, encontra-se a interface gráfica, pela qual o usuário terá acesso às várias opç̃es do ambiente (inserir e gerenciar classes de software, benchmarks, métricas e políticas dẹ escalonamento). Na camada inferior, encontram-se os algoritmos disponíveis para a realização do escalonamento, assim como a interface necessária ao relacionamento com o ambiente de passagem de mensagens utilizado.

A camada inferior do AMIGO trabalha de maneira quase independente à camada superior. Para que a camada inferior possa funcionar, a camada superior não precisa estar executando, necessitando que apenas o arquivo de configuração (que relaciona as políticas ativas) exista. Caso este arquivo não exista, uma política é eleita como "padrão" e passa a atender a todas as solicitações.

O acesso à camada inferior do AMIGO é feito através do ambiente de passagem de mensagens. Dessa forma, a aplicação paralela do usuário não sofre nenhuma alteração, fazendo do AMIGO um ambiente totalmente transparente para o usuário final.

A camada inferior está estruturada basicamente em três módulos: o ambiente de passagem de mensagens, o AMIGOD (daemon AMIGO) e as políticas de escalonamento. 


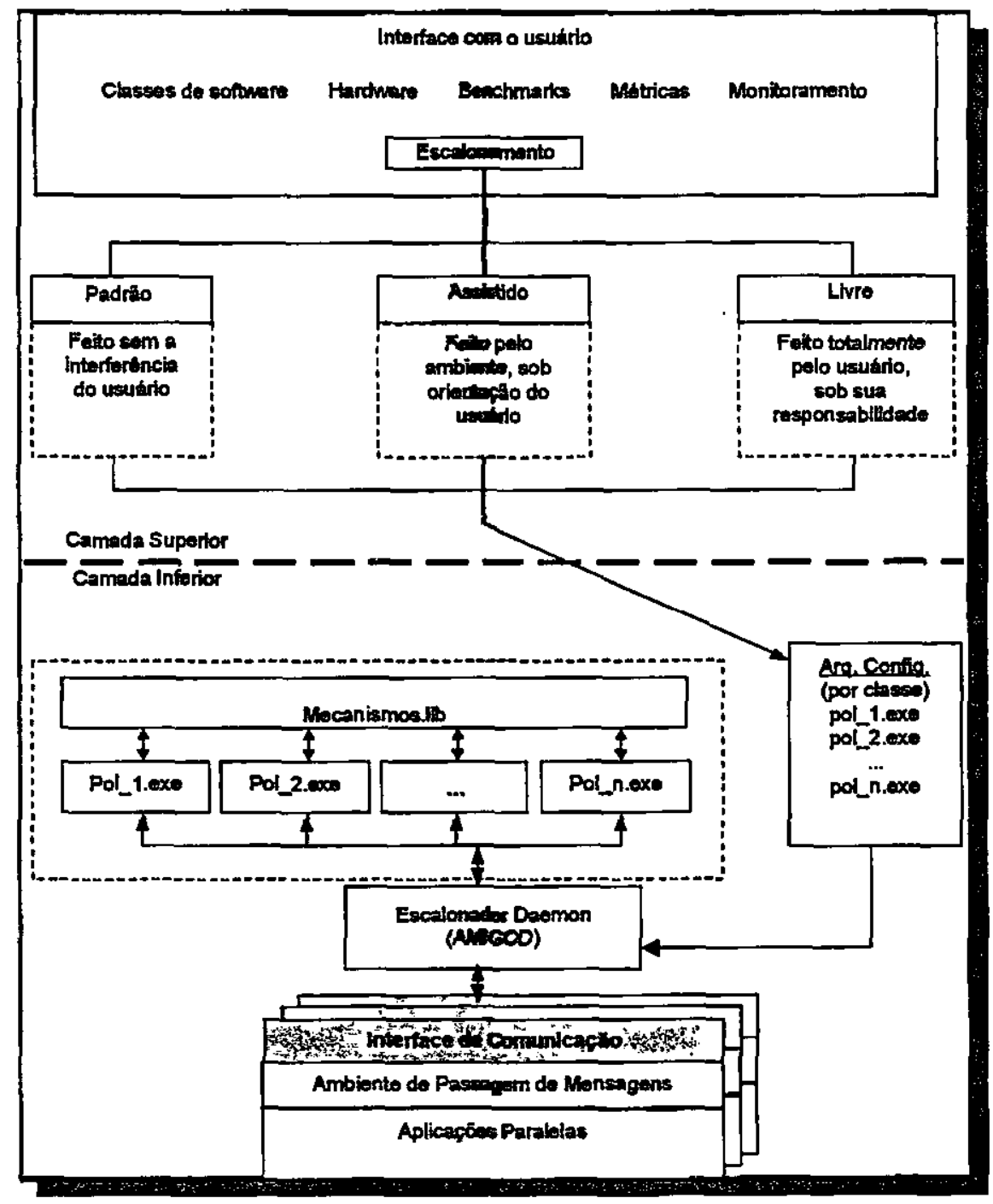

Figura 4.2 - Esquema Estrutural do AMIGO (Souza et al, 1998)

O AMIGOD é o componente central dessa camada, sendo responsável por interligar o ambiente de passagem de mensagens às polícias de escalonamento. Assim, o AMIGOD não realiza o escalonamento em si, mas age como um roteador e controlador de mensagens entre os componentes envolvidos no escalonamento.

A estrutura interna do AMIGOD é formada por alguns mecanismos de comunicação entre processos, responsáveis pelas trocas de mensagens, pelas estruturas de dados que mantêm as tabelas de roteamento e pelas políticas ativas no momento.

A comunicação entre processos realizada pelo AMIGOD é baseada em sockets TCP (Transmission Control Protocol) e sockets UDP (User Datagram Protocol) através do protocolo 
de comunicação TCP/TP (Comer, 1995). Os sockets TCP são utilizados para comunicação entre os módulos num mesmo elemento de processamento enquanto os sockets UDP são destinados à comunicação entre os módulos em elementos de processamento distintos. Basicamente, existem três conexões: AMIGOD $\Leftrightarrow$ Política, AMIGOD $\Leftrightarrow$ Ambiente de passagem de mensagens, AMIGOD $\Leftrightarrow$ AMIGOD.

Descrições mais detalhadas a respeito da implementação do AMIGOD podem ser obtidas em (Araújo, 1999) e (Souza, 2000).

\subsection{Balanceamento de Carga}

O balanceamento de carga é um dos grandes objetivos que pode ser atingido através do escalonamento de processos. Como o principal objetivo dos sistemas paralelos distribuídos tem convergido para a busca de alto desempenho, o balanceamento de carga é a disciplina que pode permitir a esses sistemas alcançá-lo (Silva, 1997).

Balancear as cargas de um sistema consiste em distribuir cargas (ou tarefas) entre as diversas unidades de processamento, de maneira que nenhuma delas fique sobrecarregada ou ociosa, equilibrando o sistema.

Devido aos vários tipos de heterogeneidade de hardware (como potências computacionais, tipos arquiteturais e memórias) e de software (sistemas operacionais) presentes em plataformas

- distribuídas, a distribuição das cargas não pode ser feita de maneira uniforme, ou seja, para cada máquina deve ser alocada uma quantidade de carga proporcional ao seu estado e capacidade (Araújo,1999).

\subsubsection{Caracterização da Carga de Trabalho}

A informação a respeito da carga é um dos elementos fundamentais no processo de balanceamento de cargas. A eficiência do esquema de balanceamento de cargas pode ser altamente afetada pela maneira através da qual a informação de carga é colẹtada e quando essa informação é atualizada. 
A Carga de trabalho consiste na seleção das aplicações utilizadas no sistema e a caracterização da demanda pelos processos. Dessa forma, torna-se necessária uma forma de quantificar essa carga para poder efetuar o processo de balanceamento.

\subsection{2 Índice de Carga}

$O$ indice de carga (load index) é o fator que quantifica a carga geral de um sistema, objetivando aumentar sua eficácia e satisfação. Consiste de um valor não negativo que varia proporcionalmente à carga atual do sistema, onde valores próximos de zero representam máquinas ociosas e valores acima de um dado limite representam máquinas sobrecarregadas.

A escolha de um índice de carga adequado é considerada um ponto essencial no projeto de um algoritmo de distribuição de cargas, por apresentar relação direta com o desempenho final do escalonamento. Para ser eficiente, $o$ índice de carga deve refletir precisamente o estado de uma máquina. Além disso, a técnica usada para medir a carga deve ser eficaz e impor a menor sobrecarga possível (Shivaratri et al, 1992) (Araújo, 1999).

Segundo Shivaratri (Shivaratri et al, 1992), um bom índice de carga deve apresentar as seguintes características:

* Considerar não apenas as necessidades de CPU de um processo, mas também os requisitos de operações de entrada/saida e memória;

- Deve ser utilizado para prever a carga em um futuro próximo, visto que o tempo de resposta de uma tarefa é mais afetado pela carga futura de uma unidade de processamento do que pela carga atual;

* Deve ser relativamente estável, onde flutuações de alta frequêencia na carga devem ser desconsideradas ou ignoradas;

* Possuir uma relação direta entre o índice de carga e o desempenho do sistema. 
É dificil, talvez impossivel, encontrar um indice de carga que satisfaça a todos os requisitos acima. No entanto, os índices de carga podem ser julgados de acordo com o grau com que satisfazem tais características.

Alguns indices de carga bastante utilizados são o tamanho da fila de CPU, taxa de utilização da CPU e tempo de resposta ou tempo de processamento.

\subsection{Considerações Finais}

O escalonamento de processos sobre plataformas paralelas e/ou distribuidas tem se tornado um dos grandes temas de pesquisa, por proporcionar um considerável ganho no desempenho final do sistema.

No entanto, o escalonamento e, por conseguinte, o balanceamento de carga, ainda constituem técnicas caras e difíceis de serem implementadas. Nesse sentido, é de fundamental importância que se construam ferramentas eficientes e capazes de propiciar que o balanceamento de carga seja fácil e adaptável às diversas plataformas distribuidas e paralelas.

A escolha dos mecanismos e politicas de escalonamento a serem empregados devem considerar os objetivos almejados com a distribuiç̃o dos processos, de maneira que possam contribuir satisfatoriamente no desempenho final do sistema. Dessa forma, a finalidade da plataforma computacional utilizada, o hardware disponivel, ambientes multiusuários, diferentes

- classes de aplicação e diferentes classes de trabalhos, são fatores que devem ser cuidadosamente analisados.

O escalonamento de processos sendo executado de forma correta é, sem dúvida, um grande aliado para que os recursos disponiveis sejam utilizados com eficácia (Araújo, 1999). Da mesma forma, atingindo o balanceamento das cargas ganha-se em estabilidade e desempenho.

O próximo capítulo aborda as politicas de escalonamento, bem como a DPWP (Dynamic Policy Without Preemption), politica desenvolvida por um mestrado do grupo e utilizada neste trabalho. 


\section{5 \\ Políticas de Escalonamento}

\subsection{Considerações Iniciais}

Há várias propostas para algoritmos de escalonamento na literatura pesquisada. Todavia, essas propostas são, geralmente, de propósito geral que tentam ser eficientes sob qualquer tipo de aplicação. Por outro lado, pesquisas vêm sendo realizadas com o objetivo de viabilizar o desenvolvimento de políticas direcionadas a um tipo específico de aplicação, visando a obtenção de melhor desempenho e eficiência.

Nesse aspecto, este capitulo apresenta algumas classes de software mais utilizadas e as vantagens que podem ser encontradas com uma nova abordagem às políticas de escalonamento, que considera uma classe de software em particular. Também está descrita, de forma simplificada, a DPWP (Dynamical Policy Without Preemption) uma política devolvida para aplicações CPU-Bound.

\subsection{Classes de Software}

As classes de software compreendem os diversos tipos de aplicações existentes no meio computacional. Dentre elas, destacam-se as aplicações CPU-Bound, I/O Bound, Interativas e Batch. 


\subsubsection{CPU-Bound}

As aplicações classificadas como CPU-Bound são caracterizadas por consumirem muito tempo de processamento e apresentarem pouca comunicação.

Um mecanismo para balanceamento de carga nesse tipo de aplicação deve considerar as máquinas com maior potência computacional, visto que os dispositivos de entrada e saída não interferem de maneira significativa no desempenho final do sistema.

Dessa forma, um bom indice de carga pode estar baseado no número de processos prontos na fila da CPU, o qual representa exatamente o recurso mais importante para esse tipo de aplicação. Essa afirmação pode ser questionada, pois o número de processos não está, obrigatoriamente, diretamente relacionado à complexidade ou demanda por processamento dos processos. Porém, essa abordagem é largamente utilizada em diversos trabalhos de destaque na área (Ferrari \& Zhou, 1987).

\subsubsection{I/O-Bound}

As aplicações consideradas como I/O Bound se caracterizam por realizar muitas chamadas aos dispositivos de entrada e saída, quando comparados à demanda por processamento.

Nesse tipo de aplicações não faz sentido dar prioridade a máquinas com maior potência computacional, pois o que influencia são as chamadas de $\mathbf{I} / O$ que independem da capacidade de processamento.

Dessa forma, o índice de carga deve considerar os fatores relacionados às chamadas de $\mathrm{I} / \mathrm{O}$ que, certamente, contribuirão para uma melhor distribuição das cargas. Novamente tem-se uma afirmação polêmica, porque não é trivial avaliar-se a carga do sistema sob esse enfoque (Ferrari \& Zhou, 1987). 


\subsubsection{Interativas}

As aplicações que necessitam de grande interação dos usuários são classificadas como interativas.

Nesse tipo de aplicações, o tempo de resposta é o fator mais importante e deve ser o mais rápido possivel, evitando causar a espera inconveniente pelos usuários.

O mecanismo para balanceamento de carga nesse tipo de aplicações também pode considerar as máquinas com maior capacidade computacional que, geralmente, levariam ao melhor tempo de resposta (Tanenbaum, 1992).

\subsubsection{Batch}

As aplicaçöes batch correspondem aos arquivos de lote, que podem com um único comando realizar uma seqüência de tarefas programadas anteriormente. Portanto, os usuários de aplicações batch, ao contrário dos usuários interativos, não esperam respostas imediatas. Assim, a estratégia de escalonamento para esse tipo de aplicação é mais flexível.

Embora o mecanismo para balanceamento de cargas nesse tipo de aplicação seja mais simples, visto que não necessitam de respostas imediatas, deve ser analisado cuidadosamente pois o comportamento pode influenciar no desempenho final de todo o sistema (Tanenbaum, $-1992)$.

\subsection{Uma Nova abordagem às Políticas de Escalonamento}

Uma proposta de algoritmo de escalonamento tem por meta atuar sobre certos tipos de aplicaç̋̃es, tentando-se prever o tipo e a quantidade de trabalho que irão ocorrer. Mudando-se essas características, por algum motivo qualquer, o algoritmo de escalonamento pode não apresentar a eficiência esperada. Considerar que serão executadas aplicações de apenas um tipo é, portanto, uma grande limitação (Souza et al, 1998). 
Nesse aspecto, a idéia é que se desenvolvam diversas políticas direcionadas aos tipos de aplicações, considerando suas características próprias e agregando-as em um ambiente global de escalonamento. Assim, para qualquer classe de software, tem-se a política de escalonamento correspondente, que possibilita a eficiência compatível com as reais necessidades.

Em um trabalho anterior (Araújo, 1999) implementou-se uma política de escalonamento voltada a aplicações CPU-bound e agregada ao ambiente AMIGO (descrito anteriormente). Nesse algoritmo pôde-se levar em consideração não somente as características próprias da aplicação, mas também as características relevantes da plataforma utilizada. Esse fato constitui um forte diferencial em relação às políticas disponibilizadas na literatura.

Pode parecer bastante complicado o requisito de se desenvolver diversas políticas, onde cada uma delas leve em consideração uma situação específica. No entanto, quando se tem um ambiente flexível e dinâmico o suficiente para adaptar automaticamente a política ao tipo de aplicação, essa complexidade diminui e o desempenho pode ser elevado consideravelmente. É claro que manter esse ambiente não constitui uma tarefa simples e uma série de fatores devem ser analisados e viabilizados, o que foi estudado em um projeto maior, descrito em diversos trabalhos publicados recentemente (Souza et al, 1998) (Souza et al, 1999a) (Souza et al, 1999b).

\subsubsection{A DPWP - Dynamical Policy Without Preemption}

A DPWP é uma política de escalonamento desenvolvida com o objetivo de melhorar e facilitar a atividade de balanceamento de cargas em ambientes computacionais distribuídos sobre uma rede de estações de trabalho heterogênea (Araújo, 1999).

O algoritmo base da DPWP está voltado para aplicações CPU-bound e, portanto, preocupase em distribuir a carga de trabalho entre as máquinas portadoras de melhor potência computacional. Segundo a classificação de Casavant, esse algoritmo pode ser classificado como um algoritmo de escalonamento global, dinâmico, fisicamente distribuído e não cooperativo. Ele também adota as idéias propostas por Shivaratri (Shivaratri et al, 1992) que divide o algoritmo em quatro componentes, conforme já visto anteriormente (no capítulo 4). 
O índice de carga utilizado pela DPWP é o tamanho médio da fila de processos prontos na CPU nos últimos 20 segundos. Essa escolha deve-se ao fato de ocorrerem grandes flutuações de carga em se tratando de redes de estações de trabalho. Maiores detalhes a respeito desse assunto podem ser obtidos em (Araújo, 1999).

Quando a carga de uma máquina é calculada, elà pode ser classificada como sobrecarregada, moderada ou ociosa, de acordo com alguns valores limites impostos pela DPWP. Vale ressaltar que a DPWP se preocupa com a heterogeneidade de hardware encontrada em redes de estaçסes de trabalho. Dessa forma, a partir de um arquivo de configuração que contém a potência relativa de cada máquina é feita uma normalização com o indice de carga obtido gerando um valor que traduza a carga relativa de cada máquina pertencente ao sistema.

A atualização da carga é feita em duas condições: quando a política está se configurando e quando houver mudaņa de estado na máquina. Nesse último caso, a atualização é feita através de um timeout implementado na função select() do Unix (Stevens, 1990), que quando ativada se encarrega de chamar a função responsável pela atualização da carga.

\subsection{Considerações Finais}

Considerar o dominio de aplicação e definir a melhor política de escalonamento para atender aos requisitos desse domínio é, sem dúvida, a melhor solução para se otimizar o desempenho esperado em um ambiente computacional paralelo/distribuído. As dificuldades intrínsecas a essa abordagem podem ser facilmente superadas no ambiente AMIGO (Souza et al, 1998) que, além de permitir essa sintonia entre política e aplicação, traz transparência e flexibilidade, permitindo que mais de uma plataforma de passagem de mensagens seja considerada no sistema.

O próximo capítulo descreve todo o estudo efetuado para a criação da interface AMIGOMPI, bem como o funcionamento da implementação escolhida - o Local Area Multicomputer (LAM). 


\section{6}

\section{Interface AMIGO-MPI}

\subsection{Considerações Iniciais}

A integração de um ambiente de escalonamento ao MPI, com os objetivos aos quais o AMIGO se propõe, é importante por possibilitar um melhor aproveitamento dos recursos computacionais, permitindo uma diminuição do tempo de processamento e, conseqüentemente, aumentando o desempenho das aplicações e do sistema com um todo.

O desenvolvimento da Interface de comunicação AMIGO-MPI desencadeou a necessidade de se escolher uma das implementações existentes do padrão MPI. Alguns requisitos fundamentais para essa escolha foram levados em consideração como, por exemplo, tratar-se de uma implementação de domínio público e destinada à plataforma Unix. Diante disso, alguns fatores, que serão descritos no decorrer deste capitulo, deram suporte à escolha da implementação denominada Local Area Multicomputer - LAM.

Assim, este capítulo define as partes relevantes do funcionamento interno da implementação LAM e os mecanismos utilizados para a elaboração da Interface AMIGOMPI/LAM. As informações aqui contidas estão amplamente baseadas em (LAM, 1999). 


\subsection{Local Area Multicomputer}

O Local Area Multicomputer (LAM) é um ambiente de programação MPI baseado em daemons, sendo um sistema desenvolvido para execução em rede de computadores heterogêneos. Com o LAM, um cluster dedicado (ou uma rede de computadores) pode ser utilizado como sendo um computador paralelo (multicomputador - arquitetura MIMD).

O LAM é uma implementação completa da especificação MPI-1, com exceção do suporte para cancelamento de mensagens (MPI_CANCEL). Para adicionar alta qualidade de gerenciamento, a implementação LAM oferece capacidade extensiva de monitoramento visando a depuração dos aplicativos. Esse monitoramento acontece em dois níveis: (1) o LAM permite que o status da distribuição de processos e mensagens seja capturado enquanto a aplicação está rodando. Esse status inclui todos os aspectos de sincronização, mapeamento de tipos de dados, membros de um comunicador e conteúdo de mensagens; (2) no segundo nível, a biblioteca MPI está voltada para produzir um registro de toda a comunicação efetuada, que pode ser visualizado em tempo de execução ou posteriormente.

O LAM não constitui um ambiente cliente/servidor onde um único daemon pode servir a todos os usuários em uma máquina. Ao contrário, cada usuário que desejar utilizar o LAM deve iniciar (boot) seu próprio ambiente LAM.

A versão 6.3 do LAM, utilizada neste trabalho, inclui algumas partes da especificação MPI-2, tais como: o pacote ROMIO (A High-Performance, Portable MPI-IO Implementation) para $\mathrm{V} / \mathrm{O}, 0$ pacote $\mathrm{CH}$, interoperabilidade entre linguagens, criação dinâmica de processos, suporte a pseudo-tty para I/O remoto, capacidade para passar variáveis de ambiente através do mpinun, capacidade para executar programas que não são MPI através do multicomputador e capacidade para liberar os buffers internos antes que sejam utilizados. 


\subsubsection{Descrição Interna do LAM}

O LAM executa em cada computador como um único daemon Unix estruturado como um nanokernel (kernel base) e um gerador virtual de processos (virtual porque na realidade é executado peło sistema operacional). Ele retrata uma evolução do sistema Trollius (Burns et al, 1990).

O componente nanokernel fornece uma simples passagem de mensagem e serviço rendezvous para processos locais. Ele é composto por diversos processos daemons independentes, com funções especificas. Alguns desses processos formam um subsistema de rede de comumicação para transferir mensagens entre os daemons, localizados em diferentes nós, adicionando caracteristicas tais como empacotamento e armazenamento para a sincronização básica. Há processos daemons que são responsáveis por tarefas remotas tais como execução de programa e acesso a arquivos. Há também os processos responsáveis pela criação e gerenciamento de processos. Contudo, a estrutura interna do LAM é transparente para usuários e administradores do sistema, que vêem somente um daemon convencional.

\subsubsection{Ferramentas disponiveis no LAM}

Uma característica importante do LAM é o total controle do multicomputador. Há poucas coisas que não podem ser vistas ou modificadas em tempo de execução. Em particular, mensagens não recebidas e a sincronização dos estados dos processos podem ser examinadas com as ferramentas mpimsg e mpitask. As variáveis chaves de sincronização podem ser exibidas: rank origem, rank destino, tag e comunicador. Dentro de um comunicador, um objeto opaco MPI, o usuário pode examinar um membro de um grupo. $O$ conteúdo de uma mensagem também pode ser exibido (LAM, 1999).

A ferramenta mpirum encontra e carrega o programa que constitui a aplicação. Uma simples aplicação SPMD (Single Program Multiple Data) pode ser especificada no comando de linha do mpīrm enquanto uma configuração mais complexa é descrita em um arquivo separado, chamado de esquema da aplicação (application schema). 


\subsubsection{A Biblioteca LAM/MPI}

A biblioteca de comunicação do LAM/MPI está dividida, basicamente, em três partes: a camada MPI, a Request Progression Interface (RPI) e o núcleo Trollius. A Figura 6.1 mostra um diagrama com os componentes principais dessa biblioteca.

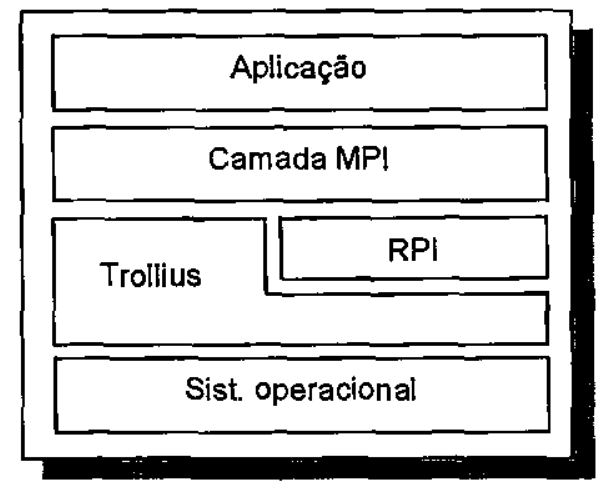

Figura 6.1 - Componentes da biblioteca LAM/MPI (Squyres et al, 2000)

Uma das principais funções da camada MPI é criar e manter as filas de comunicação. Toda comunicação (send/receive) dentro do LAM é tratada como uma requisição (requests). A unificação de todos os tipos de comunicação sob uma única nomenclatura permite o uso de um sistema de gerenciamento uniforme.

A camada RPI é responsável por todos os aspectos de comunicação com outros ranks. Essa camada processa as requisições que foram formadas e enfileiradas na camada MPI. Dessa forma, a RPI é responsável por mover dados de um rank para outro. Assim, quando uma requisição é finalizada, ela é marcada como completada e a camada MPI então a retira da fila.

Há dois tipos de RPIs: (1) baseado no LAM daemon (lamd) e (2) conexão direta clientecliente (c2c). As Figuras 6.2 e 6.3 ilustram os dois tipos de RPIs. 


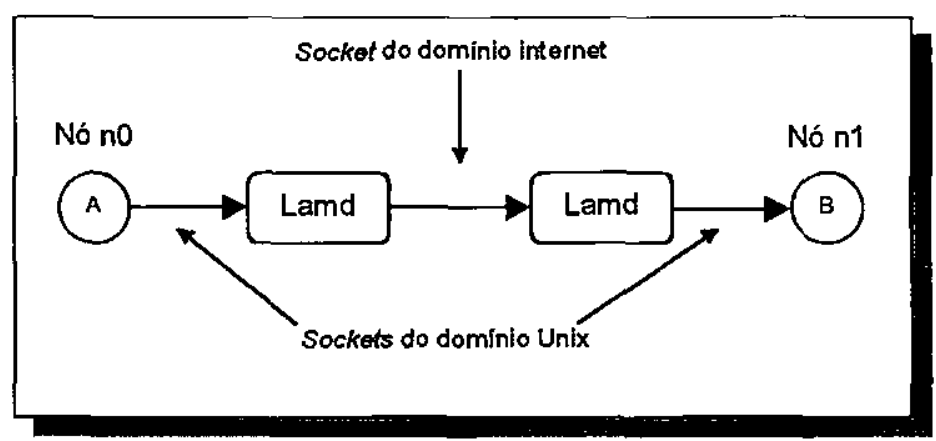

Figura 6.2 - Esquema da RPI lamd (Squyres et al, 2000)

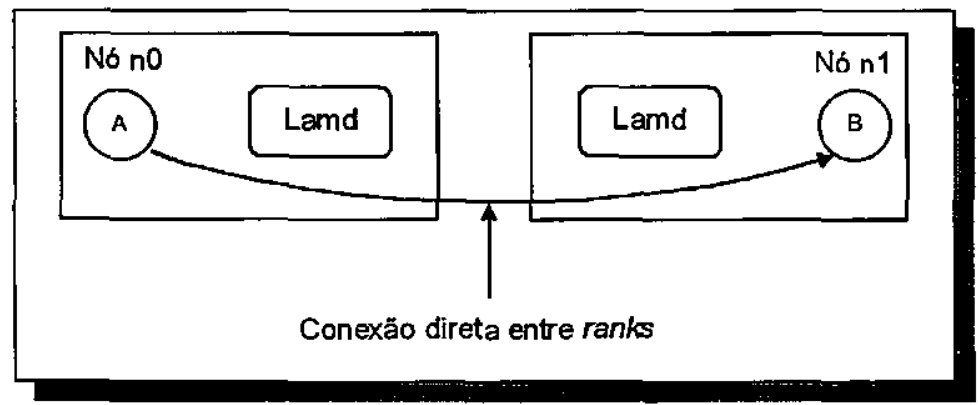

Figura 6.3 - Esquema da RPI c2c (Squyres et al, 2000)

A implementação da RPI lamd utiliza o subsistema de passagem de mensagens do LAM, incluindo seu daemon buffer. Assim, toda a comunicação entre os ranks é feita através do LAM daemon.

A RPI c2c inclui um mecanismo de alto desempenho, desviando do daemon e conectando diretamente entre os processos da aplicação. Essa RPI possui três tipos de implementação:

* Transporte TCP - Utiliza sockets TCP para toda a comunicação entre processos.

- Transporte Usysv - O transporte usysv é multiprotocolo. Os processos no mesmo nó se comunicam via memória compartilhada e processos em diferentes nós se comunicam via sockets TCP. Ele utiliza spin-locks para sincronização da memória compartilhada entre os ranks.

- Transporte Sysv - O transporte sysv é semelhante ao transporte usysv, exceto que semáforos são utilizados para sincronização de mensagens ao invés de spin-locks. Em alguns sistemas uniprocessadores (como Linux) a natureza bloqueante dos semáforos pode melhorar o 
desempenho obtido em relação à utilização de spin-locks. O transporte usysv obtém, geralmente, melhor desempenho em máquinas paralelas.

A camada Trollius contém diversas funções para operações mais complexas e fornece um backbone para a maioria dos serviços (incluindo os daemons) que são invocados através do LAM.

Há uma propriedade no LAM chamada Guaranteed Envelope Resources (GER), cuja responsabilidade é garantir que um espaço mínimo para os buffers de mensagens vai estar disponível para cada par de processos. Dessa forma, é mais fácil detectar qual processo pode ter gerado algum overflow excedendo esse limite e, se necessário, um erro é reportado. Esse valor mínimo para os buffers é definido no momento da configuração do LAM (LAM, 1999).

Várias constantes podem ser definidas nos arquivos de cabeçalho do LAM, relacionadas a protocolos de transferência de mensagens, à alocação de memória compartilhada e a outros serviços. Duas dessas constantes relacionadas à camada interna de transporte estão descritas a seguir visando um melhor entendimento do comportamento e do desempenho oferecido pela biblioteca LAM/MPI.

- Protocolo short/long - o LAM/MPI utiliza um protocolo de mensagem short/long. Se uma mensagem é pequena (short), ela é enviada junto com o cabeçalho em um transmissor para o processo destino. Se a mensagem é grande (long), então o cabeçalho é enviado para o destino. O processo emissor então espera por uma confirmação ( $a c k$ ) do receptor antes de enviar o restante da mensagem. $O$ processo receptor envia a confirmação quando o receive correspondente é postado. A alternação entre short e long é configurada em cada transporte.

- Send/Receive com desvio (shortcircuit)- Tipicamente, quando uma mensagem é enviada ou recebida, o LAM cria uma estrutura de pedidos contendo a informação sobre a mensagem, conecta esse pedido em uma lista de mensagens e invoca um engine para efetuar a transferência dos dados. Quando não há pedidos ativos e um send bloqueante ou receive é feito, o overhead criado pelo pedido e conexão na lista pode ser desviado (shortcircuited) e o engine é chamado diretamente para efetuar a transferência. 


\subsubsection{O Software LAM - Descrição e utilização típica}

O software LAM é de domínio público, onde permite-se que seja redistribuído e/ou modificado sob os termos da GNU (General Public License). Está estruturado, basicamente, como ilustra a Figura 6.4.

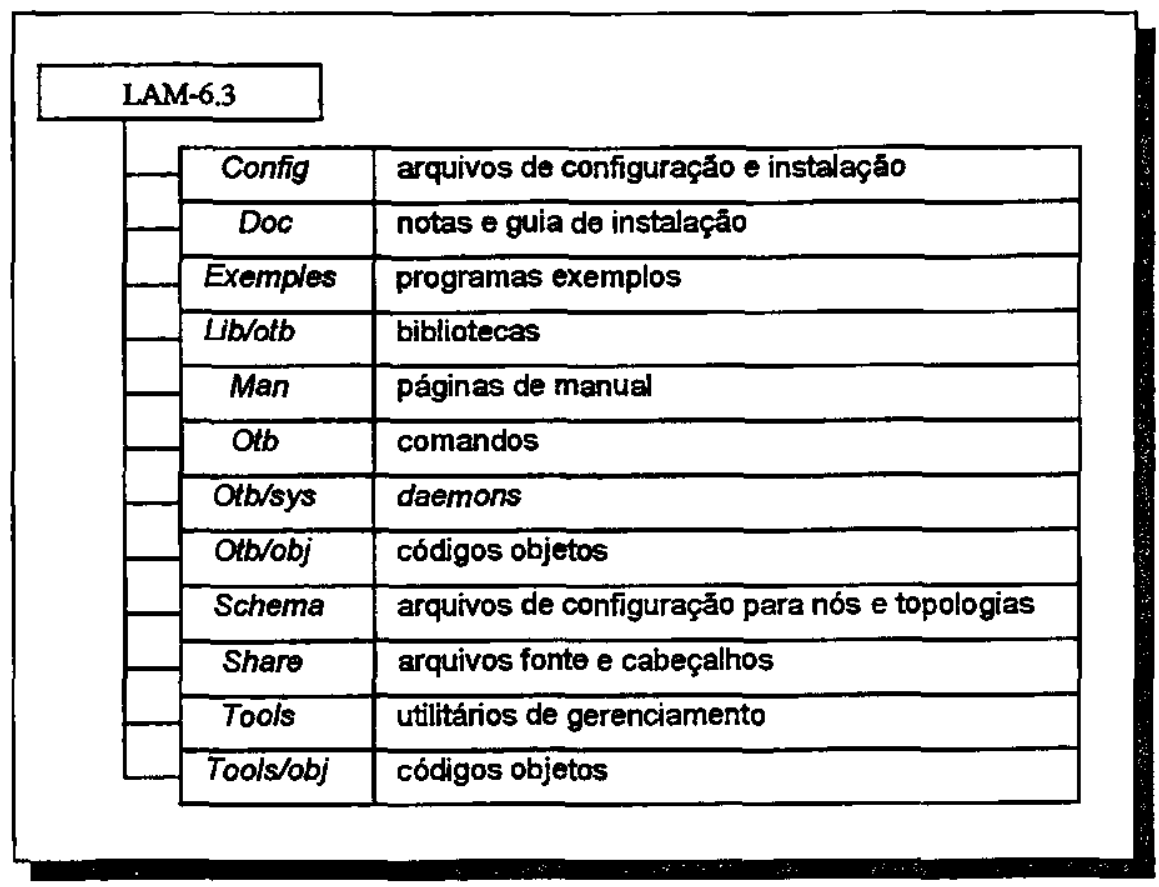

Figura 6.4 - Estrutura do software LAM

Tipicamente, a utilização do LAM consiste na chamada do comando lamboot, que cria os daemons baseado em uma lista de máquinas (esquema de boot) fornecida pelo usuário. Esses daemons ficam ociosos nas máquinas remotas até que eles recebam uma mensagem para carregar o MPI e iniciar a execução de alguma aplicação. Resumidamente, têm-se:

- O boot LAM cria daemons em suas máquinas;

- Os programas MPI são executados enquanto os daemons existem em background;

- Finalmente, para concluir a sessão, deve-se encerrar o LAM (shutdown). 


\subsubsection{Comandos para o Gerenciamento do Multicomputador}

Os comandos descritos a seguir são algumas das ferramentas disponibilizadas pelo LAM para a manipulação e controle do multicomputador (LAM, 1999).

\section{(1) Início/Término do LAM:}

Tabela 6.1 - Comandos para manipulação dos nós.

\begin{tabular}{|c|l|}
\hline Comando & \multicolumn{1}{c|}{ Função } \\
\hline Recon & Verifica se uma sessão LAM pode ser iniciada. \\
\hline Lamboot & Inicia uma sessão LAM com as máquinas especificadas no esquema de boot. \\
\hline Wipe & Encerra uma sessão do LAM. \\
\hline Tping & Verifica o estado das máquinas em uma sessão corrente. \\
\hline Lamgrow & Adiciona um nó em uma sessão, em tempo de execução. \\
\hline Lamshrink & Remove um nó de uma sessão, em tempo de execução. \\
\hline
\end{tabular}

(2) Compilação de aplicações MPI:

Tabela 6.2 - Comandos para compilação.

\begin{tabular}{|c|l|}
\hline Comando & \multicolumn{1}{c|}{ Função } \\
\hline Hcc & Compila a aplicação e gera o executável utilizando o compilador C. \\
\hline Hcp & Compila a aplicação e gera o executável utilizando o compilador C++. \\
\hline$H f 77$ & Compila a aplicação e gera o executável utilizando o compilador Fortran. \\
\hline
\end{tabular}

(3) Execução de aplicações MPI:

Tabela 6.3 - Comandos para execução de aplicaçōes.

\begin{tabular}{|c|l|}
\hline Comando & \multicolumn{1}{|c|}{ Função } \\
\hline Mpirun & Executa uma aplicação. \\
\hline Lamexec & Executa programas que não são MPI nos nós LAM. \\
\hline Lamclear & Remove os processos e mensagens de usuários (usado para depuração). \\
\hline
\end{tabular}


(4) Monitoramento de processos MPI:

Tabela 6.4 - Comandos para monitoramento de processos.

\begin{tabular}{|c|l|}
\hline Comando & \\
\hline Mpitask & Exibe informaçōes do estado corrente do programa que está sendo executado. \\
\hline Mpimsg & Exibe informaçöes a respeito de mensagens pendentes (não recebidas). \\
\hline Lamtrace & Descarrega o trace de dados. \\
\hline Fstate & Exibe informações do estado corrente do daemon remoto. \\
\hline Doom & Emite um sinal para um processo. \\
\hline Bfctl & Controla buffers de mensagens. \\
\hline MPIL_Comm id & Obtém o ID do contexto de um comunicador. \\
\hline MPIL_Trace_on & Inicia um tracing de uma aplicação LAM/MPI. \\
\hline
\end{tabular}

\subsubsection{Detalhamento das Ferramentas Principais do LAM}

Algumas das ferramentas do LAM constituem o alvo de alterações para a elaboração da Interface AMIGO-MPI/LAM. Essas alterações implicam na inclusão de novas funções relacionadas ao AMIGO que, inseridas em códigos-fontes específicos do LAM, permitam a comunicação entre os dois ambientes.

A maioria das ferramentas permite a utilização de diversas opções (parâmetros) para configuração do ambiente, as quais são transferidas ao LAM através da linha de comando e, portanto, devem ser analisadas.

Dessa forma estão descritos, de maneira detalhada, o funcionamento, a utilização e as opções oferecidas por cada uma das ferramentas estudadas. 


\section{LAMBOOT}

Inicia uma sessão LAM em cada uma das máquinas especificadas no esquema de boot.

lamboot [-dhvxH] [<bhost>]

Opções:

-d : Depuração.

$-h$ : Ajuda (exibe informações do comando).

-v : Exibe os passos importantes que estão sendo executados.

$-\mathrm{x}$ : Modo tolerante a falhas.

-H : Não exibe o cabeçalho do comando.

$\mathrm{O}$ arquivo <bhost> é um esquema de boot LAM, que contém os nomes das máquinas pertencentes ao multicomputador. Ao invés de comando de linha, um esquema de boot pode ser especificado na variável de ambiente LAMBHOST. Em último caso, um arquivo default pode ser utilizado (bhost.def).

O lamboot usa um esquema de processos para os nós individuais, cujo objetivo é descrever os processos que constituem o ambiente LAM em um nó particular. Em geral, um esquema de processos default (conf.lam) é utilizado.

Iniciar uma sessão LAM consiste em um procedimento de três passos:

$1^{\circ}$. A ferramenta hboot é invocada em cada uma das máquinas especificadas;

$2^{\circ}$. Cada máquina cria uma porta dinâmica para comunicação;

$3^{\circ}$. O lamboot obtém em cada máquina, a lista de máquinas/portas em ordem para formar a topologia completamente conectada.

Se uma máquina não é capaz de iniciar ou se o seu timeout expirou antes que o primeiro passo se complete, o lamboot invoca a ferramenta wipe para terminar o LAM e reporta um erro. 


\section{$\underline{\text { HBOOT }}$}

Inicia o LAM em um nó local.

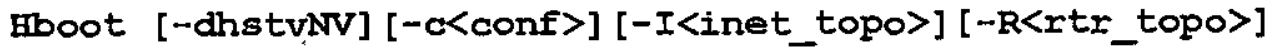

Opções:

-d : Depuração (implica em -v).

-h : Ajuda (exibe informações do comando).

-s : Fecha o stdio dos processos filhos.

-t : Termina alguma sessão prévia antes de iniciar a nova sessão.

-v : Exibe os passos importantes que estão sendo executados.

-N : Apenas simula e não executa nenhuma ação.

$-\mathrm{V}$ : Formata e exibe o esquema de processos.

$-c<$ conf $>$ : Usa $<$ conf $>$ como o esquema de processo.

-I $<$ inet_topo $>$ : Configura a variável \$inet_topo no esquema de processos.

$-\mathrm{R}<\mathrm{rtr}$ topo $>$ : Configura a variável $\$ \mathrm{rtr}$ topo no esquema de processos.

A ferramenta hboot pode ser entendida como um utilitário genérico que inicia múltiplos processos no nó local, baseado em informação de urn esquema de processos. Naturalmente, esse esquema de processos utilizado pelo hboot deve ser um que descreva o LAM em um nó.

A variável \$inet_topo é tipicamente usada pelo LAM Internet datalinks que comunica com outros nós. A variável \$rtr_topo é passada para o roteador LAM que é responsável por manipular a rede e as informações de topologia. Essas variáveis podem também ser configuradas por um arquivo de esquema de processos, mas seus valores são sobrepostos pela opção do comando de linha. 
Quando o LAM é iniciado, o Kernel registra todos os processos anexados a ele, incluindo todos os processos no esquema de processos. É função do tkill usar essas informações para removê-los de cada nó.

\section{$\underline{\text { MPIRUN }}$}

Executa os programas MPI nos nós pertencentes ao LAM.

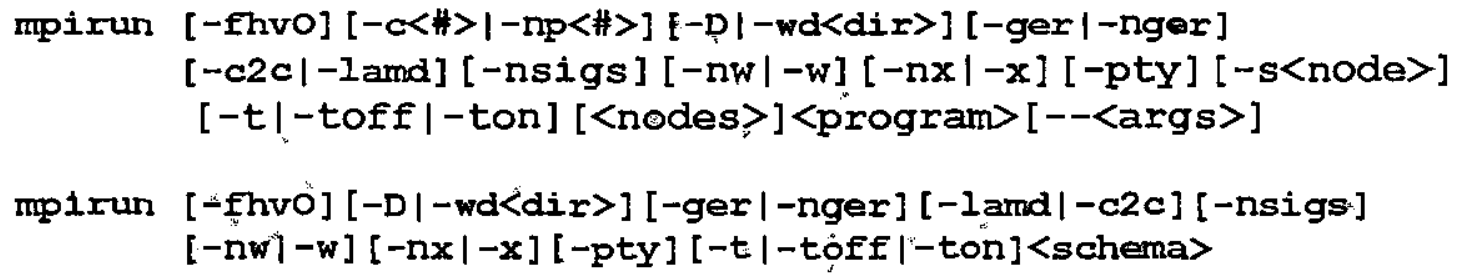

Opções (default -w -c2c -nger):

-f : Não configura descritor de arquivo padrão, usa o default.

-h : Ajuda (exibe informações do comando).

$-v$ : Exibe os passos importantes que estão sendo executados.

-O : Diz que o multicomputador é homogêneo (sem conversão de dados).

$-\mathrm{c}<\#>\mid-n p<\#>$ : Executa cópias do programa nos nós. Essa opção indica que o arquivo especificado é um programa executável e não um esquema de aplicação. Se nenhum nó é especificado todos os nós são considerados para o escalonamento.

-D : Usa a localização do programa executável como o diretório de trabalho corrente para criar processos.

-wd <dir> : Permite mudar arbitrariamente de diretório antes que o programa seja invocado. Essa opção é mutuamente exclusiva com a opção -D. 
-ger |-nger : Habilita/desabilita o protocolo de comunicação GER (Guaranteed Envelope Resources) e a exibição de erros.

-c2c : Utiliza o modo de comunicação cliente-cliente, desconsiderando o LAM daemon. Essa opção é mutuamente exclusiva com a opção lamd.

-lamd : Utiliza o LAM daemon para comunicação.

-nsigs : Desabilita a captura de sinais.

-nw | -w : Não espera/espera todos os processos completarem antes de reportar algum código de saída anormal.

-nx : Não exporta automaticamente variáveis de ambiente para os nós remotos.

-x : Exporta variáveis de ambiente para os nós remotos antes de executar o programa.

-pty : Habilita suporte para pseudo-tty.

-s <node> : Carrega o programa no nó especificado. Essa opção não é válida no comando de linha se houver um esquema de aplicação.

-t, -ton : Habilita geração de trace de execução para todos os processos. A geração de trace procede sem a necessidade de alguma ação futura.

-toff : Habilita geração de trace de execução para todos os processos. A geração de trace começará depois que todos os processos tenham chamado a função MPIL_Trace_on

- <args> : Transfere os argumentos, em tempo de execução, para todos os novos processos. Esse deve ser sempre o último argumento e não é válido se um esquema de aplicação é especificado.

A chamada do comando mpirun executa uma aplicação MPI em uma sessão LAM. Se a aplicação é simplesmente SPMD, ela pode ser especificada no comando de linha. Caso seja uma aplicação MPMD, com múltiplos programas, um esquema de aplicação é requerido em um arquivo separado. 
Para diferenciar as duas formas, esquema de aplicação e programa executável, o mpirun procura no comando de linha pela opção <nodes> ou -c. Se nenhuma das duas é especificada, então o arquivo nomeado no comando de linha é assumido ser um esquema de aplicação. Se qualquer uma das op̧̧̃es ou ambas são especificadas, então o arquivo é assumido ser um programa executável. Se ambas são especificadas, então cópias do programa são iniciadas nos nós de acordo com uma política de escalonamento interna do LAM. Especificar apenas um nó, efetivamente força o LAM a rodar todas as cópias do programa em um único lugar. Se a opção -c é obtida mas <nodes> não, então todos os nós são utilizados. Se a opção <nodes> é obtida e -c não, então uma cópia do programa é executada em cada nó.

Por default, o LAM procura pelo programa executável no nó referenciado onde uma instância particular vai executar. Se o sistema de arquivo não é compartilhado, os nós referenciados são homogêneos e o programa é freqüentemente recompilado, pode ser conveniente transferir o programa de um nó origem (usualmente o nó local) para cada nó referenciado. A opção -s especifica esse comportamento e identifica o único nó origem.

O LAM procura por um programa executável pesquisando os diretórios na variável de ambiente PATH do usuário definida no nó origem. Nos nós remotos, o path "." é o diretório home.

O LAM procura por um esquema de aplicação em três diretórios: o local, o valor da variável de ambiente LAMAPPLDIR e o LAMHOME/boot, onde LAMHOME é o diretório de instalação do LAM. 


\section{WIPE}

Encerra uma sessão do LAM (shutdown).

wipe $[-d h v][-n<\#>][\langle$ bhost $>]$

Opções:

-d : Depuração (implica em -v).

-h: Ajuda (exibe informações do comando).

$-\mathrm{v}$ : Exibe os passos importantes que estão sendo executados.

$-n<\#>$ : Encerra somente os primeiros <\#> nós.

A ferramenta wipe encerra o software LAM em cada máquina especificada no esquema de boot $<$ bhost $>$, invocando a função tkill em cada uma dessas máquinas.

O wipe não termina se um nó remoto particular não puder ser encontrado ou se o tkill falhar em algum nó. Uma mensagem é impressa se alguma dessas falhas ocorrer e, nesse caso, 0 usuário deve investigar a causa da falha e, se necessário, encerrar o LAM manualmente, executando o tkill no nó problemático. Em casos extremos, o usuário pode ter que terminar os processos individualmente com o comando kill. 


\section{TKILL}

Encerra o LAM em um nó.

tkil] [-dhvN] [-f<killfile $>]$

Opções:

-d : Depuração (implica em -v).

-h : Ajuda (exibe informações do comando).

-v: Exibe os passos importantes que estão sendo executados.

-N : Apenas simula e não executa nenhuma ação.

-f $<$ killfile $>$ : Usa $<$ killfile $>$ como o nome do arquivo criado pelo kernel.

A ferramenta tkill termina a sessão LAM iniciada pelo hboot no nó local. Faz uso de um arquivo criado pelo kernel LAM, que contém os identificadores de todos os processos em formato ASCII. Um sinal SIGHUP é enviado para todos os processos listados no arquivo.

No LAM, o primeiro processo a ser terminado é sempre o kernel. Quando o kernel recebe o sinal de término, ele propaga esse sinal para todos os processos constituintes. 


\subsection{Desenvolvimento da Interface}

Para a elaboração da interface AMIGO-MPI, a implementação LAM foi escolhida devido aos seguintes fatores:

- Por se tratar de uma implementação de dominio público;

- Por ser uma implementação para plataforma Unix;

- Por possuir semelhanças aparentes com o ambiente PVM;

- Por apresentar melhor desempenho, segundo pôde ser constatado em um trabalho siteriormente efetuado em (Souza, 1996b).

Para tanto, foi necessário todo o estudo já mencionado, objetivando a possibilidade e viabilidade para o seu desenvoivimento. Inicialmente são necessários alguns passos básicos tais como:

(1) Fazer com o que LAM inicie o daemon do AMIGO em todas as máquinas pertencentes ao multicomputador: isso implica na aiteração dos códigos-fontes do LAM responsáveis pelo boot.

(2) Para o escalonamento é necessário desviar o fluxo normal do LAM, para que os processos sejam escalonados peio AMIGO através de sua política: isso implica na alteração dos códigos-fontes do LAM responsáveis pela execução da aplicaç̃̃

(3) Finalmente, o shutdown em uma sessão LAM deve também finalizar os daemons referentes ao AMIGO e à política ativa: para isso, é necessário alterar os códigos-fontes do LAM responsáveis por encerrar a sessão. 


\subsubsection{Iniciando o AMIGO no LAM}

O processo de iniciação do LAM, incluindo o AMIGO, implica no entendimento do seu funcionamento interno. A Figura 6.5 especifica o esquema de boot do LAM, referenciando seus códigos-fontes principais.

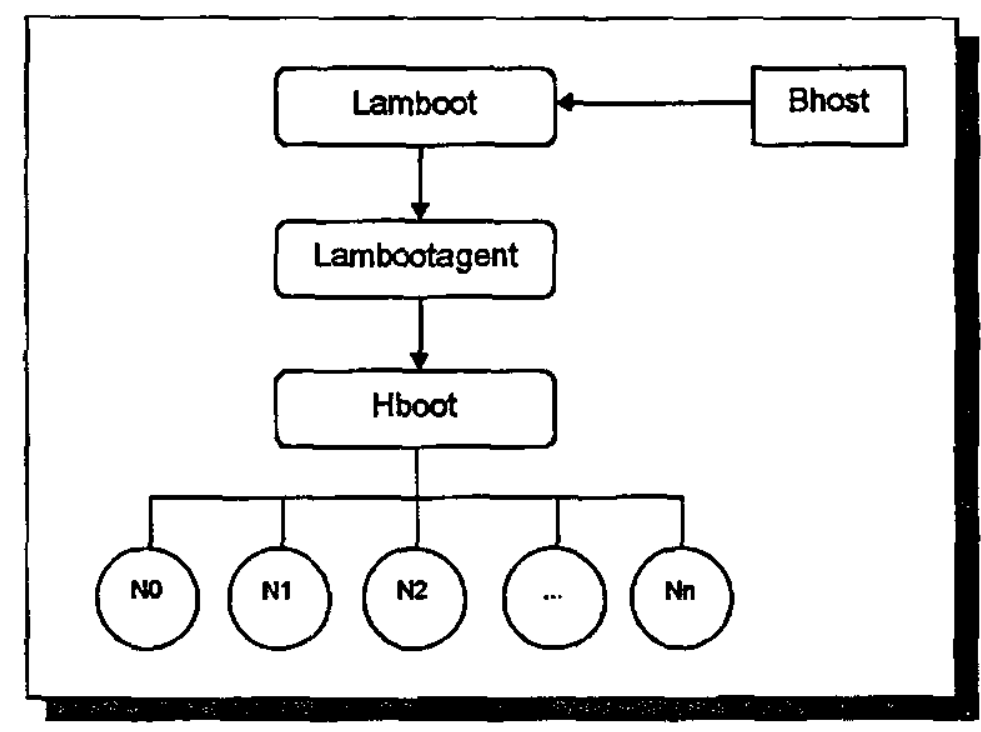

Figura 6.5 - Esquema de boot do LAM

A ferramenta lamboot é invocada em linha de comando, passando como parâmetro o arquivo $<$ bhost $>$ que contém os nomes das máquinas que devem ser utilizadas para a formação do multicomputador. O lamboot efetua a chamada do lambootagent, que é o agente de boot, responsável por invocar o hboot em cada máquina via shell remoto, o qual inicia o LAM daemon em todas as máquinas.

Sendo assim, quando o LAM daemon inicia a sua execução, o AMIGOD é executado através da função StartAMIGOD(), a qual foi inserida no código do LAM daemon em kouter.c (.../otb/sys/kernel/kouter.c).

A função StartAMIGOD() é responsável por criar o ambiente necessário para a execução do AMIGOD. Inicialmente, é criado um port TCP para a comunicação AMIGOD-Ambiente de Passagem de Mensagens, depois o AMIGOD é executado com alguns parâmetros de entrada, incluindo o port UDP (para comunicação AMIGOD-AMIGOD), caso não seja o primeiro 
AMIGOD a ser criado e, em seguida, aguarda o AMIGOD se configurar e conectar com o Ambiente de Passagem de Mensagens.

O AMIGOD cria, então, os sockets UDP para comunicação entre AMIGOD's e sockets TCP para comunicação com as políticas de escalonamento ativas no ambiente. Após criar esses mecanismos de comunicação, o AMIGOD configura suas estruturas de dados e ativa as políticas de escalonamento especificadas. É importante ressaltar que os valores do port UDP, o número IP local e o port TCP são mantidos e utilizados também pelo LAM daemon para que a comunicação seja realizada.

Além da inclusão da função StartAMIGOD(), os makefiles (arquivos de configuração para compilação) originais utilizados pelo LAM foram alterados para incluir os códigos de configuração do AMIGO.

\subsubsection{Escalonamento de processos no LAM utilizando o AMIGO}

Conforme já comentado, uma aplicação no LAM é executada a partir da ferramenta mpirum. Dessa forma, o escalonamento feito pelo LAM varia de acordo com as opções passadas na linha de comando para o mpirm. Basicamente, tem-se duas formas: (1) Utilizando a opção <nodes>, onde os processos são escalonados somente nos nós especificados; (2) Utilizando a opção $\langle\mathrm{N}\rangle$, onde os processos säo escalonados considerando todos os nós pertencentes ao multicomputador. A Figura 6.6 ilustra as duas formas citadas. É importante ressaltar que, nesse ponto, consideram-se apenas aplicações do tipo SPMD (Single Program Multiple Data) já que para aplicações do tipo MPMD (Multiple Program Multiple Data) o escalonamento é feito previamente através do arquivo que contém o esquema da aplicação.

A quantidade de processos a serem executados também varia conforme as opções passadas ao mpirun. Caso seja utilizada a opção <-c n_cópias>, então n_cópias do programa serão executadas nos nós que fazem parte do escalonamento. Supondo-se que a quantidade de processos seja maior que a quantidade de nós, o LAM utiliza a política de escalonamento roundrobin. Se a opção <-c n_cópias> não foi especificada, então todos os nós que fazem parte do escalonamento executam uma cópia do programa (um processo). 


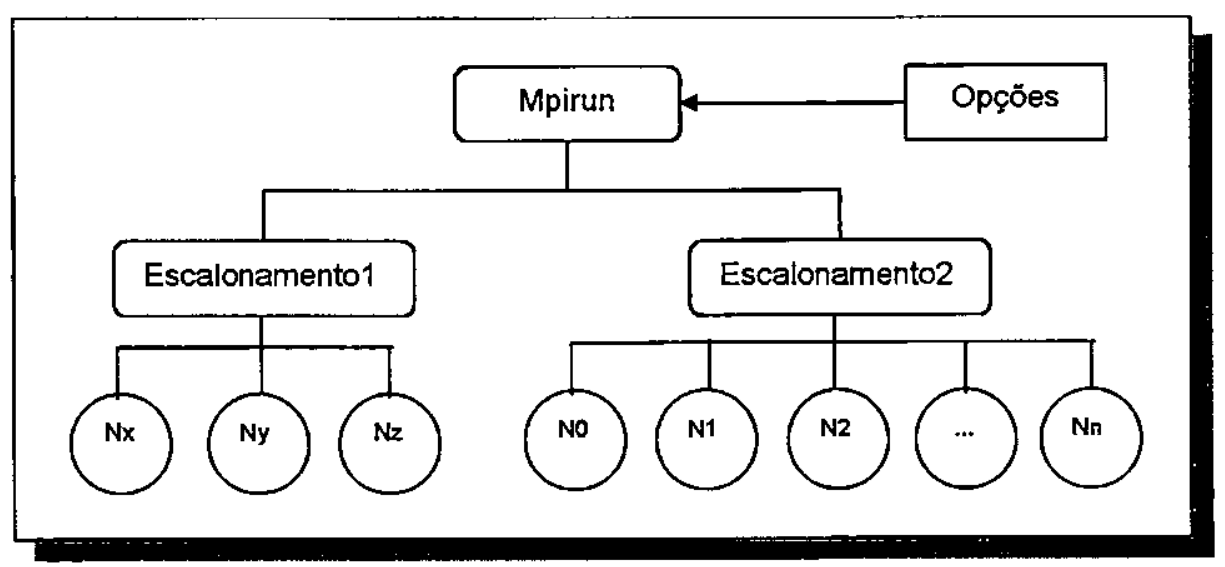

Figura 6.6 - Modos de escalonamento feitos pelo LAM

A criação dos processos (fork) é feita quando o mpirun envia uma mensagem ao LAM daemon, referenciando em qual nó o processo deve ser criado. A Figura 6.7 ilustra o mecanismo descrito.

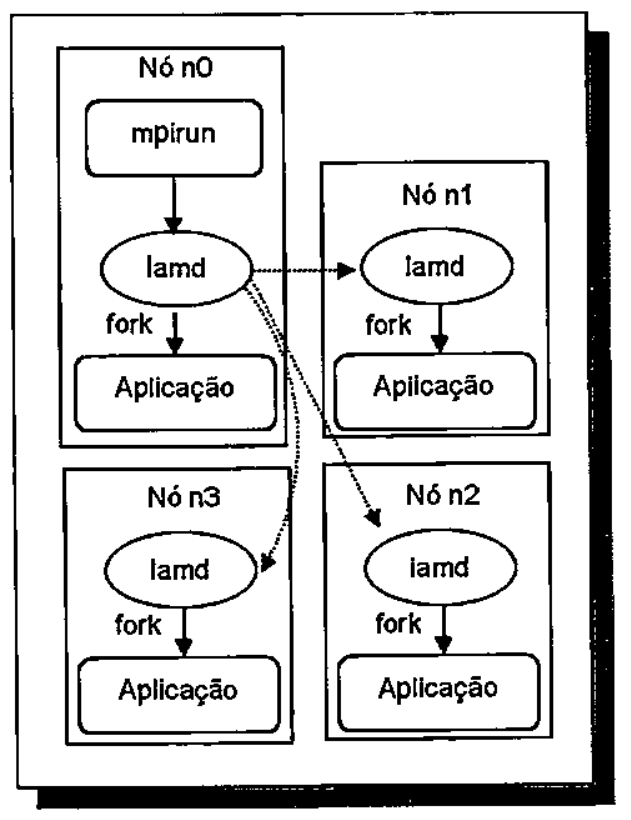

Figura 6.7 - Criação dos processos (Squyres et al, 2000)

Inicialmente, toda a comunicação entre o AMIGO e o LAM deveria ser feita através do socket TCP criado quando o AMMGOD é iniciado. Porém, esse socket não fica disponível para utilização no mpirun pelo fato de serem códigos distintos compilados separadamente, gerando 
arquivos executáveis diferentes e, evidentemente, áreas de memória diferentes. Dessa forma, foi necessária a criação de um segundo socket TCP que possibilitasse a comunicação AMIGODMPIRUN, visto que toda a modificação necessária ao escalonamento seria feita no código do mpirum. A Figura 6.9 ilustra todo o processo de comunicação envolvido entre os ambientes AMIGO e LAM e a necessidade da criação de outro socket.

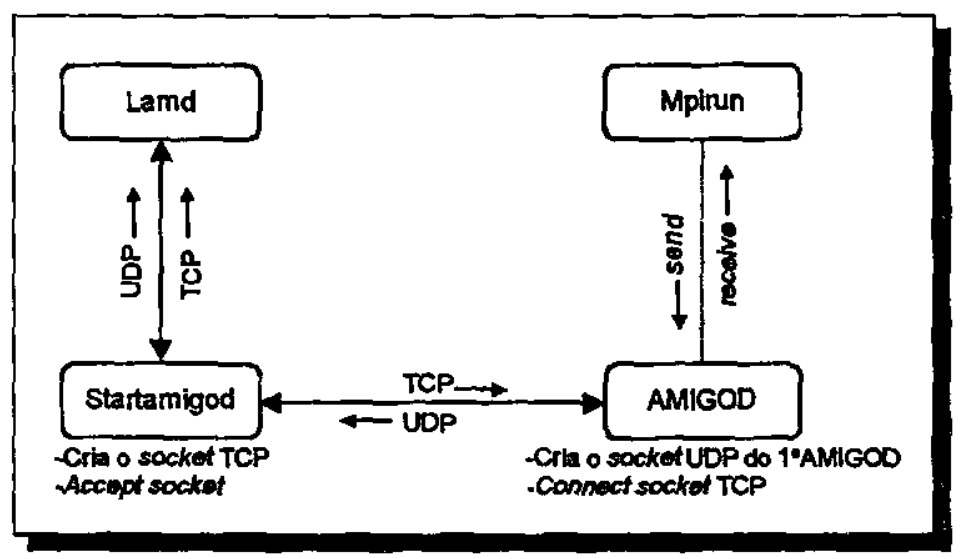

Figura 6.8 - Processo de comunicação envolvido entre os ambientes LAM e AMIGO

A função StartAMIGOD(), invocada pelo LAMD, cria o socket TCP, executa o AMIGOD e fica aguardando pela conexão com o AMIGOD (accept). Quando o AMIGOD é executado, ele recebe o valor do port TCP, efetua o connect() estabelecendo a conexão com o LAMD e cria o socket UDP para comunicação com os outros AMIGODs. Esse port UDP é disponibilizado para - LAMD que fica responsável por repassá-lo para cada novo AMIGOD a ser criado. Esse constitui o processo de comunicação envolvido em toda a configuração inicial do AMIGOD.

Quando o mpirun é executado, o canal de comunicação LAMD-AMIGOD não fica disponivel por se tratar de um outro processo independente dos demais. Dessa forma, seria necessário estabelecer uma nova conexão entre AMIGOD-MPIRUN. Se fosse utilizado o socket TCP inicial, a comunicação seria estabelecida entre LAMD-MPIRUN já que a StartAMIGOD() invocada pelo LAMD fica aguardando a conexão. Assim, uma solução possível foi criar um novo socket TCP que possibilitasse a comunicação AMIGOD-MPIRUN. Como é o AMIGOD que espera pela conexão, esta solução toma-se viável e reutilizável por qualquer outro Ambiente de Passagem de Mensagens que funcione de maneira semelhante ao LAM. 
A criação do socket é feita pelo AMIGOD que fica aguardando por uma conexão do mpirun. Isso está implementado na função select() já utilizada pelo AMIGOD. Quando uma mensagem é destinada a esse socket, ela é tratada e, caso seja um pedido de conexão, este é aceito efetuando-se o accept( ). Nesse momento, a comunicação AMIGOD-MPIRUN fica disponivel e, a partir desse ponto, as mensagens referentes ao escalonamento são efetivadas utilizando-se esse novo canal de comunicação.

Para que o escalonamento seja feito pela política definida pelo AMIGO, a lista de nós que são transmitidos ao LAM daemon deve ser alterada. Para tanto, implementou-se a função GetHostsFromAmigod( ), inserida no código do mpirun (em .../otb/mpirun/mpirun.c), cuja finalidade é enviar uma mensagem com código AM_SCHED ao AMIGOD local solicitando arelação de máquinas receptoras de carga. Nessa mensagem estão contidos o nome do executável da aplicação, a quantidade de processos a serem criados e a arquitetura utilizada. Como resultado, essa função obtém uma lista com os números IPs das máquinas escalonadas. A Figura 6.8 ilustra todo o mecanismo de comunicação envolvido nesse processo.

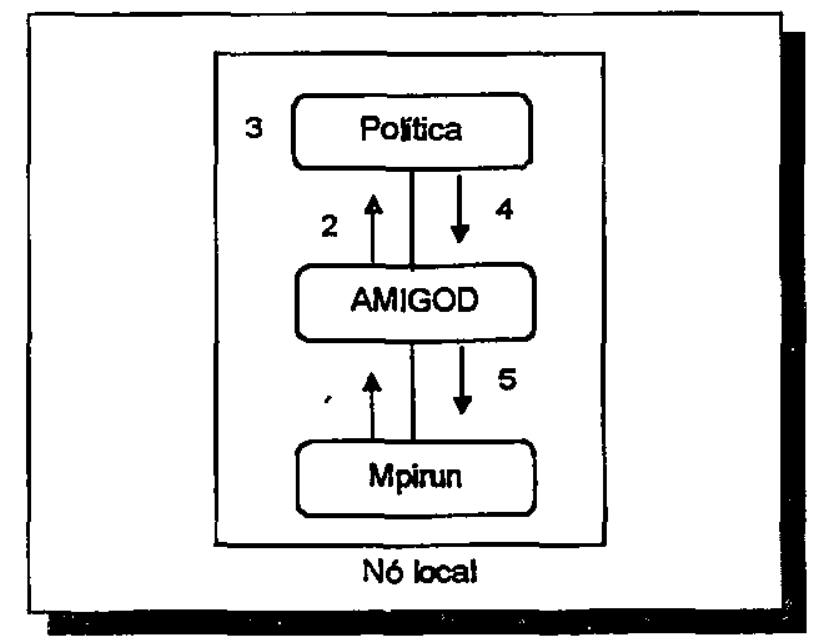

Figura 6.9 - Mecanismo de comunicą̧ão envolvido no escalonamento

O passo 1 ilustra o envio da mensagem ao AMIGOD solicitando as máquinas receptoras de carga. O AMIGOD recebe essa mensagem e envia uma nova mensagem com código AP_SCHED para a política ativa (passo 2). A política recebe a mensagem e inicia a sua função de procurar pelas melhores máquinas no sistema (passo 3). Feito isso, a política envia ao AMIGOD local uma lista com as máquinas escalonadas (passo 4). O AMIGOD recebe essa lista e repassa ao mpirun para que o escalonamento seja efetuado (passo 5). 
A função List_nodes() implementada no código do mpirun cria uma lista com n posições (onde $\mathrm{n}$ é igual à quantidade de nós que foram iniciados pelo lamboot) contendo os valores IPs e identificadores para cada nó. Os valores IPs são obtidos através de um arquivo criado pelo lamboot e os identificadores são valores inteiros sucessivos e iniciados em zero, criados para cada IP obtido do arquivo. A Figura 6.10 mostra o mecanismo descrito.

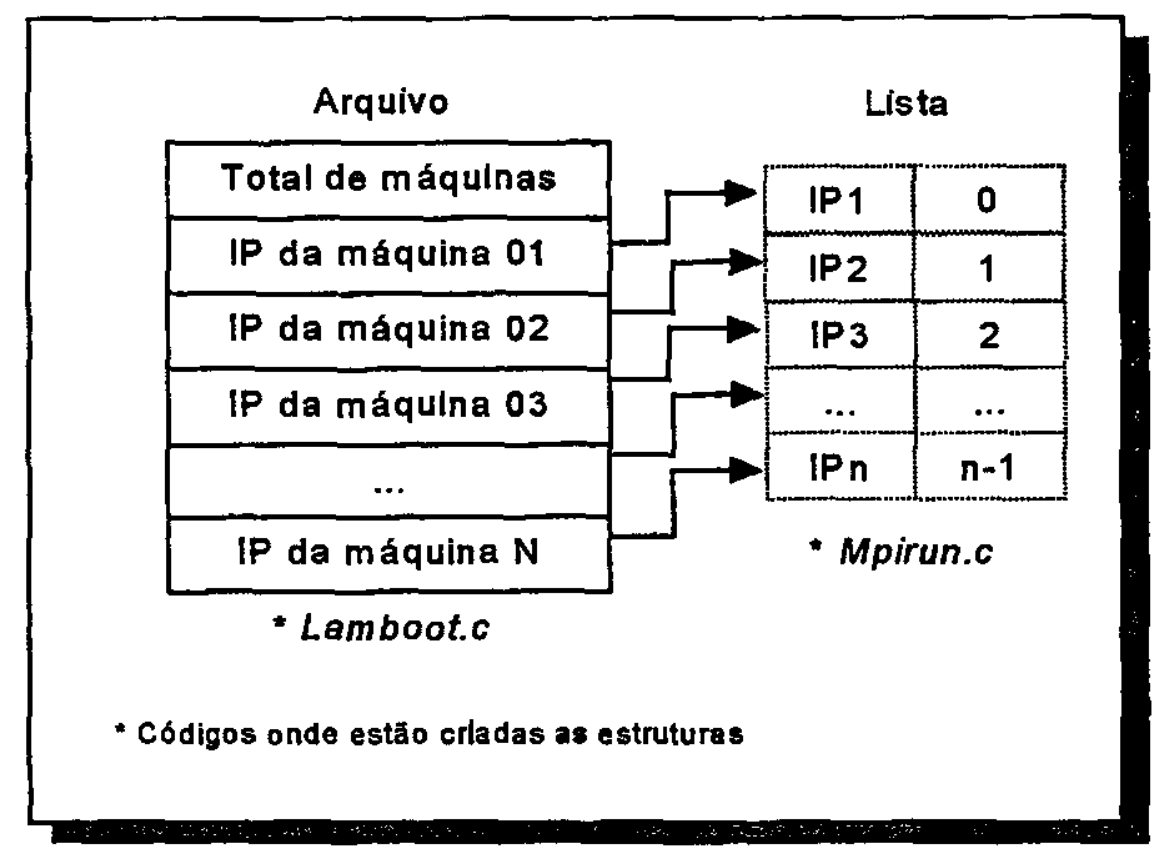

Figura 6.10 - Manipulação de valores IPs e Identificadores dos nós

A primeira linha do arquivo contém 0 total de máquinas que constituem o multicomputador. Nas linhas seguintes estão os valores IPs relativos à cada máquina iniciada pelo lamboot. Quando a GetHostsFromAmigod() é invocada, a função List_nodes( ) é chamada para a criar a lista de IPs e Identificadores (conforme mostra a Figura 6.10). Essa lista é alocada dinamicamente dependendo da quantidade de máquinas utilizadas no multicomputador.

Quando o buffer de recebimento é desempacotado pelo mpirun, para cada valor IP recebido a função Search() efetua uma busca na lista para obter o Identificador referente a esse valor IP e assim sucessivamente para todos os nós escalonados. Uma lista de IDs é então criada e passada como parâmetro para a fưnção asc_schedule_AMIGO(), responsável por configurar o esquema da aplicação dizendo em quais nós (ou em quais identificadores) o programa deve ser executado. A partir daí, o LAM continua sua execução normalmente criando e executando os processos da aplicação nos nós escalonados pelo AMIGO. 


\subsubsection{Finalização do LAM e do AMIGo}

O LAM é finalizado através da ferramenta Wipe, cuja função é executar a ferramenta tkill em todas as máquinas (via Shell remoto) encerrando os processos relacionados à sessão LAM iniciada. A ferramenta thill faz uso de um arquivo criado no diretório /tmp (lam-user@host) de cada máquina, cujo conteúdo é composto pelos identificadores dos processos da sessão LAM. É através desse arquivo que os processos são finalizados.

Sendo assim, a finalização do AMIGO segue a mesma filosofia do LAM. Quando o AMIGOD vai ser iniciado, seu PID (Process Identifier) é gravado no arquivo utilizado pelo LAM, de maneira que ao encerá-1o, automaticamente o AMIGOD e sua política são finalizados.

O PID do AMIGOD é capturado logo após a função StartAMIGOD() executar o comando fork() do Unix para a criação do processo. Dessa forma, para cada AMIGOD iniciado, o valor do seu PID é gravado no arquivo/tmp/lam-user@host referente a cada máquina.

\subsection{Considerações Finais}

Integrar ambientes é, geralmente, um processo trabalhoso especialmente em se tratando de ambientes já construídos e complexos, como é o caso do LAM e do AMIGO.

Diante disso, o domínio do funcionamento interno dos três ambientes envolvidos (LAM, AMIGO e DPWP) no desenvolvimento da interface constituiu um fator crucial para o sucesso dessa etapa do trabalho.

Grande parte dos esforços foram concentrados no entendimento do software LAM devido à sua maior complexidade. Embora as dificuldades encontradas tenham sido grandes, os desenvolvedores do LAM (através de uma lista de discussão) deram um apoio relevante para o entendimento dos códigos-fontes originais do LAM.

O próximo capítulo descreve os testes realizados bem como os resultados obtidos com a utilização do LAM/AMIGO. 


\section{7}

\section{Avaliação e Resultados}

\subsection{Considerações Iniciais}

Os resultados obtidos na etapa de avaliação são de suma importância pois permitem verificar a eficiência alcançada quando se utiliza o ambiente AMIGO juntamente com o LAM. Diante disso, algumas aplicações paralelas foram executadas utilizando-se o LAM original (sem - AMIGO) e o LAM alterado para utilizar o AMIGO como escalonador. As execuções das aplicações foram cuidadosamente analisadas e comparadas através do tempo médio (em segundos) obtido em cada uma das execuções.

Este capítulo descreve o ambiente utilizado para o desenvolvimento e avaliação do trabalho, os testes efetuados e os resultados obtidos através das execuções.

\subsection{Plataforma Utilizada}

O ambiente utilizado para a realização tanto do trabalho quanto dos testes para avaliação foi composto por seis computadores do tipo PC, formando uma arquitetura MIMD de memória distribuída. Esse ambiente está disposto no Laboratório de Sistemas Distribuídos e Programação Concorrente, do Instituto de Ciências Matemáticas e de Computação da USP, executando o Sistema Operacional Linux. A Figura 7.1 ilustra o ambiente descrito. 


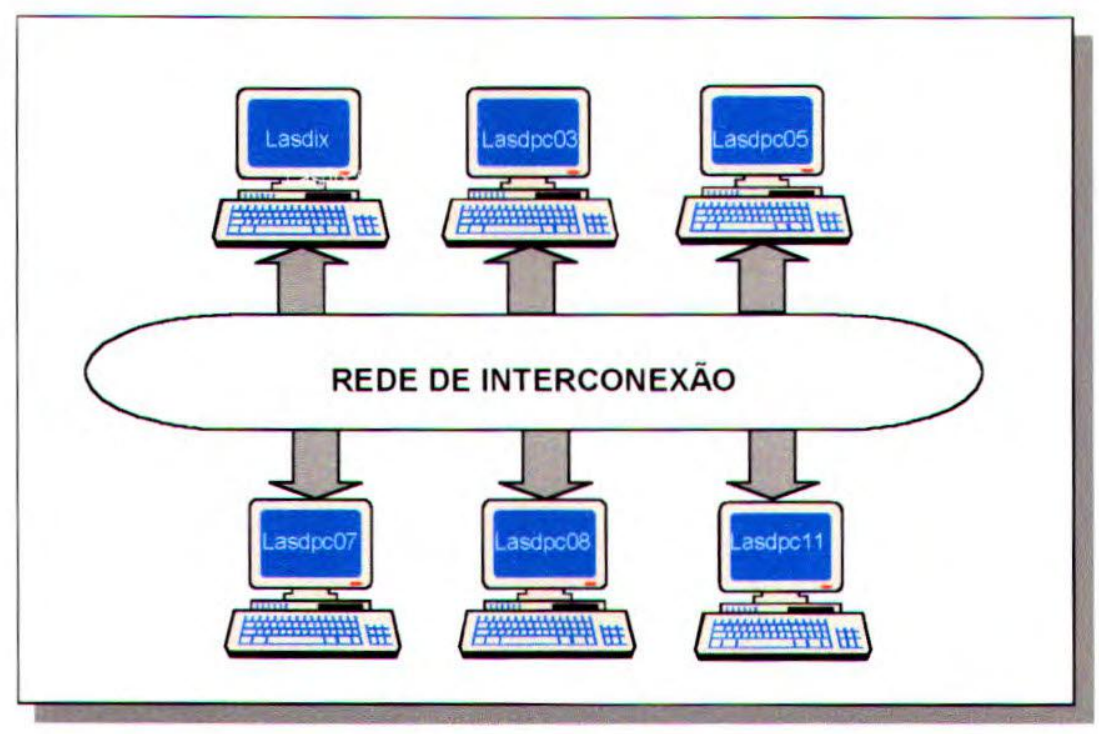

Figura 7.1 - Plataforma utilizada para avaliação

As máquinas possuem características computacionais distintas (como capacidade de processamento e memória) e estão conectadas por uma rede FastEthernet (100Mbps). A heterogeneidade encontrada no ambiente descrito constitui um fator motivante para o estudo das técnicas de escalonamento de processos quando se deseja aumentar o desempenho de um sistema, utilizando-se o balanceamento de cargas como objetivo. A Tabela 7.1 descreve a configuração das máquinas utilizadas.

Tabela 7.1 - Configuração das máquinas utilizadas

\begin{tabular}{|c|l|}
\hline Máquina & \multicolumn{1}{|c|}{ Configuração } \\
\hline Lasdix & Pentium 200MHz 32MB RAM HD 4GB \\
\hline Lasdpc03 & Pentium 200MHz 32MB RAM HD 3GB \\
\hline Lasdpc05 & Pentium II 266MHz 120MB RAM HD 3GB \\
\hline Lasdpc07 & Pentium II 400MHz 64MB RAM HD 13GB \\
\hline Lasdpc08 & Pentium II 400MHz 64MB RAM HD 13GB \\
\hline Lasdpc11 & Pentium II 233MHz 64MB RAM HD 13GB \\
\hline
\end{tabular}




\subsection{Testes Realizados}

Para efetuar os testes necessários para a avaliação da Interface AMIGO-MPI foram utilizadas duas aplicações numéricas: (1) multiplicação de matrizes quadradas e (2) método dos trapézios compostos para solução de integrais. O motivo que levou à escolha dessas aplicações é justificado pelo fato de apresentarem uma alta demanda por processamento, caracterizando-as como CPU-Bound, fato considerado pela política DPWP utilizada pelo ambiente AMIGO.

\subsubsection{Multiplicação de Matrizes}

$\mathrm{Na}$ aplicação que multiplica duas matrizes quadradas $(\mathrm{AxB})$ compostas por números em ponto flutuante, a paralelização é feita da seguinte maneira: o nó mestre gera a matriz A e, paralelamente, os nós escravos geram a matriz B. O mestre envia a matriz $\mathrm{A}$ e as posiçōes da linha onde cada um dos escravos deve iniciar a multiplicação. Apenas um dos escravos envia a matriz B ao nó mestre, que também efetua a multiplicação e recebe os resultados calculados por cada escravo formando a matriz $\mathrm{C}$ resultante da multiplicação das matrizes A e B. A Figura 7.2 ilustra o mecanismo de paralelização dessa aplicação.

Para a execução dessa aplicação foram utilizadas seis máquinas e seis processos, variando a ordem da matriz quadrada $(120 \times 120,240 \times 240,360 \times 360,480 \times 480)$. Esses números foram escolhidos porque a aplicação exige que a divisão das tarefas (posições da matriz) seja igualmente partilhada entre todos os processos e, portanto, deveriam ser números divisíveis por seis (seis processos). 


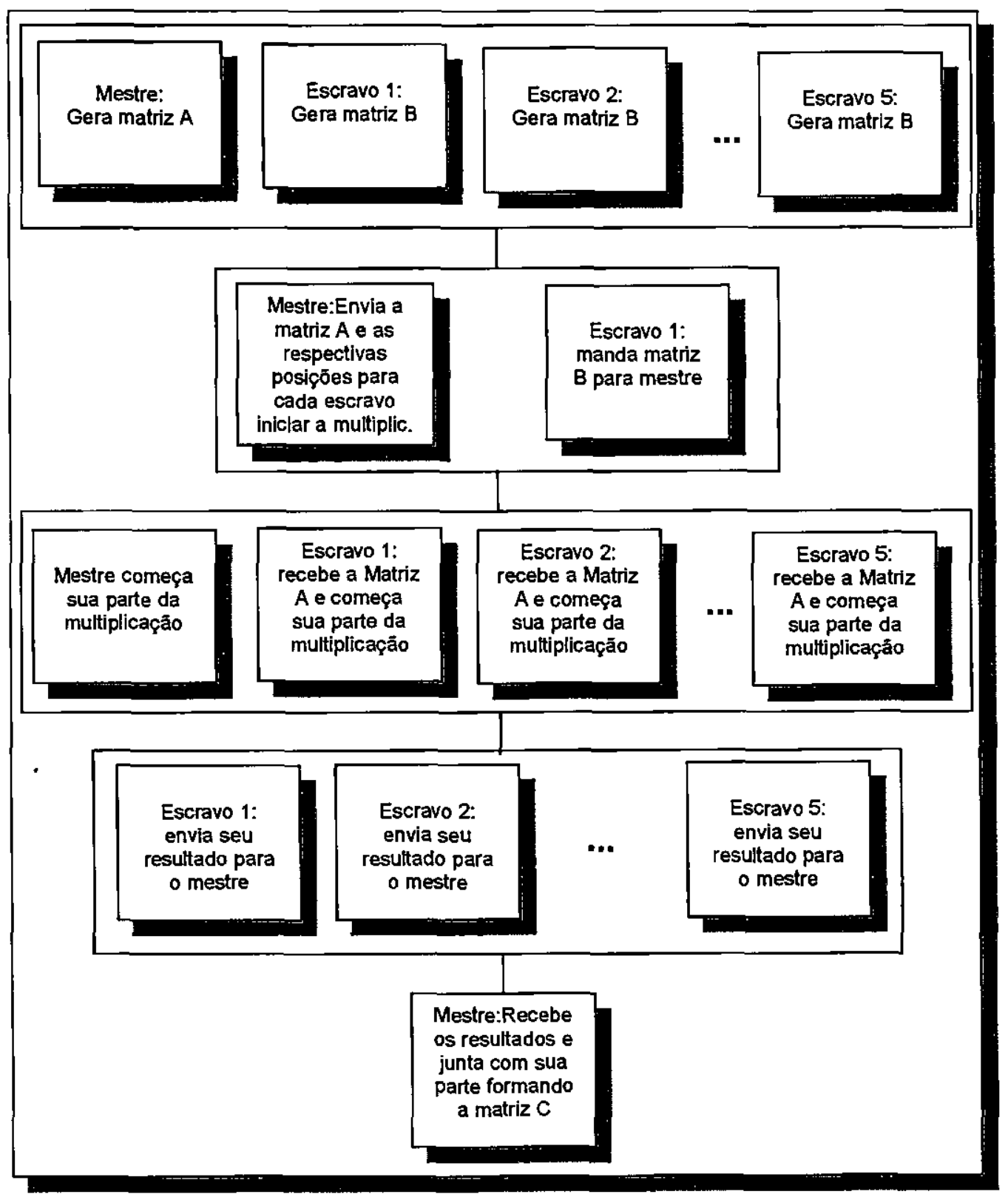

Figura 7.2 - Paralelização do Algoritmo de Multiplicação de Matrizes adaptado de (Cortés, 1999)

\subsubsection{Método dos Trapézios Compostos}

$\mathrm{Na}$ aplicação que utiliza o método dos trapézios compostos para solucionar integrais definidas, o algoritmo utilizou-se de uma propriedade das integrais, onde dada uma função qualquer $\mathrm{f}(\mathrm{x})$ que pode ser integrada nos pontos de a até $\mathrm{b}$, ela pode ser dividida no somatório de n outras integrais. Assim, o cálculo das integrais é dividido entre os processos da aplicação. 
Para a execução dessa aplicação foram utilizadas seis máquinas e três processos com uma divisão total de três milhões de trapézios e um intervalo de $a=0$ e $b=1.2$.

A paralelização dessa aplicação foi feita da seguinte maneira: o nó mestre calcula os intervalos (entre 0 e 1.2) para cada processo e os envia aos escravos. Os escravos recebem os seus intervalos, calculam a quantidade de divisões e, após calcularem a integral, enviam o resultado ao mestre. $O$ mestre já tendo calculado também a sua integral efetua o somatório dos resultados obtendo a solução final. A Figura 7.3 ilustra o mecanismo de paralelização dessa aplicação.

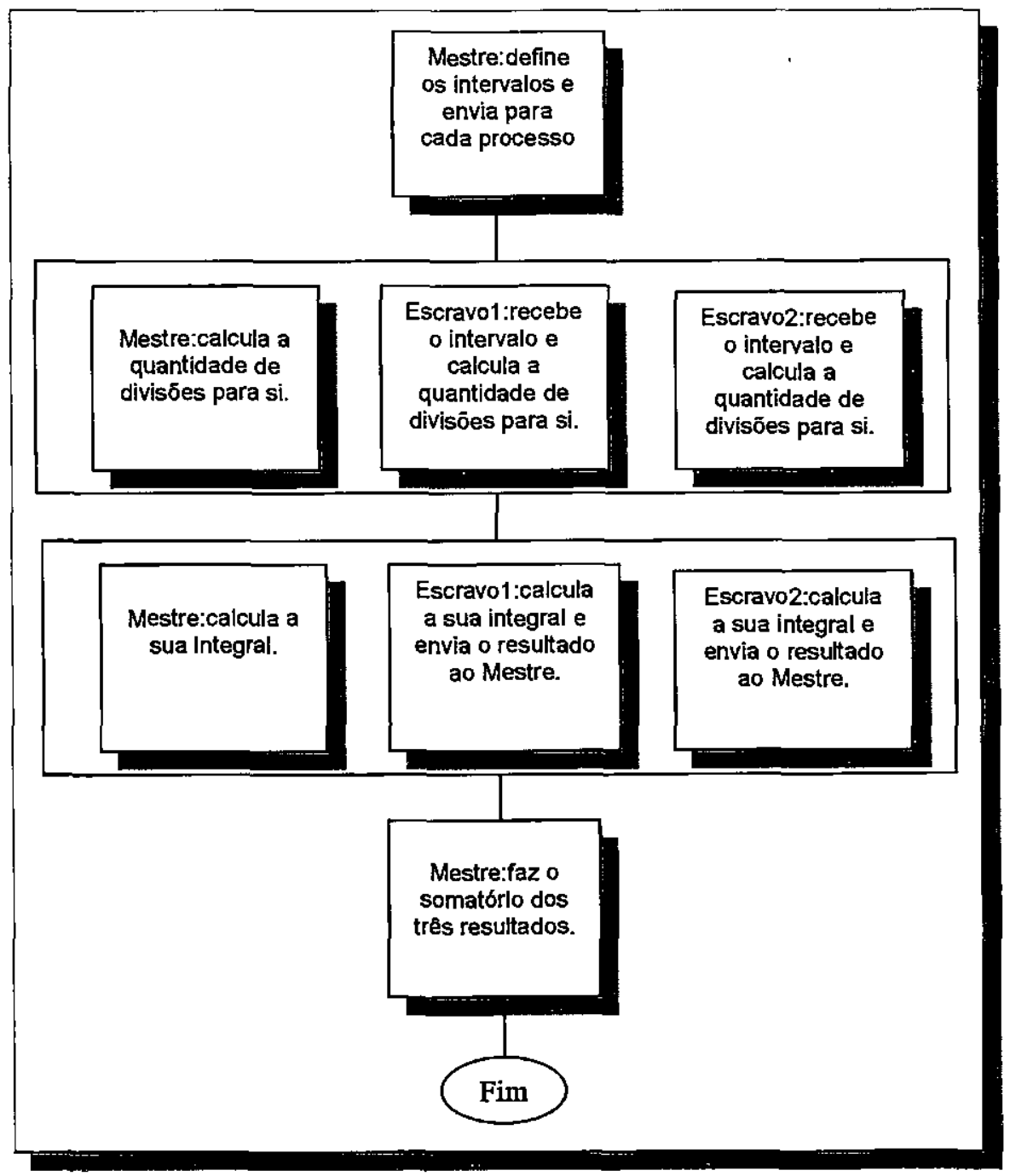

Figura 7.3 - Paralelização do Algoritmo dos Trapézios Compostos (Cortés, 1999) 
Essas aplicações foram desenvolvidas, testadas e utilizadas em um trabalho efetuado anteriormente em (Cortés, 1999).

\subsection{Resultados Obtidos}

Os resultados obtidos refletem a média de 50 execuções para cada aplicação descrita anteriormente. $\mathrm{O}$ ambiente utilizado para as execuções foi controlado, o que significa que a rede foi isolada e tinha-se o controle sob as cargas do sistema de maneira que se pudesse obter análises mais precisas.

Foram utilizadas duas formas de execução para salientar as vantagens em se utilizar um ambiente de escalonamento com os propósitos do AMIGO: (1) considerando-se o sistema totalmente ocioso executando apenas a aplicação paralela em questão; (2) considerando-se o sistema carregado, onde as cargas foram inseridas de maneira gradativa no sistema.

\subsubsection{Multiplicação de Matrizes}

Essa aplicação foi executada utilizando-se seis máquinas para seis processos e os tempos coletados utilizam segundos como unidade de medida. A Tabela 7.2 exibe as médias calculadas e os ganhos em porcentagem através da execução da aplicação, considerando o sistema ocioso e aumentando gradativamente o tamanho da matriz quadrada.

Tabela 7.2 - Resultados Obtidos com a Multiplicação de Matrizes (sistema ocioso)

\begin{tabular}{|c|c|c|c|c|}
\hline Tamanho da matriz & $120 \times 120$ & $240 \times 240$ & $360 \times 360$ & $480 \times 480$ \\
\hline $\begin{array}{l}\text { Média em ségundos } \\
\text { (LẢM original) }\end{array}$ & 4,485023 & 13,76356 & 33,00435 & 61,58267 \\
\hline $\begin{array}{l}\text { Média emsegứndos } \\
\text { (LAM-AMIGO) }\end{array}$ & 2,288307 & 11,59266 & 25,64523 & 45,5817 \\
\hline Gańho'em \% & $48,98 \%$ & $15,77 \%$ & $22,30 \%$ & $25,98 \%$ \\
\hline
\end{tabular}


O Gráfico 7.1 exibe a queda do tempo de execução obtido quando o ambiente AMIGO é utilizado. Isso é justificado pelo fato de nem sempre a política utilizar todas as máquinas para executar os processos e sim aquelas que oferecem melhor capacidade computacional. Diminuir a quantidade de máquinas utilizadas faz com que o número de comunicações entre os processos via rede de interconexão diminua, fazendo com o tempo de execução também seja diminuído.

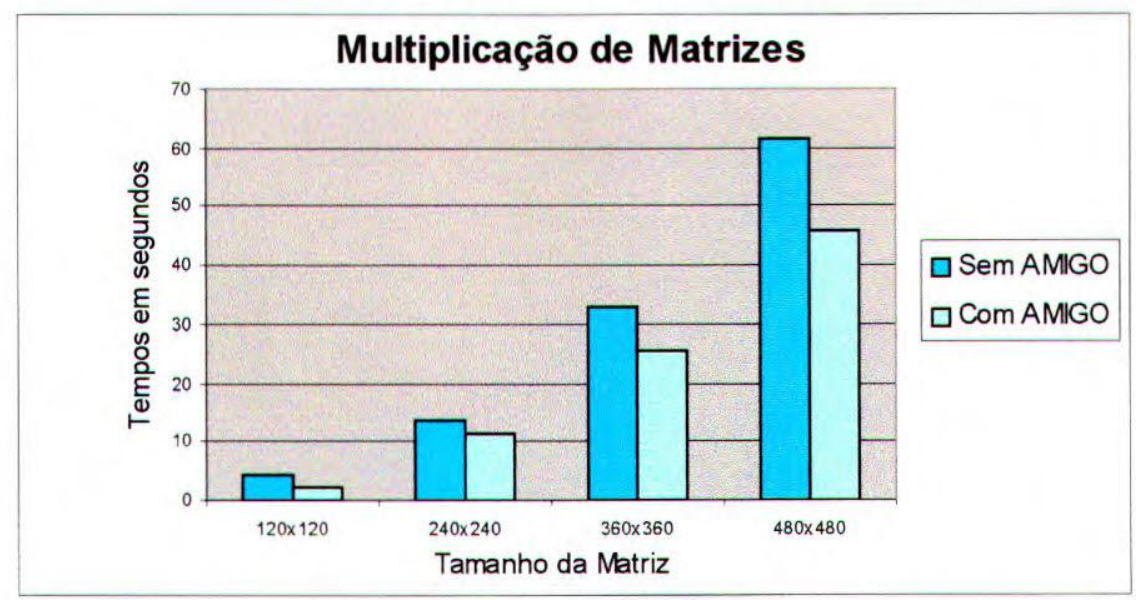

Gráfico 7.1 - Tempos de Execução (Multiplicação de Matrizes)

O Gráfico 7.2 exibe o ganho de desempenho obtido.

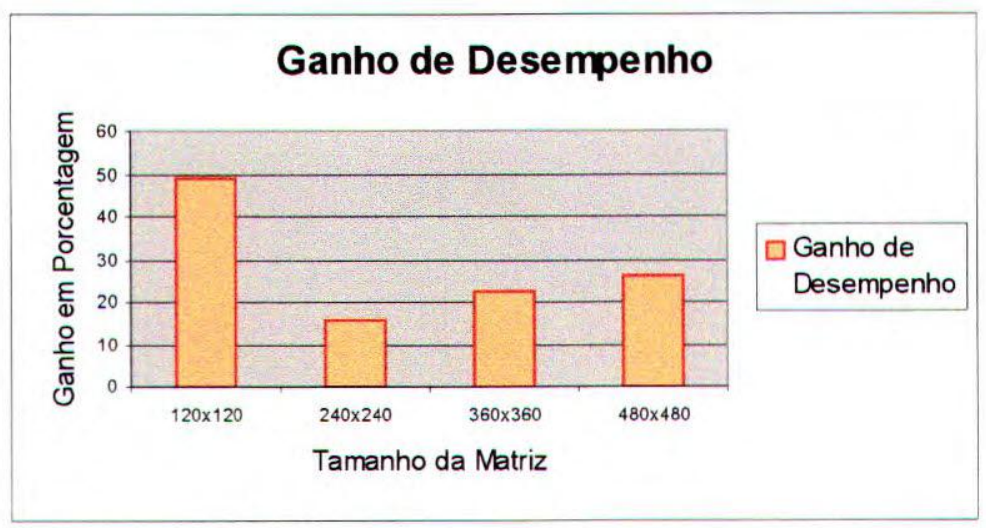

Gráfico 7.2 - Ganho de Desempenho (Multiplicação de Matrizes) 
A Tabela 7.3 exibe as médias calculadas e os ganhos em porcentagem através da execução da aplicação multiplicação de matrizes, considerando o sistema carregado e mantendo a ordem da matriz quadrada em $360 \times 360$. Para carregar o sistema foram inseridos processos seqüenciais em todas as máquinas do sistema. No primeiro caso, três das máquinas foram carregadas com quatro processos seqüenciais cada e as três máquinas restantes com dois processos seqüenciais cada. No segundo caso, essa carga foi duplicada sendo que três das máquinas foram carregadas com oito processos seqüenciais cada e as três restantes com quatro processos seqüenciais cada.

Tabela 7.3 - Resultados Obtidos com a Multiplicação de Matrizes (sistema carregado)

\begin{tabular}{|c|c|c|c|}
\hline Carga adicionada ao sistema & Ocioso & 18 seriais & $\mathbf{3 6}$ seriais \\
\hline $\begin{array}{c}\text { Média em segundos } \\
\text { (LAM Original) }\end{array}$ & 33,00435 & 38,24065 & 44,17267 \\
\hline $\begin{array}{c}\text { Média em segundos } \\
\text { (LAM-AMIGO) }\end{array}$ & 25,64523 & 36,63093 & 42,57714 \\
\hline Ganho em \% & $22,3 \%$ & $4,21 \%$ & $3,61 \%$ \\
\hline
\end{tabular}

O Gráfico 7.3 exibe a queda do tempo de execução da aplicação quando o ambiente AMIGO é utilizado. Nesse caso, o ganho não é muito significativo porque todo o sistema se encontra carregado $\mathrm{e}$ as máquinas de melhor potência computacional foram mais sobrecarregadas. Contudo, como as cargas nas máquinas são variadas o escalonamento feito pela política do AMIGO considera aquelas em estados menos carregados. Isso faz com que o tempo de execução diminua, aumentando o desempenho do sistema. 


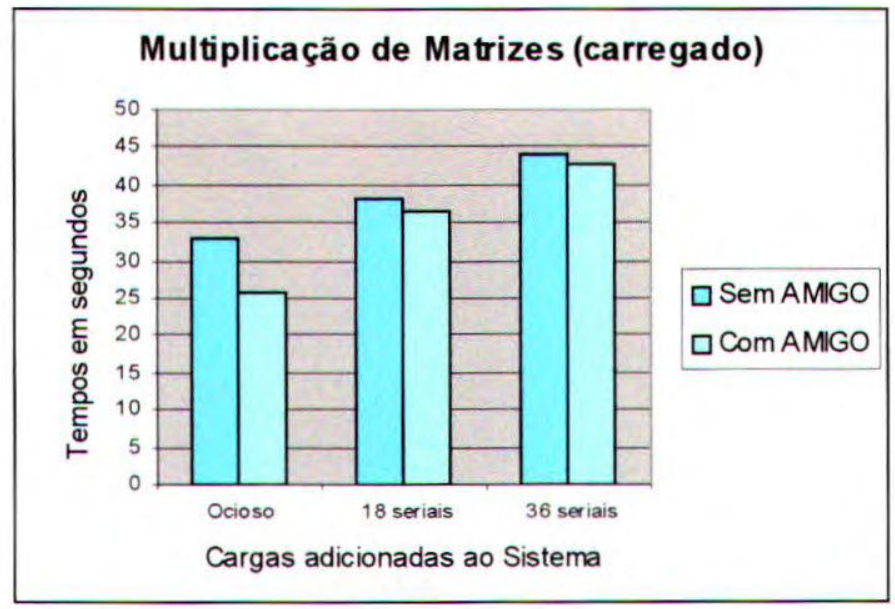

Gráfico 7.3 - Tempos de Execução (Multiplicação de Matrizes - Sistema Carregado)

O Gráfico 7.4 exibe o ganho de desempenho obtido.

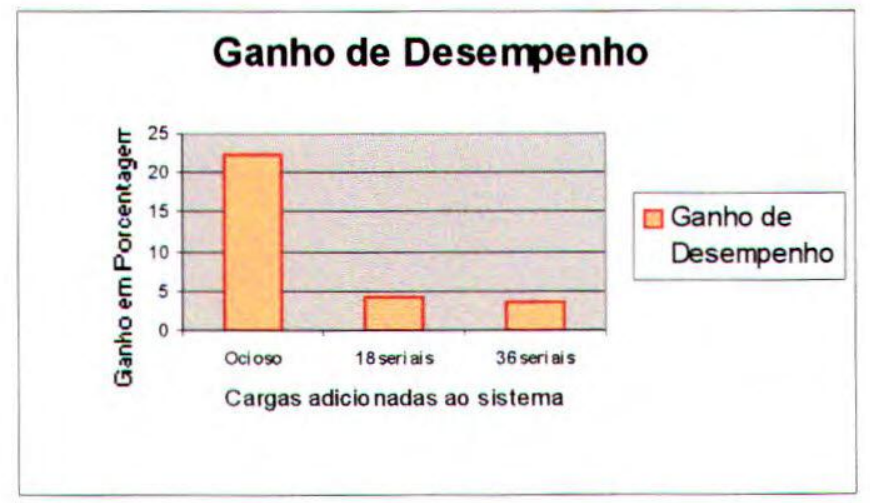

Gráfico 7.4 - Ganho de Desempenho (Multiplicação de Matrizes - Sistema Carregado)

\subsubsection{Método dos Trapézios Compostos}

Essa aplicação foi executada utilizando-se seis máquinas para três processos e os tempos coletados utilizam segundos como unidade de medida. A Tabela 7.4 exibe as médias calculadas através da execução da aplicação, considerando o sistema ocioso e carregado. Para carregar o sistema, foram inseridos processos seqüenciais a três das seis máquinas utilizadas. Isso foi feito 
para salientar a forma como a política utilizada pelo AMIGO efetua o escalonamento considerando sempre as máquinas que estejam menos carregadas.

Os resultados obtidos com o LAM-AMIGO oscilam (de 1,192083 a 1,396401) porque o escalonamento nem sempre é feito da mesma maneira, isto é, ora os processos podem ser executados utilizando três máquinas, ora utilizando duas e ora utilizando apenas uma das máquinas. Isso faz com que o tempo de execução varie dependendo da forma como é feito o escalonamento.

Tabela 7.4 - Resultados Obtidos com o Método dos Trapézios

\begin{tabular}{|c|c|c|c|c|c|}
\hline Carga adicionada ao sistema & 0 seriais & 2 seriais & 4 seriais & 6 seriàis & $\mathbf{8}$ seriais \\
\hline $\begin{array}{c}\text { Média em segundos } \\
\text { (LAM original) }\end{array}$ & 1,234773 & 2,347238 & 4,484696 & 6,366779 & 8,706318 \\
\hline $\begin{array}{c}\text { Média em segundośs } \\
\text { (LAM -AMIGO) }\end{array}$ & 1,192083 & 1,28112 & 1,396401 & 1,339435 & 1,340044 \\
\hline Ganho em \% & $3,46 \%$ & $45,42 \%$ & $68,86 \%$ & $78,96 \%$ & $84,61 \%$ \\
\hline
\end{tabular}

O gráfico 7.5 mostra os resultados obtidos com a execução do método dos trapézios compostos. São claramente percebidas a queda do tempo de execução e a estabilidade encontrada quando o AMIGO é utilizado. Isso pode ser justificado pelo fato da política definida pelo AMIGO sempre efetuar o escalonamento nas máquinas menos carregadas, o que não é considerado pelo LAM original.

No entanto, caso o usuário tenha controle sobre o ambiente e informações a priori a respeito do estado das máquinas, ele mesmo poderia definir, com o LAM original, quais as melhores máquinas para efetuar a execução. Apesar disso, a intenção aqui é salientar que o AMIGO realiza essa tarefa de forma transparente e com uma precisão maior devido ao fato de obter, dinamicamente, informações a respeito do sistema. 


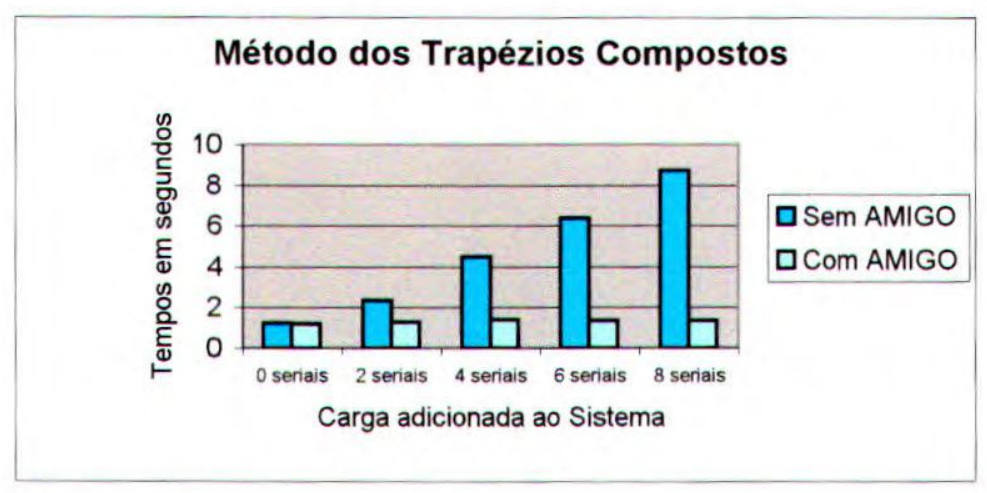

Gráfico 7.5 - Tempos de Execução (Método dos Trapézios)

O Gráfico 7.6 exibe o ganho de desempenho obtido.

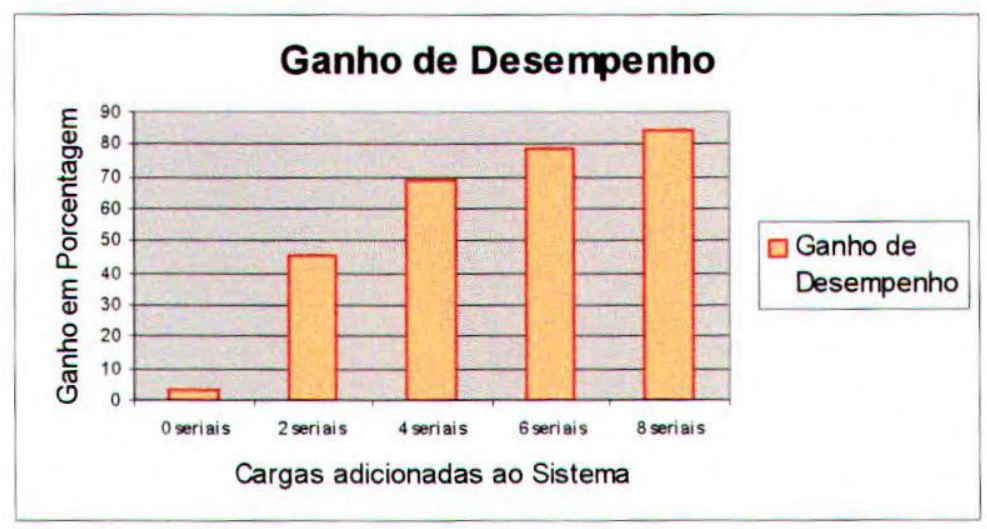

Gráfico 7.6 - Ganho de Desempenho (Método dos Trapézios)

\subsection{Considerações Finais}

Este capitulo mostrou os testes efetuados e os resultados obtidos a partir da Interface desenvolvida. Pôde-se perceber que os resultados não apenas validam a Interface proposta e implementada como também mostram a viabilização de sua utilização.

As aplicações escolhidas possuem como característica principal o grande consumo por processamento, devido ao fato da política utilizada pelo AMIGO (atualmente) considerar esses propósitos para realizar o escalonamento. Como o AMIGO possibilita a inserção de novas 
políticas com propósitos diferentes, posteriormente será possível efetuar análises mais profundas e com resultados bastante promissores.

Está demonstrado que a independência das políticas de escalonamento definidas para o AMIGO reflete uma maneira eficaz e flexível o suficiente para ser utilizada com qualquer ambiente de passagem de mensagens. Isso se deve ao fato de que a política utilizada neste trabalho foi previamente projetada para funcionar com o ambiente PVM (Parallel Virtual Machine) e, sem alterações, funcionou perfeitamente bem quando utilizada com o ambiente MPI/LAM. 


\section{8 \\ Conclusões e Trabalhos Futuros \\ "Pode-se vencer pela inteligência, pela babilidade ou pela sorte, mas nunca sem trabalbo." \\ (A. Destoef)}

\subsection{Considerações Iniciais}

Este trabalho descreve a implementação desenvolvida para a integração dos ambientes AMIGO e MPI/LAM. Portanto, também estão descritos o funcionamento interno e a utilização de cada um dos ambientes, incluindo a DPWP (Dynamical Policy Without Preemption), que é a política de escalonamento definida para o AMIGO (Souza, 2000) e utilizada neste trabalho.

Neste capítulo, estão descritas as contribuições do trabalho, as dificuldades encontradas e as propostas para trabalhos futuros concluindo, dessa forma, esta dissertação.

\subsection{Contribuições deste Trabalho}

- Como contribuição principal deste trabalho, destaca-se a integração do AMIGO com mais um ambiente de passagem de mensagens validando, dessa forma, a sua flexibilidade. 
- A descrição do funcionamento interno do LAM (Local Area Multicomputer) e do padrão MPI pode ser vista como mais uma contribuição do trabalho, pois pode servir de base para outras pesquisas.

- As considerações a respeito do escalonamento de processos e balanceamento de cargas também contribuem para os trabalhos futuros da área.

- A utilização dos algoritmos do AMIGO e da DPWP é, de certa forma, uma maneira adicional de validar esses algoritmos.

- Com a Interface AMIGO-MPI definida e implementada com sucesso nesta dissertação, pode-se implementar aplicações MPI convencionais que serão executadas com melhor desempenho.

\subsection{Dificuldades Encontradas}

Trabalhar com ambientes paralelos distribuídos é por si só uma tarefa complexa. A falta de ferramentas de depuração para encontrar erros de implementação nesses tipos de ambientes constitui uma grande dificuldade.

Uma das maiores dificuldades encontradas no decorrer do desenvolvimento do trabalho foi o entendimento dos códigos-fontes do LAM (Local Area Multicomputer) devido a sua complexidade. A descoberta dos pontos para alterações no código foi uma tarefa bastante complicada e que demandou a maior parte do tempo disponível ao trabalho.

Os mecanismos de comunicação envolvidos no processo também mostraram um alto grau de dificuldade, devido aos diversos problemas encontrados para se conseguir uma forma que não alterasse a especificação do AMIGO. 


\subsection{Propostas para Trabalhos Futuros}

Como continuidade deste trabalho, é possível traçar algumas idéias para trabalhos futuros nesta mesma área de pesquisa:

* Verificar a possibilidade de utilizar o AMIGO para aplicações MPMD no LAM.

* Verificar a possibilidade de se integrar outras implementações do padrão MPI ao AMIGO (como MPICH) e, possivelmente, efetuar diversas comparações.

- O desenvolvimento de uma nova política de escalonamento voltada para diferentes classes de aplicações permitindo a obtenção de novas análises que, agora com a integração do MPI ao AMIGO pode ser testada tanto no PVM como no MPI.

\subsection{Considerações Finais}

Esta dissertação serve como teste decisivo para a avaliação da característica fundamental do ambiente AMIGO que é a flexibilidade. Com a Interface AMIGO-MPI implementada e os testes efetuados utilizando-se a DPWP (originalmente testada com aplicações PVM) fica documentado que as políticas de escalonamento definidas no AMIGO são independentes do ambiente de passagem de mensagens utilizado.

Em adição, a Interface AMIGO-MPI construída introduz a possibilidade de execução com melhor desempenho de aplicações convencionais desenvolvidas em MPI.

As dificuldades operacionais enfrentadas na integração do MPI/LAM ao AMIGO reforçam a necessidade de se ter códigos bem documentados e com interfaces bem planejadas. 


\section{Referências Bibliográficas}

(Almasi \& Gottlieb, 1994) ALMASI, G.S., GOTTLIEB, A., Highly Parallel Computing, $2^{\mathrm{a}}$ ed., The Benjamin Cummings Publishing Company, Inc., 1994.

(Araújo, 1999) ARAÚJO, A. P. F., "DPWP - Uma nova Abordagem ao Escalonamento Dinâmico em Computação Paralela Virtual", Dissertação de Mestrado, Instituto de Ciências Matemáticas e de Computação (ICMC-USP), maio, 1999.

(Beguelin et al, 1994) BEGUELIN, A., GEIST, A., DONGARRA, J., JIANG, W., MANCHEK, R., SUNDERAM, V., 'PVM: Parallel Virtual Machine. A User's Guide and Tutorial for Networked Parallel Computing", The MTT Press, 1994.

(Burns et al, 1990) BURNS, G. D., DIXIT, V. S., DAOUD, R. B., MACHIRAJU, R. K., “All About Trollius", Occam Users Group Newletter, Agosto, 1990.

(Burns \& Daoud, 1995) BURNS, G., DAOUD, R, "MPI Primer/Developing with LAM", Ohio Supercomputer Center, The Ohio State University, ftp://tbag.osc.edu/pub/lam, 1995.

(Butler \& Lusk, 1994) BUTLER, R. M., LUSK, E. L., "Monitors, messages and clusters: The p4 parallel programming system", Parallel Computing, vol. 20, pp. 547-564, 1994.

(Calkin et al, 1994) CALKIN, R., HEMPEL, R., HOPPE, H. C., WYPIOR, P., 'Portable programming with the PARMACS message-passing library", Parallel Computing, vol. 20, pp. 615-632, 1994.

(Carriero et al, 1994) CARRIERO, N., GELERNTER, D., MATTSON, T., SHERMAN, A. H., "The Linda alternative to message-passing systems", Parallel Computing, vol. 20, pp. 633$655,1994$. 
(Casavant \& Kuhl, 1988) CASAVANT, T. L., KUHL, J. G., “A Taxonomy of Scheduling in General-Purpose Distributed Computing Systems", IEEE Transactions on Software Engineering, pp. 141-154, fevereiro, 1988.

(CENAPADNe, 1999) Centro Nacional de Processamento de Alto Desemepenho do Nordeste, "Curso de MPI", http://www.cenapadne.br, 1999.

(Comer, 1995) COMER, D. "Internetworking with TCP/IP - Principles, Protocols and Architecture", Vol.1, Third Edition, Prentice Hall, 1995.

(Cortés, 1999) CORTÉS, O. A. C., "Desenvolvimento e Avaliação de Algoritmos Numéricos Paralelos", Dissertação de Mestrado, Instituto de Ciências Matemáticas e de Computação (ICMC-USP), março, 1999.

(Coulouris et al, 1994) COULOURIS, G., DOLLIMORE, J., KINDBERG, T., Distributed Systems Concepts and Design, Addison-Wesley Publishing Company, $2^{a}$ ed., 1994.

(Dongarra et al, 1996) DONGARRA, J. J., OTTO, W., SNIR, M., WALKER, D., "A Message Passing Standard for MPP and Workstations", Communications of the $A C M, \mathrm{v} .39, \mathrm{n} .7$, pp.84-90, julho, 1996.

(Doss, 1996) DOSS, N., "MPI Frequently Asked Questions", http://www.erc.msstate.edu/mpi/ mpi-faq.html, 1996.

(Duncan, 1990) DUNCAN, R., "A survey of parallel computer architectures", IEEE Computer, pp. 5-16, fevereiro, 1990.

(Feitelson et al, 1997) FEITELSON, D. G., RUDOLPH, L., SCHWIEGELSHOHN, U., SEVCIK, K. C., WONG, P., "Theory and Practice in Parallel Job Scheduling", IPPS'97 Workshop on Job Scheduling Strategies for Parallel Processing, Lecture Notes in Computer Science v. 1291, Geneva, Switzerland, abril, 1997. 
(Ferrari \& Zhou, 1987) FERRARI, D., ZHOU, S., "An Empirical Investigation of Load Indices for Load Balancing Applications", Proceedings Performance'87, The $12^{\text {th }}$ Annual International Symposium on Computer Performance Modeling, Measurement and Evaluation, pp.515-528, 1987.

(Flower \& Kolawa, 1994) FLOWER, J., KOLAWA, A., "Express is not just a Message Passing System. Current and Future Directions in Express", Parallel Computing, v.20, pp.597-614, 1994.

(Flynn, 1972) FLYNN, M. J., "Some computer organizations and their effectiveness", IEEE Transactions on Computers, vol. C-21, pp.948-960, 1972.

(Geist et al, 1996) GEIST, G. A., KOHL, J. A., PAPADOPOULOS, P. M., "PVM and MPI: a comparison of feature", U. S. Department of Energy, maio,1996.

(Gropp \& Lusk, 1996) GROPP, W., LUSK, E., "A high-performance, portable implementation of the MPI Message Passing Interface standard", http://www.mcs.anl.gov/mpi/mpich, 1996.

(Hwang \& Briggs, 1984) HWANG, K, BRIGGS, F. A., Computer Architecture and Parallel Processing, McGraw-Hill, 1984.

(Kirner, 1991) KIRNER, C., "Arquiteturas de sistemas avançados de computação", Anais da Jornada EPUSP/IEEE em Sistemas de Computação de Alto Desempenho, pp. 307-353, 1991.

(LAM, 1999) LAM web site, "LAM/MPI Parallel Computing", http://www.mpi.nd.edu/lam, 1999.

(Macdonald et al, 1997) MACDONALD, N., MINTY, E., HARDING, T., BROWN, S., "Writing Message-Passing Parallel Programs with MPI", Curse Notes, The University of Edinburg, 1997. 
(McBryan, 1994) MCBRYAN, O. A., "An overview of message passing environments", Parallel Computing, vol. 20, pp. 417-444, 1994.

(Meyer, 1994) MEYER, J., "Message-passing interface for Microsoft Windows 3.1", Msc. Thesis, Department of Computer Science, University of Nebraska, 1994.

(MPI, 1997a) MPI Forum, "MPI-2: Extensions to the Message Passing Interface", http://www.mpi-forum.org, 1997.

(MPI, 1997b) MPI Forum, "MPI-2 Journal of Development", http://www.mpi-forum.org/, 1997.

(Navaux, 1989) NAVAUX, P. O. A., "Introdução ao processamento paralelo", $R B C$ - Revista Brasileira de Computação, vol. 5, nº 2, pp. 31-43, 1989.

(Shivaratri et al, 1992) SHIVARATRI, N. G., KREUGER, P., SINGHAL, M., 'Load Distribution for Locally Distributed Systems", Computer, v. 25, pp. 33-44, dezembro, 1992.

(Shirazi et al, 1995) SHIRAZI, B. A., HURSON, A. R., KAVI, K. M., "Scheduling and Load Balancing in Parallel and Distributed Systems", IEEE Computer Society Press, $1^{\mathrm{a}}$ ed., 1995.

(Silva, 1997) SILVA, F.A.B., "Balanceamento de Carga em Ambientes Paralelos Virtuais com Aplicações no PVM-W95", Dissertação de Mestrado, Instituto de Ciências Matemáticas e de Computação (ICMC-USP), junho, 1997.

(Skjellum et al, 1994) SKJELLUM, A., SIMTH, S.G., DOSS, N. E., LEUNG, A. P., MORARI, M., "The design and evolution of Zipcode", Parallel Computing, v.20, pp.565-596, 1994.

(Snir et al, 1996) SNIR, M., OTTO, S., STEVEN, H., WALKER, D., DONGARRA, J. J., MPI: The Complete Reference, The MIT Press, Massachusetts, 1996. 
(Souza, 1996a) SOUZA, P. S. L., "Máquina Paralela Virtual em Ambiente Windows", Dissertação de Mestrado, Instituto de Ciências Matemáticas e de Computação (ICMCUSP), maio, 1996.

(Souza, 1996b) SOUZA, M. A., "Avaliação das Rotinas de Comunicação Ponto-a-Ponto do MPI", Dissertação de Mestrado, Instituto de Ciências Matemáticas e de Computação (ICMC-USP), dezembro, 1996.

(Souza, 1997) SOUZA, P. S. L., "MPI - Um Padrão para Ambientes de Passagem de Mensagens", Exame Geral de Qualificação, Instituto de Física de São Carlos (IFSC-USP), novembro, 1997.

(Souza et al, 1998) SOUZA, P. S. L., ARAÚJO, A. P. F., SANTANA, M. J., SANTANA, R. H. C., 'Escalonamento de Processos: Características, Divergências e Soluções", SEPAI'98, 1998.

(Souza et al, 1999a) SOUZA, P. S. L., SANTANA, M. J., SANTANA, R. H. C., 'Dynamical Flexible Scheduling Environment ", Third World Multiconference on Systemics, Cybernetics and Informatics (SCI'99) and the Fitth International Conference on Information Systems Analysis and Sysnthesis (ISAS'99), Orlando, USA, julho, 1999.

(Souza et al, 1999b) SOUZA, P.S. L., SANTANA, M. J., SANTANA, R. H. C., "Ambiente de Escalonamento Flexível e Dinâmico", Relatório Técnico, Instituto de Ciências Matemáticas e de Computação, Universidade de São Paulo (ICMC/USP), 1999.

(Souza, 2000) SOUZA, P.S.L., “AMIGO: Uma Contribuição para a Convergência na Área de Escalonamento de Processos", Tese de Dourado, Instituto de Física de São Carlos (IFSCUSP), junho, 2000.

(Squyres et al, 2000) SQUYRES, J.M., LUMSDAINE, A., GEORGE, W. L., HAGEDORN, J. G., DEVANEY, J. E., “"The Interoperable Message Passing Interface (IMPI) Extensions to LAM/MPI", MPIDC 2000 conference, 2000. 
(Sunderam et al, 1994) SUNDERAM, V. S., GEIST, A., DONGARRA, J., MANCHEK, R., "The PVM concurrent computing system: evolution, experiences and trends", Parallel Computing, vol. 20, pp. 531-545, 1994.

(Stevens, 1990) STEVENS, W. R., UNIX Network Programming, Prentice Hall, 1990.

(Tanenbaum, 1992) TANENBAUM, A. S., Modern Operating Systems, Prentice Hall, 1992.

(Walker, 1994) WALKER, D. W., "The design of a standard message passing interface for distributed memory concurrent computers", Parallel Computing, vol. 20, pp. 657-673, 1994. 